\title{
Nuclear Division in the Pollen Mother-cells of Lilium canadense.
}

\author{
BY \\ CHARLES E. ALLEN, \\ Assistant Professor of Botany in the University of Wisconsin.
}

With Plates VI, VII, VIII, and IX.

$T$

$\mathrm{HE}$ investigations to be described in the present paper were carried on upon the pollen mother-cells of Lilium canadense, L., which is abundant in this vicinity. Some study, for purposes of comparison, was made of the pollen mother-cells of L. tigrinum, Andr., and L. longiflorum, Thunb. So far as they went, my results with these species were entirely in harmony with those obtained from the first-named species, in which alone, however, a complete series of stages was studied. All the figures and descriptions have reference to $L$. canadense.

I shall speak, for the most part, only of the behaviour of the nuclear substances, with especial reference to the history of the chromosomes. Some of the more important results have already (Allen, 04) been briefly announced. The process of spindle-formation, which I hope to describe in a future paper, agrees in general, though with some interesting variations in detail, especially in the second division, with the course of events as I have ('03) observed it in the pollen mother-cells of Larix.

\section{METHODS.}

A number of fixing fluids were tried; the best results were obtained from Flemming's stronger chrom-osmic-acetic acid solution, and from the slight modification of this formula used by Mottier ('97). There seemed to be little choice as between the two. Some good preparations were obtained from material fixed in Flemming's weaker solution, but as a rule this fluid produced more or less plasmolysis and distortion of the cell.

Material was fixed in the field from day to day during the season of development and division of the pollen mother-cells. Anthers containing

[Annals of Botany, Vo1. XIX. No. LXXIV. April, 1905.] 
pollen mother-cells may be found by the end of the first week of June; and stages in their division during the rest of June and the first week of July. The anthers were removed from the bud, usually cut transversely in half, and immersed at once in the fixing fluid. Collections were made during each of five summers, from 1899 to 1903 inclusive.

Sections were cut from three to thirty micra in thickness, and before staining were immersed from fifteen to thirty minutes in a solution of hydrogen peroxide. For the study of the cytoplasmic structures and of the processes connected with spindle-formation, sections of 5-6 $\mu$ thick, stained with Flemming's triple stain, were found of most use. For the study of the chromatin, the best results were obtained from sections from twelve to thirty micra in thickness, stained with Heidenhain's iron-alum-haematoxylin. The two staining methods, however, supplement each other, and a comparison of sections from the same anther, some treated in one way, some in the other, is always helpful.

\section{DESCRIPTION OF OBSERVATIONS.}

\section{The Heterotypic Division.}

\section{The Period of the Nuclear Reticulum.}

The divisions in the sporogenous tissue of the anther sac which precede the formation of the pollen mother-cells go on very rapidly, accompanied by growth of the cells and by a corresponding increase in size in all dimensions of the anther itself. A section taken at any stage during this series of divisions shows cells and nuclei in all stages of division. Even when the majority of the cells in the sac have entered upon the long period of growth which characterizes the pollen mother-cells, occasional figures may be found showing stages in the last preceding division. But soon these isolated divisions are completed, and the sporogenous tissue then consists of a cylinder, from six to eight cells in diameter, all the cells being in substantially the same stage of development. A section taken at any time from this period down to the appearance of the multipolar spindle-figures shows a striking uniformity as to stage of development among all the mother-cells of a sac. Apparently the processes concerned in the development of the cell and in the preparation for the heterotypic division go on very slowly and at about the same rate in all the cells of a sac. In some cases a certain amount of progress may be noted in passing from one end of a sac to the other ; more often there is a sort of rhythmical variation, so that at two or three regions of the sac the greatest progress has been made, while in moving from one to another of these points we pass through a region showing gradually earlier, and then gradually later stages, 
until we reach the second point of greatest progress. The variation within one sac is, however, extremely small. The same general statement is true as to a uniformity between different sacs of the same anther, and different anthers of the same flower, but in these cases there is a somewhat greater range of variation as to the stages represented.

I have attempted to follow carefully the processes concerned in the reconstruction of the daughter-nucleus of the last pre-heterotypic division, and its growth to the size characteristic of the nucleus of the pollen mothercell. The daughter-chromosomes of the mitosis just mentioned aggregate into a dense mass at either pole of the spindle. After the formation of the new nuclear membrane, nuclear sap appears within it, and the mass of chromatin becomes less dense. The chromosomes are now seen to have lost their regular outline and to have become reticulated, so that it is impossible to trace in the newly-formed nucleus the outline of any individual chromosome. Fig. I, Pl. VI, shows the nucleus of a young pollen mother-cell at the time when cell-division has just been completed by the splitting of the cell-plate and the formation of a thin, orange-staining wall. The old spindle-fibres (not shown in the figure) are still attached to the nucleus, and on the side to which they are attached (the lower side in the figure) the outline of the nucleus is flattened and still quite irregular, while on the opposite (polar) side it is convex and more evenly rounded. The nucleus, as a whole, is still small and considerably flattened, its shortest diameter coinciding with the axis of the spindle. The chromatic material is massed on the equatorial side of the nucleus. It is broken up into irregular masses, the shape of some of which suggests that of the chromosomes which were their source. The larger masses show an affinity for the safranin stain, and are connected by blue-staining fibres of varying thickness, down to that of very fine threads. The blue-staining fibrous material also forms short threads attached to various portions of the red-staining masses, the whole effect being that of a very ragged and irregular reticulum occupying the greater part of the nuclear cavity, especially on the equatorial side. The colours of the constituents of this network vary, of course, with the time of exposure to the different stains, also to some extent with the time of exposure to the bleaching reagent and with the degree of penetration of the fixing fluid. Preparations may be obtained in which the whole reticulum is violet, others in which it is all stained orange-red. Even in these cases, however, a certain difference is observable between the affinity of the substance of the larger masses and that of the fibres for the different stains, and by careful regulation of the times of exposure a fairly distinct differentiation may be secured. The substance of the larger masses also shows a stronger affinity for the haematoxylin than does that of the fibres. This construction of the nuclear reticulum, out of rather red-staining masses and blue-staining fibres of 
uneven thickness, is retained, as will be seen, until the time of the formation of the spirem. There is no such stage in the history of the pollen mothercells of this species as is found by Miss Sargant ('97) and Mottier ('97) in other species of Lilium, in which there appears a fine network of linin fibres, containing imbedded chromatin granules.

The two differently staining substances that I have described are certainly not to be considered respectively as the chromatin and linin, which may be sharply differentiated later in the spirem; it is more probable that the larger masses, which may correspond to the 'net knots' described by Flemming ('78, '80, ' 82 ) in the resting nucleus, contain both chromatin and linin, remaining for the present in these clumps derived from the chromosomes of the preceding division, and destined later to be distributed more uniformly along the spirem. This notion is confirmed by the fact that in iron-haematoxylin preparations of nuclei at the stage shown in Fig. 8, the knots are sometimes seen to be composed of dark granules imbedded in a more lightly stained substance. I have seen nothing at all comparable to Miss Sargant's ('97) 'amorphous chromatin.'

An apparently similar construction of the nuclear reticulum is described and figured by K. and A. E. Schreiner ('04) in the primary spermatocytes of Myxine. In this case, however, each knot of the reticulum is formed by one of the fifty-two chromosomes, which is connected with its neighbours by linin fibres. This condition in Myxine becomes transformed, by the spreading out of the chromatin along the linin fibres, into a fine reticulum.

The amount of nuclear sap is still (at the stage of Fig. I) relatively small. Masses of nucleolar matter are already present, varying in number and shape. In the figure two of these are shown, and they are quite rounded, but in many cases they are more irregular in outline. In this case, too, the nucleoles appear on the polar side of the nucleus, as though the material from which they have been re-formed had entered the nucleus from the side opposite that to which the spindle-fibres are attached. This is the position usually occupied by the nucleolar masses at a very early stage in the reconstruction of these nuclei. The nucleoles are readily distinguishable from the chromatic knots, not only by their size, but also by their staining properties. In preparations which have been exposed to the hydrogen peroxide for but a brief period, the nucleoles show little affinity for the safranin, but remain orange or yellow. If they have been bleached somewhat longer, they take on a bright red colour, which is still quite different from the dull red of the knots of the reticulum. The staining properties of the nucleoles seem also to be affected by the degree of penetration of the fixing fluid.

The nucleus soon rounds itself up, as the old spindle-fibres disappear, and increases in size, apparently by the taking in of additional sap, since the amount of chromatic material increases slowly if at all, while its consti- 
tuent parts are separated more widely and form a rather uniformly distributed but very ragged and irregular reticulum (Fig. 2). There is a tendency for the material of the reticulum to aggregate about the periphery, but this tendency is not very marked as yet, and a considerable amount of it is distributed through the central portion of the nuclear cavity. The nucleolar material has considerably increased in amount and is gathered into large, often very irregular bodies, in contact with which is a considerable amount of the material of the reticulum, resulting in one or more large, ragged masses in the interior of the nucleus. The outlines of the nucleole can, however, always be distinguished in such a mass. The number of nucleoles in a nucleus is variable, two, three and four being common numbers. Fig. 3 shows a small portion of the reticulum, as seen in a tangential view of the nucleus. It will be seen that there is as yet no suggestion of a spirem-thread, but instead, irregular knots of all sizes, connected by narrower strands and fibres, the whole system branching and anastomosing in the most varied fashion.

As the nucleus increases still further in size, the nucleolar masses round up and separate themselves to a large extent from the reticulum (Fig. 4), the material of the latter tending more and more to take up a peripheral position. During the period of growth of the nucleus, the cell has also been growing, though somewhat more slowly. The cells are separated by rather thin, orange-staining walls.

After the chromatic material of the nucleus has become located almost wholly in the peripheral region (Fig. 5), there begins a period of rapid growth of the chromatin, evidenced by a marked increase in size of the knots; and this growth continues until just previous to the formation of the spirem (compare Figs. 4, 5, and 7). The relation between fibres and knots, and the ragged appearance of the whole reticulum, are as yet (Fig. 5) little changed. Fig. 6 shows a tangential view of a portion of the reticulum at this stage. The nucleoles (usually two or more) are now large, approximately spherical bodies of quite regular outline, lying in the nuclear sap, either entirely free from the reticulum or in contact with small portions of it. The nucleoles quite constantly at this stage show a number of rounded, lightly-stained areas in their interior. This 'vacuolated' appearance is first noticed after the rounding up of the nucleole and its nearly complete separation from the reticulum. Since these vacuoles appear so early in the prophases, at a time when the nucleole itself has just assumed its typical size and form, it seems hardly likely that their presence, in this or later stages, is indicative of the giving up of material by the nucleole toward the formation of the chromosomes.

The nucleus, as a whole, now grows rapidly until it has reached nearly or quite its final size; the knots of the reticulum (Figs. 7 and 8), having likewise grown considerably, lose their ragged look, because of the dis- 
appearance of the short, fine threads, and show a tendency to an elongation in the direction of the connecting fibres. These fibres also become more uniform in thickness. All these changes are in the direction of the formation of a spirem; but, as may be seen from Fig. 8, the whole structure is still plainly a reticulum. At this stage there appears not infrequently a pairing of the fibres, due to the fact that two fibres, sometimes short, sometimes of a length equal to half the diameter of the nucleus, run close together and approximately parallel, terminating at either end in the same knot. Instances of this sort appear in Fig. 8, and a particularly good illustration in Fig. 9. Cases of paired fibres at this stage, however, are hardly numerous enough to attract special attention, except in view of subsequent events.

The nuclear membrane, which in the earlier stages has appeared in section as a deeply blue-stained line, is now much less easily distinguishable, though it can always be followed. The difference in appearance seems to be due to some change which takes place at this stage that affects the affinity of the membrane for stains. The nucleus in its growth has become in general longer in one diameter, whereas in previous stages it was nearly or quite spherical. It is sometimes located toward one side of the cell, but its position is still usually central.

\section{Synapsis.}

The transformation of the reticulum into a spirem goes on rapidly. The fibres increase in length, tending more and more toward a uniform thickness; the whole intra-nuclear system is now (Fig. IO) seen to be composed of rather slender blue-staining fibres or strands, still interrupted in many places by red-staining bodies of irregular size and shape. It appears as though the material of the knots were being drawn out along certain of the fibres of the former reticulum, and in the process were assuming the staining properties of the fibres. Cases of the pairing of the fibres now become gradually more frequent, due, apparently, to an approximation of the individual strands during or after their formation from the knots; and at the same time there appears a tendency toward a heaping up or aggregation of the nuclear materials, a tendency which is first noticeable in occasional nuclei at a stage similar to that shown in Fig. 8. The density of this aggregation, which is the beginning of the synapsis stage, increases (Figs. 10, II, I 2), about in proportion as the pairing of the fibres becomes more frequent; and it is impossible to avoid the impression that the heaping up of the whole system is closely related to the approximation of the fibres in pairs. Almost simultaneously with the first occurrence of the aggregated condition (Fig. ro), the greater part of the nucleolar material appears as one or more masses flattened against the 
nuclear membrane; and this flattening of the nucleole or nucleoles becomes more pronounced as the aggregation of the other nuclear materials becomes closer. The aggregation is at first more commonly in the central portion of the nuclear cavity, and has no apparent relation to the eccentric position of the nucleole; but later the whole mass moves over to one side of the nucleus (Figs. 12, I4), usually to that side already occupied by the nucleole, and then the appearance is as if the nucleole were pressed against the membrane by the synaptic mass.

As the material of the reticulum becomes more and more densely aggregated, the fibres grow in length at the expense of the knots, which finally disappear entirely (Fig. 12); the fibres become quite uniform in thickness. The nuclei represented in Figs. 10 and II are from sections respectively twenty and thirty micra in thickness; the nuclei in question were uncut, and the free ends of fibres which appear in them are not due to the cutting of strands. At this time, therefore, a continuous spirem has not been formed. But at the stage shown in Fig. I2, no such free ends are to be observed in an uncut nucleus. It is impossible to say with certainty that no free ends are present in such a dense mass as is shown in this figure ; but the fact that they never appear in any of the strands that pass out from the peripheral portion of the mass makes it extremely probable that there is now present a continuous spirem.

The most important fact to be noted in connexion with the spirem at this time (Figs. 12-I4) is that it is plainly composed of two slender threads lying side by side. This double nature of the spirem is best distinguished in relatively thin tangential sections of the nucleus, such as that shown in Fig. I3, rather lightly stained with iron-haematoxylin. Often the two threads run closely together for a considerable distance, sometimes loosely twisted about each other; at other times they are in contact and appear to be fused; in some places they diverge more or less widely. Fig. 12 represents a tangential view of a nucleus whose chromatic materials are massed at the surface turned toward the observer. Here on account of the density of the mass the construction of the spirem-thread is not so easily determined; but all the portions which are disengaged from the main mass have the same double structure as appears in Fig. I3; and the same structure is occasionally visible even in the interior of the synaptic mass. For the most part the paired threads within the mass are in close contact, if not actually already fused, giving the appearance of a single strand of double thickness. In a thin median section, such as that shown in Fig. I4, less evidence appears of the double nature of the spirem; though even in such a section the loops of the spirem, which occasionally run out from the synaptic mass into other portions of the nuclear cavity and back again (as the one shown at $a$ ), are almost invariably seen to be composed of two parallel or twisted threads. From what has been said of the process of 
transformation of the reticulum into the spirem, it is plain that the double nature of the latter is not due to a longitudinal splitting of a single thread; but that the two threads are formed independently of each other out of the materials of the reticulum, and approach each other while they are in process of formation. From such appearances as that of Fig. 9, it seems that the approximation of the materials of the two threads may begin during the period of the reticulum, resulting, perhaps, in a fusion of some of the knots in pairs. But Figs. 10 and I m make it plain that this approximation is brought about for the most part while the material of the knots is being distributed along the strands of the future spirem, and that the approximation of these strands has some causal relation to the massing of the whole system in the synaptic figure.

There seems to be no rule as to the side of the nuclear cavity which shall be occupied by the synaptic mass. In a longitudinal section of an anther sac, there are no more cases of nuclei in which the massing is on any particular side-e.g. toward one end of the sac-than there are in which it is toward any other side. As has been said, the greater part of the nucleolar material is flattened against the nuclear membrane, nearly always in the immediate neighbourhood of the aggregated spirem. Sometimes two or three flattened nucleoles appear in the same nucleus. All stages may be found in the transition from the rounded to the flattened form, so there can be no doubt that these bodies are the same as the nucleoles of the earlier stages. The vacuolated appearance is also often retained, even in cases of considerable flattening. The nucleoles shown in Figs. I I, I2, and 14 , represent only moderate instances of the flattening, which often continues until the nucleole is an extremely thin plate, just inside the membrane, and extending, in section, around a quarter or even a third of the periphery of the nucleus. Seen in surface view, this plate has an irregular, lobed outline, and is perforated by occasional irregular holes. The nuclear membrane is still very lightly stained, though plainly present.

Fig. I4 represents a median section of a cell whose nucleus is in the condition just described. Both cell and nucleus have reached approximately their final size. The nucleus has, in most cases, taken up an eccentric position within the cell. In case the cell is longer in one diameter, the nucleus is commonly nearer one end. The long axis of the nucleus generally, though not always, coincides with that of the cell. The cells are still angular, united into a tissue, with orange-staining walls of about the same thickness as in younger stages. The tapetal cells of the inner layer, bounding the mass of spore mother-cells, are very much vacuolated and often shrunken, the majority of them with their nuclei and the remaining cytoplasm at the end of the cell which is in contact with the spore mother-cells.

Even at the stage represented in Figs. I 3 and I4, the parallel threads 
are in many places in close contact and seemingly fused. They now approximate much more closely throughout their length, twist tightly about each other and fuse into what appears to be a single thread. Although the close approximation of the threads occurs quite early in the synapsis period, the completion of their fusion is a matter of considerable time. During the process all stages of fusion may be observed in the same nucleus. In places the two strands are parallel but not in contact; some portions of the thread show their double nature only by a lighter line in the middle; in other places the two threads are twisted about each other, and in still others there appears a single homogeneous thread. After a considerable time all signs of a double nature disappear, and the synaptic mass contains apparently a single relatively thick thread (Fig. I9). After the fusion and during the continuance of synapsis, the spirem shortens and thickens to some extent, but the thickness of the thread at the close of synapsis, as may be seen by comparing Figs. I9-2I with Figs. I 2 and I3, is not much greater than its thickness immediately after the fusion. The diameter of the thread, as the figures show, is at no time perfectly uniform. The synaptic aggregation still persists (Figs. 19), and the mass of the strands composing it is about the same as at its first appearance, but the cluster is looser, and it is easier to follow a single strand for a considerable distance. The looser arrangement is partly accounted for by the fusion of two threads into one, and the consequent lessening by one-half of the total length involved, partly by the shortening and thickening just noted; but there is also already evident a tendency of the thread to disentangle itself and to become distributed more uniformly within the nuclear cavity.

In the most favourable preparations of material in the stages just described, lightly stained with iron-haematoxylin, there appears very clearly the differentiation into chromatin and linin already mentioned as occasionally visible at the stage of Fig. 8. The thread in such a preparation is seen to be composed of a lightly-stained ground substance in which darker bodies are imbedded. By careful washing in the iron alum, the ground substance may be almost entirely decolorized, so that the thread at first sight seems to consist merely of a row of granules (Figs. I $5^{-1}$ ). In preparations stained with the triple stain, the chromatin bodies are blue, the linin is red. If the section is over-stained with safranin, the chromatin bodies are dark red, the linin being much lighter.

This differentiation within the spirem thread appears most plainly in cells at or near the ends, especially the cut ends, of the sections, where the fixing fluid first came in contact with the tissues, and where, therefore, its effect may be supposed to have been strongest. In these regions, both cells and nuclei are often shrunken, and the cytoplasm has the peculiar granular appearance which is a characteristic effect of exposure to a too strong solution of osmic acid. The spirem shows little or no change. 
Something of the same differentiation in the spirem may often be made out in cells which appear in other respects more normal than those just described, and which are, on the whole, much better fixed; this fact is evidence that the appearances described within the spirem are not artefact, but that they correspond to an actual distinction between the substances of which the thread is composed. This distinction is best preserved by a strength of the fixing fluid which is less favourable for the fixation of the cell as a whole, and especially of the cytoplasmic structures.

Many observers, beginning with Balbiani ('76, '81), have noted in the spirems of both plant and animal nuclei a similar differentiation into darklystaining granules or discs and a lighter ground substance. The application of Flemming's ('80) term 'chromatin' was restricted by Pfitzner ('81) to the substance of the darker bodies, the 'chromomeres' of Fol ('91), which E. Zacharias ('82) found to be composed of nuclein ; and Schwarz ('87) proposed for the lightly-staining ground substance the name 'linin.'

Fig. I 5 shows, at a higher magnification than the previous figures, a portion of the two parallel threads before fusion, at the stage of Figs. I 2 and $\mathrm{I}_{3}$; in Fig. $\mathrm{I} 6$ is shown the beginning of the fusion of the threads, some portions of the two threads being still separate, others showing a fusion of the linin, the chromomeres being distinct, and others showing the chromomeres also fused. The chromomeres are very irregular in outline, each seeming to be made up of a number of smaller granules. They vary considerably in size. In general the threads approximate in such a way that the chromomeres come together in pairs; but this is not an invariable rule, for in some places there seems to be a chromomere in one thread which does not find a mate in the other. All stages in the fusion of these bodies in pairs may be found; often a dumb-bell-shaped figure is formed first, but eventually the two fuse into an approximately spherical mass, still with an irregular outline and the appearance of being composed of a number of smaller granules. Fig. I 7 shows the structure of the thread in a somewhat older nucleus; here the threads have fused along their whole length, but the chromomeres in some parts are separate, and all stages of their fusion may still be observed. It will be noticed that in some cases successive chromomeres, especially some of the smaller ones, on the same half of the fusion thread are in contact or very close together; and such a series of two or more may be in contact with a similar series on the other half-thread. It is quite possible that this appearance of a fusion of successive chromomeres is connected with the shortening of the thread as a whole, whereby is brought about a combination of the smaller bodies into progressively larger ones.

Fig. I 8 (from a nucleus at about the stage of Fig. 19) shows the fusion more nearly completed; but even here there is occasionally a pair of chromomeres which have not yet united. I have not found instances of 
complete fusion of all the chromomeres of the thread until after the close of the synaptic period. Fig. 24, Pl. VII, from a nucleus in the stage of the uniformly distributed spirem (shown in Fig. 23), shows such an apparently complete fusion. There now remains no evidence that the thread ever was anything other than a single structure, containing a single row of chromomeres. In Fig. 24 there appears occasionally a small chromomere located near one edge of the thread, and it may be that these represent the occasional chromomeres of one fusing thread, already noted, which failed to find mates in the other thread.

The chromomeres are imbedded in the linin, and seem to project from it slightly at the edges of the thread. To the projecting points a fine, short linin fibre can sometimes be seen to be attached. These fine fibres are not often easily distinguishable in iron-haematoxylin preparations, but in those stained with the triple stain (Figs. I9-2I), they are more plainly visible. In the cells represented in Figs. 19-2I, the internal structure of the thread is not apparent, but there appear on the surface of the thread two rows of external swellings or granules, usually quite small, but occasionally (as in Fig. 19) having a diameter equal to a third or even a half of that of the thread itself; these swellings stain blue in preparations in which the thread, as a whole, is red, dark blue when the body of the thread is light blue or purple. The two rows lie on opposite sides of the thread, and for the most part are so arranged that each swelling in one row is opposite one in the other row. In preparations which show the internal differentiation of the thread into linin and chromatin, the position of these pairs of external swellings, where they can be made out, corresponds with that of the chromomeres. The swellings, therefore, are the projecting points of the chromomeres. These projections are not always differentially stained, even with the triple stain, and then do not show except as they give to the thread an irregular outline; but they are frequently very noticeable, especially on portions of the thread which lie comparatively free. From each one may be traced a very fine fibre extending out perpendicularly to the surface of the spirem thread, usually extremely short, but sometimes of considerable length. Where the attached fibres are of some length they may be seen, even in preparations in which the swellings are not differentially stained. I have not been able to distinguish these swellings nor the regular attachment of the fibres to the spirem before the fusion of the parallel threads; but after the fusion they are of regular occurrence.

Miss Sargant ('96, '97) seems to have considered these external swellings to be the chromatin bodies themselves. She finds that at a very early stage the threads of the nuclear network contain a single row of dots ; this row becomes double during the transition to synapsis, as a result, she thinks, of a fission of each dot of the single row. The spirem is formed, therefore, with two rows of dots on opposite margins, which are separated 
later by the splitting of the thread. From some of her figures ('96, Figs. I 5-18), it seems possible that the dots she describes may be the chromomeres; but others ('96, Figs. $13 a, \mathrm{I}_{3} b$; '97, Figs. $\left.2 a, 3 b, 4,5\right)$ make it plain that the 'chromatin dots' are merely the external swellings on the thread. The description of Farmer and Moore ('95) also seems to refer to these swellings. They find that, before synapsis, the much-convoluted linin filament 'becomes charged with chromatin granules which are especially arranged along the parallel edges of the somewhat flattened thread.' After synapsis, as the thread thickens, the chromatin becomes more abundant in it, and its distribution along the edges is then very apparent. Splitting occurs in the middle line between the rows of chromatin material. In a more recent paper, however, Farmer and Moore ('03) give figures of the longitudinally split spirem which show a row of what appear to be the real chromomeres in each daughter-spirem.

From my preparations it is apparent that the external dots or granules are not the chromatin bodies themselves, but merely the portions of these bodies which project beyond the linin in which they are imbedded. The appearance of the two rows of 'dots' is not, therefore, a preliminary to longitudinal splitting, since the dots of a pair are simply the external projections of a single chromomere.

After the fusion of the parallel threads, and at about the time that the spirem first shows signs of a looser arrangement, the 'sickle-shaped' nucleoles begin to lose their extremely flattened appearance and to return to a more or less spherical shape. All stages in this transition may be found. On regaining the rounded shape (Fig. 19), the nucleoles again show the vacuolated condition characteristic of earlier stages. The nuclei from this time onwards resemble those of the pre-synaptic period in the size of the nucleoles and in their varying number, usually two or three, sometimes more, appearing in each nucleus. Nucleoles may now be found in any part of the nucleus, but for the most part they lie either close to, or within, the still closely crowded coils of the spirem. The nuclear membrane again displays a decided affinity for stains, and from this time onwards it stands out in triple-stained sections as a fairly thick, dark blue line.

While these processes are going on in the nucleus, the cell as a whole has been undergoing a change of shape. At a very early period, even before the completion of the fusion of the parallel nuclear threads, the cell walls connecting the pollen mother-cells into a tissue begin to dissolve, and the cells round up. By the time of the return of the nucleoles to their spherical shape, the cell walls have for the most part disappeared, and the cells have separated and rounded up, each surrounded only by a plasma membrane. In many places, however, two or more cells are directly in contact with one another by their plasma membranes, their outlines being flattened along the surfaces of contact. The size of the cavity of the 
anther-sac has been increased to allow room for the rounding up of the cells, partly by the collapse of the bounding layer of tapetal cells, partly by the increase in size of the anther as a whole. In the fluid filling the sac, in which the cells now float, there are numerous drops of a substance which stains bright red in the triple stain, and deep black in the haematoxylin. There now begins to be formed about each mother-cell a new independent cell wall, which, while it is still very thin, is often demonstrable in slightly plasmolyzed cells. There is considerable variation in the thickness of the new walls of different cells at the same stage of development. At the close of synapsis the wall is often still very thin (Fig. 20), but in some instances it has attained a considerable thickness (Fig. 2I); in the latter case its thickness is usually unequal on different sides of the same cell.

The series of stages which I have described under the general term 'synapsis' (Moore, '95 a) is marked by the continuous presence of an aggregation of the chromatic materials within the nucleus, at first approximately central, but soon becoming eccentric. This period is an extremely long one, as is evidenced by the large proportion of anthers in material fixed from day to day through a considerable period, the cells of which show synaptic figures. It seems to me certain that these stages in the lily extend over a period of some days at least, very probably of a week or more. The peculiar aggregation of the nuclear thread at this period seems to have been first observed by Tschistiakoff ('75). He gives (in his Fig. VI) a very good representation of a synaptic nucleus in the 'pollen grain' of Cupressus. The figure is plainly that of a pollen mother-cell. Synaptic figures were observed in various pollen mother-cells by Tangl ('82), Strasburger ('82), Heuser ('84), and Guignard ('84), all of whom, however, thought the peculiar appearance due to the action of reagents. Tangl and Strasburger observed flattened nucleoles at the same period, and the latter interpreted them as secretion products, the real nucleole having, as he thought, disappeared at an earlier stage. Strasburger also noted the slight affinity of the nuclear membrane at this period for stains. E. Overton ('91) observed a similar stage in the prophases of the first division in the embryosac of Lilium. Van Beneden and Julin ('84) found that the chromatin strand in the nucleus of the primary spermatocyte of Ascaris megalocephala originates from a nucleolus-like mass; a similar aggregation was found by Kultschitzky ('88), O. Hertwig ('90), and Brauer ('93). Brauer's description makes it plain that this mass is of the same nature as the synaptic aggregation in plant nuclei. Hertwig also observed flattened nucleoles at this or an immediately preceding stage. It is worth noting in this connexion that Winiwarter ('00), whose description of the processes occurring during synapsis is similar to mine, finds that in the primary oöcyte of the rabbit the nuclear membrane is very indistinct during synapsis.

These and numerous other observations seem to show that the peculiar 
phenomena connected with synapsis are remarkably uniform throughout the plant and animal kingdoms; and though some of these phenomena, such as the behaviour of the nucleoles and the changes in the affinity of the nuclear membrane for stains, are difficult to account for at present, it is possible that they may ultimately be shown to have a very important relation to the transformations going on in the substance of the spirem.

\section{The Period of the Uniformly Distributed Spirem.}

There now occurs a set of simultaneous processes which affect the arrangement of the spirem thread and the position of the nucleus within the cell. The rearrangement of the spirem (Figs. 20,2I) is a further manifestation of the tendency, already noted during the latter part of the synaptic period, toward a loosening of the coils of the spirem and its more even distribution throughout the nuclear cavity. The thread is quite uniform in thickness, showing very regularly in triple-stained preparations the two rows of dark-staining granules, to which short fibres are attached. The effect is, in triple-stained material, to give to the thread a somewhat ragged look; in material stained with haematoxylin this is much less apparent, owing to the lack of differentiation of the granules in question, and to the general failure of the fibres to take up the stain. In the latter mentioned preparations the outline of the thread appears irregularly wavy, but not ragged. The thread, as shown by cross sections, is practically cylindrical. The nuclear membrane stands out sharply.

During the rearrangement of the thread, there occurs a change in the location of the nucleus as a whole, so that, instead of the position it has for some time maintained near one side or one end of the cell, it comes to be approximately central. The final result is such a symmetrical arrangement of the various parts of the cell as is shown in Fig. 22, Pl. VII.

The nuclear thread is now very uniformly distributed throughout the whole nuclear cavity. Portions of it are in contact at many points with the nuclear membrane. The course of the thread may best be studied in sections cut thick enough to include the whole or the greater part of a nucleus, stained with iron-haematoxylin and washed out in such a way as to decolorize the cell wall and cytoplasm, leaving the intra-nuclear substances still black. Fig. 23 is from such a preparation twenty-four micra in thickness. Even at this thickness the most favourably situated nucleus will be sectioned in one or both of the cutting planes, but enough is left to give an adequate notion of the course of the thread. The free ends observable in the figure are all on one or the other of the cut surfaces, and I have never found a free end except at a cut surface, or at so short a distance from the surface as to be easily accounted for by a slight displacement in cutting. A section thirty micra thick includes some entirely uncut 
nuclei, and from a study of such sections it is quite certain that the thread at this stage is continuous.

I have been able to find no regularity whatever in the course of the thread, except that it seems to be as evenly distributed as possible throughout the nuclear cavity. Sections sometimes give the impression of a greater massing toward the centre of the nucleus, but careful study shows this effect to be due to the greater number of thicknesses of the thread to be seen in looking through the middle part of the spherical nucleus. The portions of the thread which reach the periphery and then run back into the interior of the cavity might be described as loops, but in the arrangement and course of these loops there seems to be no regularity. There is no apparent relation between the number of loops at this stage and the number of chromosomes which are to be formed later. There are certainly many more than twelve peripheral portions of the thread, and in some cases I have been able to count more than twenty-four, although the exact determination of the number in any nucleus is extremely difficult; but as yet there seems to be no relationship between any definable portions of the thread and the individual segments into which it is later to be divided. Neither at this nor at any later stage of this division have I been able to detect any evidence, in the arrangement of the spirem or of the chromosomes, of a polarity of the nucleus, such as was described by Rabl ('85) for the prophases of nuclear division in animal cells, and as was found by Flemming ('87) in the spermatocytes of Salamandra. In this respect the pollen mother-cell of the lily offers a striking contrast to its immediate ancestors; in these, the spirem, before segmentation, has a very uniform arrangement, corresponding closely with that of the daughter-spirem of the previous division. Strasburger ('04), however, finds that in the pollen mother-cell of Tradescantia the spirem is arranged in a very regular spiral ; and both Strasburger ('88) and E. Overton ('91) have described an arrangement of the chromosomes and the nucleole in pollen mother-cells with reference to a 'Polfeld' and a 'Gegenpolseite.'

The external projections of the chromomeres show best in thinner sections stained with the triple stain, such as the one represented in Fig. 22. It is quite conceivable that the fine fibres, which run out for a short distance from these projections, may belong to a system which connects all parts of the thread with one another, and possibly with the cytoplasm as well; in such a case the greater part of the fibrous connexions may be either too delicate to be differentiated and distinguished with our present technique, or may have been destroyed in some of the processes involved in making the preparations. I have seen no direct evidence of such connexions in the lily; but similar systems of fibrous connexions between the chromomeres of various parts of the spirem have been found by Brauer ('93) in the spermatogonia and the primary spermatocytes of Ascaris, by Winiwarter ('00) in 
the primary oöcytes of the rabbit and of man, and by Schreiner ('04) in the primary spermatocytes of Myxine and Spinax. Such a system of linin connectives between all the chromatin bodies in the nucleus, if shown to be of general occurrence, would more closely relate the spirem stage to that of the reticulum, and might help to solve some of the problems connected with the migrations and changes in form of the intra-nuclear substances. Under favourable conditions, the internal differentiation of the thread into chromatin and linin is still apparent (Fig. 24); the fusion of the individual chromomeres brought together by the fusion of the parallel threads seems to be complete. Each chromomere appears to be made up of many smaller granules, and of course the observed fusion of the larger masses tells us nothing of what, if anything, has taken place between the smaller bodies of which they are composed.

In Fig. 23 two nucleoles are shown; the number is usually more than one, commonly two or three, not infrequently more. The nucleus is now located (Fig. 22), as nearly as may be, in the centre of the cell. The cell itself has assumed a generally spherical or elliptical form ; in the latter case its long axis commonly coincides with that of the anther sac. Cells are still often in contact in two's or three's, and then are flattened on the sides of contact. The form of the nucleus is approximately that of the cell, so that the thickness of the cytoplasmic layer is very uniform. The cell wall is generally quite thick, often unevenly so; in the latter case, the thickest portions are most commonly at the ends, if the cell is longer in one diameter.

\section{Longitudinal Splitting.}

While the spirem is in the evenly distributed condition just described, it undergoes longitudinal fission into two threads. Its fission is preceded by that of the chromomeres (Fig. 27), which is not simultaneous in all parts of the thread. The division of the chromomeres seems to be followed quite rapidly by that of the portion of the thread in which they lie, so that parts of the thread may be found split, with the halves more or less divergent, while contiguous portions are still undivided and contain a single row of large chromomeres. The resultant figures are strikingly similar to those found much earlier at the time of the fusion which produced the single spirem (compare Fig. 27 with Figs. $5^{-1} 7$, Fig. 25 with Fig. 13). This similarity in appearance gives some ground for supposing that the threads which we now see separating from each other may be identical with those which formerly united. As to this possibility I have no direct evidence to offer, since the fusion has been to all appearances complete and has continued over a long period. In the pollen mother-cell of the lily, dark-staining bodies embedded in the spirem, and dividing before the splitting of the thread, have been described and figured by Guignard ('85, '91), Mottier ('97), 
and Grégoire ('99). Mottier's figures of the chromatin bodies in the pollen mother-cells of L. Martagon and Helleborus foetidus are very similar to those which I have observed.

Fig. 25 shows a tangential view of a portion of the longitudinally split spirem, in which the course of the threads is easily traceable. Fig. 26 represents a thin median section of a nucleus in the same stage, in which the threads are frequently cut and occasionally displaced by the knife. In general the two threads are more or less tightly twisted about each other, in places so tightly that it is difficult or impossible to determine more than a single strand of double thickness ; in some places they are more widely divergent, and in others they run parallel for a distance without any twisting.

The general course of the double thread and its distribution in the nuclear cavity are at this stage the same as before the fission. The external projections of the chromomeres, with the attached fibres, do not show in the figures, but in material more favourably stained they are plainly present. These projections appear on what was, before the splitting, the outer surface of the thread, the inner surface of the daughter-threads (i. e. the plane in which the splitting has occurred) being quite smooth and evenly stained. Very shortly after the completion of the longitudinal fission, there is manifest a tendency for the thread to become aggregated in the central portion of the nuclear cavity, leaving fewer loops which reach to the nuclear membrane. The nucleole shown in Fig. 26 is very irregular in outline. This, however, is exceptional. Somewhat elongated nucleoles are occasionally seen, but the great majority are nearly or quite spherical, and they are seldom vacuolated, differing in this respect from their appearance in earlier stages.

\section{Chromosome Formation.}

In nuclei in which the tendency toward a central aggregation of the spirem first becomes apparent there occasionally appear free ends of the thread; as the spirem is double, these ends are always in pairs. They occur in sections thick enough to include a whole nucleus, so that the break in the thread cannot be due to cutting. The free ends observable are usually at or near the periphery of the nucleus. Sometimes two pairs of ends lie very close together, and in some such cases they can be seen to be connected by a very lightly-staining substance. It is evident that at these places the transverse segmentation of the double thread is occurring or has just occurred. The number of free ends, if any, to be distinguished in a nucleus at this time is very small; and since, if segmentation were simultaneous in all parts of the thread, twenty-four pairs of ends would be present, it follows that the segmentation is successive. Whether any 
particular order is followed in this matter, such as a breaking of the thread first into two parts, each of these into two or three, and so on, I have been unable to determine.

The massing of the thread toward the centre becomes more and more marked, until the condition shown in Figs. 28 and 29 is reached. The close and apparently tangled mass at the centre includes a considerable part of the spirem, together with one or more rounded nucleolar masses. Another nucleole, or nucleoles, may frequently be seen in the peripheral region of the nucleus. It is while the nuclear contents are in this condition that segmentation, for the most part, occurs, although, as has been said, the first breaks may appear before the tendency toward massing has become so marked. In Fig. 28, showing a comparatively early stage of the massed condition, few free ends of the thread are to be seen, and these are all at or near the periphery of the nucleus; for the most part, the portions of the thread in the peripheral region consist of loops which originate in and return to the central aggregation. At this stage also two pairs of the free ends commonly lie close together (as at $a$ and $a^{\prime}$, $b$ and $b^{\prime}$, Fig. 28). As time goes on, fewer of the continuous loops are visible, and correspondingly more free ends. Fig. 29 shows one of the later stages, at which a considerable number of free ends are visible, all in the peripheral region. The general effect of a section of such a nucleus is that of strands radiating like the spokes of a wheel from the central mass, each spoke consisting of two separate threads more or less twisted about each other. The exact number of free ends at this stage is very difficult to determine with accuracy; but in favourable cases enough may be counted to make sure that nearly all at least of the twenty-four pairs which would be present at the time of complete segmentation are located in the peripheral region. It follows from the facts described that the central massing of the spirem is due to a rearrangement of the twisted, unsegmented double thread in such a way as to form twelve loops, continuous with each other by means of the centrally massed strands, and with the bend which produces each loop located in the peripheral region of the nucleus; and that transverse segmentation occurs in the peripheral portion of the loops, so that each of the chromosomes so formed has its ends at the periphery and its central portion in the central region of the nucleus.

Miss Sargant ('96, '97) has observed a similar stage of aggregation in both the pollen mother-cells and the embryo-sac mother-cells of Lilium Martagon. She describes this 'second synapsis' as occurring just after the completion of segmentation, and finds in it the phenomena characteristic of the earlier stage to which the term 'synapsis' is more generally applied-namely, a clustering of the chromosomes about an amorphous nucleolar mass against one side of the nuclear membrane, and the apparent 
disappearance of the latter. In each of these respects her description is inapplicable to Lilium canadense. The transition to the synapsis-like figure occurs here before segmentation, or when that process has barely begun. The nuclear membrane remains distinct, the tangled mass is always central instead of peripheral, and the nucleoles retain in general their rounded form. Occasionally a nucleole is seen that is elongated or somewhat irregular in outline, but never at all approaching the curious 'sickle shape' of synapsis. The nucleoles sometimes appear vacuolated, sometimes homogeneous. I have seen no evidence in this or in any other stage of any genetic connexion between the material of the nucleoles and that of the chromosomes.

Ernst ('02) also describes and figures a stage of aggregation following segmentation in the macrospore mother-cells of Paris and Trillium, but he confuses it with the much earlier synapsis, properly so-called, which stage he seems not to have observed.

Schaffner ('97) finds, in the macrospore mother-cell nucleus of Lilium philadelphicum, that after longitudinal fission the chromatin thread becomes arranged in twelve loops, the 'head' of each loop being near the nuclear membrane. Segmentation occurs by the breaking apart of these loops; that is, the transverse breaking occurs in the central part of the nucleus, so that the peripheral portion of each loop becomes the central portion of one of the newly-formed chromosomes. The same arrangement of the spirem and the same method of segmentation are described as characteristic for the heterotypic divisions of both animals and plants in a recent paper by Farmer and Moore ('03). My figures agree both with those of Schaffner and with those of Farmer and Moore as to the formation of the loops; my series of preparations, however, makes it certain that one of the loops does not represent that part of the spirem which is destined to form a chromosome, but that, on the contrary, the peripheral portion of the loop marks the region in which the separation between two adjacent chromosomes is to occur. While the general arrangement of the segmenting spirem is as I have just described, it is subject to occasional variation. For instance, in Fig. 29 one newly-formed chromosome $(a \alpha)$ lies comparatively free from the central mass and can be traced throughout its length. A single chromosome from a nucleus at about the same stage is shown in Fig. 33 ; but on account of the closeness of the central mass and the usual arrangement of the chromosomes with reference thereto, it is only in exceptional cases that a chromosome can be so followed for its entire length. Between the time of longitudinal fission and that of segmentation there is little if any increase in the thickness of the thread; but as soon as the free ends begin to appear, the process of thickening seems to go on more rapidly, as well as somewhat unevenly, so that a decided difference in thickness becomes apparent, even between different parts of the same 
segment. A comparison of Figs. 28 and 29 with Fig. 26 shows that for the most part the thickness is little greater at the time of segmentation than at that of longitudinal fission, although some portions of the thread have already thickened considerably. Fig. 33 shows a marked difference in thickness between different portions of the same chromosome.

The chromosomes, formed as above described, now enter upon a period of shortening and thickening, two stages in which are shown in Figs. 30 and 32. Quite early in this period, usually (Fig. 30), the chromosomes take up a position close to the nuclear membrane. This peripheral arrangement, however, may not be effected until a considerable thickening has occurred; in such cases the massing at the centre persists, sometimes nearly to the stage of Fig. 32 , with relatively short, thick chromosomes radiating toward the periphery. The various chromosomes do not shorten and thicken at the same rate; and it is common to find in the same nucleus long, slender chromosomes, and other much thicker ones, not more than half as long. Chromosomes $a$ and $b$, Fig. 32 , illustrate this difference, which is often much greater than in this instance.

Figs. 33-54 show individual chromosomes at various stages, from segmentation to a time immediately before their arrangement on the equatorial plate. Such a series shows that the original longitudinal split, which is plainly apparent at the time of segmentation (Figs. 28, 29, 33), remains distinct until the chromosomes have reached their mature form. The chromosomes are always plainly double, and their double nature does not follow, as the figures show, from a folding over of a single chromosome and the approximation of its ends. The plane of separation between the daughter chromosomes on the equatorial plate is that of the original longitudinal split. The notion of the origin of the double appearance by a folding has found support in the shape of many of the chromosomes immediately after their formation, when, owing to the fact that their length is greater than the diameter of the nucleus, they are necessarily more or less curved, bent, or even looped. The chromosome shown at aa, Fig. 29, is bent into a loop at a point not very far from its centre; and the chromosome at the same stage, shown in Fig. 33, is curved into a rather shallow $U$, the curve following in this case pretty closely the concavity of the nuclear membrane. As the chromosomes shorten they usually straighten out more or less (Figs. $34,36,37,3^{8}$ ); but in some cases (Figs. 40, 44, 53, 54) one or both daughter chromosomes remain curved down to a very late stage.

Another point upon which stress has been laid as evidencing the formation of a double chromosome by the bending of a single one is the fact that the two parts are commonly continuous or fused at one end. It is true that the daughter chromosomes often lie closely in contact at one or both ends; and sometimes it is difficult to make out a line of demarca- 
tion between the ends so in contact. This is especially true in triplestained sections; but in material carefully stained with iron haematoxylin, in which the colour is washed out of everything except chromosomes and nucleoles, it is possible in the majority of cases to determine that the ends of the daughter chromosomes, even though in contact, are really separate. In some cases it is impossible to distinguish the separate ends, and there appears, at least, to be a more or less complete fusion. The chromosomes represented in Figs. 43 and 46 show such an apparent fusion, and in those shown in Figs. $3^{6}, 3^{8}$, and $4^{2}$ the fusion is less complete. In Fig. 42 the daughter chromosomes are in close contact at both ends, and it may be, though from their position it is impossible to determine, that a similar partial fusion has occurred at both ends. The daughter chromosomes in Fig. $5^{2}$ are closely in contact at one end, but there is no evidence of fusion.

Whether this fusion at one or both ends be real or apparent, it is certain that its occurrence in Lilium canadense is much less common than has been described for many species of this and other genera. The phenomenon is not noticeably more frequent at any one stage than at any other, although I have never found it before a certain amount of shortening has occurred; and at any period the great majority of the chromosomes are plainly two-parted throughout their length.

At the time of segmentation the halves of each mother chromosome are several times twisted about each other (Fig. 33); they are closely appressed in most parts, and there is seldom any considerable divergence at any point. As the process of shortening and thickening proceeds, its natural result is a gradual lessening of the number of twists. The course of untwisting may be followed in Figs. $33,34,37,3^{8}$ and 41 . A common effect of this untwisting is a lessening of the closeness of contact between the daughter chromosomes, and a divergence from each other at one or both ends or in the middle. Some retain a considerable twist in the mature form, e. g. Fig. 50. Perhaps the commonest case is the retention of a quarter- or half-twist in the middle portion, with the ends more or less diverging (Figs. 35, 40, 45, 47, 5I). Occasionally the twist is entirely lost, and the daughter chromosomes remain in contact only at the centre of each; thus such a peculiar form may arise as is shown in Fig. 44, where each daughter chromosome is bent into a $U$, the two U's lying in planes perpendicular to each other. In some cases the daughter chromosomes lie close to each other and approximately parallel, with little or no twisting; instances of this sort are shown in Figs. 36,42 and 52 . They may remain in contact at one end, diverging widely at the other (Fig. 43); or they may be in contact at or near both ends, with the centres diverging (Figs. 49, 53). In these various ways, as a result of the untwisting of the daughter chromosomes and of their adhesion or divergence at various 
points, arise the many shapes described for the heterotypic division: I's, J's, X's, Y's, V's, U's, and O's, as well as aberrant forms which are difficult of classification.

As a rule, the daughter segments of any mother chromosome shorten and thicken at about the same rate; but this is not always the case. A marked instance of unequal shortening at an intermediate stage is shown in Fig. 35. The difference in length between chromosomes of the same nucleus or of different nuclei at about the same stage, due to variations in the rate of shortening, persists down to the time of spindle formation. When the chromosomes are being pulled into place on the equatorial plate some of them have attained nearly or quite their final form, while others are still comparatively long and slender.

At the time of segmentation the distinction between chromatin and linin may still be detected in some cases, though I have not obtained any preparations of this or later stages in which this differentiation is as well marked as in some of the earlier figures. Shortly after segmentation there appear, in a few of my preparations, chromosomes in which the differentiation is fairly clear, and which show a double row of chromomeres in each daughter chromosome, an appearance already noted at this stage in the lily by Grégoire ('99) and Strasburger ('00), and in the pollen mother-cells of Naias by Guignard ('99), and interpreted by these authors as an early indication of the second longitudinal splitting. Miss Sargant ('96, '97) also finds a double row of 'chromatin dots' in each daughter chromosome; but her figures indicate that, as in the earlier stages, these dots are merely the external projections of the chromomeres. Fig. $3^{\mathrm{I}}$ represents, on a larger scale, two chromosomes at the same stage as that of Fig. 30 , in which appears this differentiation between chromatin 'and linin. A few short fibres are also seen attached to the chromomeres. It is not uncommon to find a slight forking of the ends of the daughter chromosomes (as at $a$, Fig. 3I) ; and rarely there appears (b, Fig. 3I) a partial split in the interior of the daughter chromosome. There can be no doubt, I think, that the appearance of the two rows of chromomeres and the occasional partial fission of the daughter chromosomes really indicate the initiation of the second longitudinal split which is to be completed after the separation of the daughter chromosomes in the metaphases. As the chromosomes shorten still further, the visible distinction between chromatin and linin entirely disappears, and with it all suggestion of a longitudinal fission of the daughter chromosomes. From this time on the substance of the chromosomes appears perfectly homogeneous.

The fine fibres attached to the chromosomes remain visible, and the ragged appearance of the chromosomes increases with their shortening, partly from the crowding together of the points of attachment of the fibres, partly from a growth of the latter in length and thickness. There is thus 
a gradual increase in the total amount of fibrous material in the nucleus down to the time of the disappearance of the nuclear membrane. An indication of this increase of fibrous material appears in Fig. 32, drawn from iron haematoxylin material; but it is much more noticeable in preparations treated with the triple stain. The fibres are granular and usually crooked or wavy. Some of the longer ones are now seen to connect separate chromosomes; others run from the chromosomes to the nuclear membrane, and often seem to be continuous through the membrane with cytoplasmic fibres. Very short fibres are sometimes attached to the nucleoles, but the latter commonly appear quite detached from other nuclear substances. The chromosomes now stain distinctly red in the triple stain, and, leaving out of account the blue-staining fibres, which cause the ragged appearance mentioned, each chromosome has a somewhat uneven or undulating outline (Figs. 33-54).

The nucleoles remain generally spherical, sometimes appearing elongated, and, as time goes on, not uncommonly showing one or more small bud-like attachments ( $n$, Fig. 32 ), plainly of nucleolar matter. In stages still later than that of Fig. $3^{2}$ the number of intra-nucleolar vacuoles increases; the nucleoles show a decreasing affinity for the safranin and an increasing affinity for the orange. In the latter part of the period of chromosome development, but before the initiation of the cytoplasmic processes which directly result in the formation of the spindle, the nuclear membrane begins to lose its smooth, even appearance, becoming more or less granular and irregular or wavy in outline. Just before the disappearance of the nuclear membrane, the two or three nucleoles usually present in the nucleus up to this time break up into a much larger number of bodies, which appear as rounded droplets scattered through the nucleus. If the nucleole has retained its affinity for the safranin up to the time of its fragmentation, these small nucleoles appear at first red; but, as shown by preparations in which a succession of stages appears in the same anther sac, their staining power often gradually diminishes.

When the nuclear membrane gives way, and the cytoplasmic fibres push into the nuclear cavity, the chromosomes aggregate into a close, irregular mass at the centre of the cell (Fig. 55, Pl. VIII). At the same moment the small nucleoles already spoken of disappear, and there appear in all parts of the cytoplasm a great number of still smaller, rounded, usually red-staining bodies. It seems quite certain that these granules result from a second fragmentation of the nucleolar material and its extrusion, perhaps in a state of solution, into all parts of the cell. $U_{p}$ to this time the chromosomes have retained their ragged appearance, due to the attached fibres; but from the beginning of the transformation of the multipolar into the bipolar spindle, the chromosomes appear with smooth outlines and with fibres attached to them only in bundles and 
at definite points. The change is not in the outline of the chromosome itself, but in the attached fibrous material. It would seem that all of this material formerly present within the nucleus is made use of in the construction of the spindle.

At the time of the disappearance of the nuclear membrane, the chromosomes have not, as a rule, shortened to their final form; and, as in earlier stages, there is, between individual chromosomes, often considerable difference as to the amount of contraction that has occurred. The shortening is completed, however, by the time of their arrangement upon the equatorial plate (Figs. 56,57). Even yet, as appears best in polar view (Fig. 57), there is a considerable diversity in their length, due for the most part to an actual difference in mass between individual chromosomes; and as to their arrangement on the spindle, their degree of curvature, and the relation to each other of the daughter segments, there is, as many writers have noted, a remarkable diversity.

While the multipolar spindle is being transformed into the bipolar form the individual chromosomes become separated from the close mass in which they appear immediately after the collapse of the nuclear membrane. By the time of the formation of the 'multipolar diarch' figure the chromosomes are scattered irregularly along the whole length of the spindle. The majority of them lie with their long axes parallel, or nearly parallel, with the axis of the spindle; and a chromosome so arranged is often seen to have a bundle of fibres attached at the end nearest the equatorial plane. Others lie transversely to the spindle.

The chromosomes do not reach the equatorial plane at the same time; and the separation into daughter chromosomes of those first arriving in this plane begins while the tardier ones are still scattered along the spindle. It is also not uncommon, before a chromosome has reached its position in the plate, to find its daughter segments diverging at one end toward the poles of the spindle, with a bundle of fibres connecting each diverging end with the corresponding pole. By the time of the completion of the plate, therefore (Fig. 56), it is a regular thing to find that the separation of some at least of the daughter chromosomes has already begun; but the process of separation is for a time quite slow, even after the plate is fully formed.

The chromosomes of the equatorial plate are arranged nearly in a single plane; they seem to be somewhat crowded (Fig. 57), so that often one or more may be slightly above or below the plane of the rest. The apparent divergence from a single plane shown by the chromosomes in Fig. $5^{6}$ is due in part to the fact that the plane of the section is not quite perpendicular to the equatorial plane of the spindle.

The chromosomes still show much the same variations in shape that have been noted at earlier stages. Each chromosome is composed of two 
short, thick bodies, so closely appressed to one another that the double nature of the whole is often quite difficult of detection. In the best iron haematoxylin preparations, however, the daughter segments can always be distinguished. In no case have I found any evidence of a splitting of the daughter chromosomes at this stage, such as Strasburger ('00) describes in Lilium Martagon. Figs. 57 and 59 show their appearance in polar view; Figs. $5^{6}$ and $60-67$ represent them as seen when the line of vision is practically in the equatorial plane. The chromosomes commonly retain something of their original twist (Figs. 59,60,63-67, and most of those shown in Fig. 57); they are gradually untwisted by the separation of the daughter chromosomes. Others appear simply as pairs of straight or curved rods in contact at their middle portion or throughout their length ( $a$, Fig. 57, Fig. 6I). I have found none which were in contact at the ends and divergent in the middle, excepting in such cases as Fig. 67 , in which the opening in the middle is plainly due to the beginning of the separation of the daughter chromosomes. Rarely the daughter chromosomes appear to be completely fused at one end (Fig. 62).

Fig. 57 shows the arrangement of the chromosomes in the equatorial plate as seen in polar view. I have found no variations from the typical number (twelve) in any case in which the section was thick enough to exclude the possibility of one or more being missing. The majority of the chromosomes are arranged about the periphery of the plate, with a few, commonly two or three, lying at various angles in the central region. Of those which lie in the periphery, the usual orientation is radial, as the figure shows; but it is not uncommon to find a peripheral chromosome which lies tangentially to the spindle.

Each radially arranged peripheral chromosome (Fig. $5^{6}$ ) has a bundle of spindle fibres attached to the inner end of each daughter segment, the outer end then extending out perpendicularly from the spindle into the cytoplasm. To this statement as to the attachment of the fibres to the radial chromosomes I have found no exception. In viewing the spindle from the side (as in Fig. 56), these radially arranged chromosomes present quite different views, according as they lie in the central portion of the figure, and are then seen from the end, or as they lie at the sides, and are seen laterally. In the former case, the ends of the two daughter chromosomes turned toward the observer are usually seen to be in close contact and often flattened against each other. These two ends may lie side by side in the equatorial plane (Fig. 56 , second from right), or in a plane parallel with the spindle axis (Fig. 64), or in any intermediate position. This variation in the relative position of the outer ends is accounted for by the different degrees to which the daughter chromosomes are twisted about each other, and by the varying amounts of untwisting which they 
have undergone as they are being pulled apart. In some cases (Fig. 64) there is an appearance which may be interpreted as that of four ends turned toward the observer, especially when viewed under medium magnification. But careful study of such a figure with a higher power shows that two of the four parts are at a higher plane and are really the ends of the daughter chromosomes, while the other two are in a lower plane and represent simply lateral protrusions of the daughter chromosomes due to their twisting about each other. Fig. 64 shows how such a four-parted appearance may arise. As already remarked, I have never found an instance of an actually four-parted chromosome (i.e. one showing the second longitudinal split) in the equatorial plate.

In case the radially arranged chromosomes are seen laterally (Figs. 60-63), their two-parted nature is even more plainly evident. In this position we can note the variations in form already described; the daughter chromosomes may be somewhat twisted about each other, with their outer ends either diverging (Fig. 60), in contact (Fig. 63), or apparently fused (Fig. 62); or the daughter chromosomes may be simply in contact, with little or no twisting (Fig. 6I).

As has been said, the majority of the chromosomes are of the type already described, namely radially arranged and attached by their inner ends to the periphery of the spindle. A few, however, which lie peripherally are tangential to the spindle. These tangentially arranged chromosomes are always, so far as I have observed, of the twisted, closely appressed type. The attachment of the spindle fibres to the daughter chromosomes in such a case is not necessarily at the end; it may be at either end, or at or near the middle, or at any point between the middle and either end. Figs. $65-67$ furnish a series, showing this variety in the point of attachment of the spindle fibres. The attachment to the daughter segments of any parent chromosome is always, however, at corresponding points.

The chromosomes lying in the interior of the equatorial plate $(b, c, d$, Fig. 57), like the tangential chromosomes, typically consist of twisted, closely appressed segments; and, again like the tangential chromosomes, the attachment here is not at any definite point, but may be anywhere along the length of the segment.

To sum up the condition of the chromosomes as regards their attachment to the spindle: in a large majority of cases the fibres are attached at, or very near, one end of each daughter chromosome; but they may be attached at the middle, or at any point between the middle and either end. It will be shown that the differences between the forms exhibited by the daughter chromosomes in the metaphases and anaphases result from this variation in the point of attachment of the spindle fibres. 


\section{The Separation of the Daughter Chromosomes.}

My observations as to the orientation of the chromosomes in the equatorial plate, and their behaviour in the metaphases and anaphases, agree essentially with recent descriptions of Strasburger ('00) and Mottier ('03).

In case of the attachment of the spindle fibres to one end of each daughter chromosome, the separation is completed by the untwisting of the daughter chromosomes, if any twist remains, and their gradual pulling apart, the separation beginning, of course, at the end to which the fibres are attached, and progressing toward the other end. The last points of contact between the daughter chromosomes are, therefore, at the end of each which was originally unattached to the spindle, in the case of the radial chromosomes at the outer end, this final contact occurring in the equatorial plane. Figs. 68 and 69 show the progress of this separation, as seen when looking at the spindle in the equatorial plane. These figures represent the chromosome viewed in the same way as in Fig. 64, but at later stages. The relative position of the outer ends of the daughter chromosomes, it is seen, changes with the degree of untwisting ; in Fig. 69, the end of one daughter chromosome is turned outward, that of the other toward the interior of the spindle.

Figs. 70-72 show similar stages, the chromosomes being viewed laterally. Figs. 70 and $7 I$ show about the same amount of twisting of the daughter chromosomes as appears in Figs. 60 and 63 ; Fig. 72, in which there is no twisting, is comparable with Fig. 61. Fig. 72 illustrates the often-observed phenomenon of an elongation or stretching of the separating portions of the daughter chromosomes, due to their plasticity. This plasticity of the chromosome material is also frequently shown by the appearance of a projection (Fig. 70) at the point to which the spindle fibres are attached; the remaining substance of the attached end of the chromosome lags behind, as it were, giving to the daughter chromosome a slightly hooked form (Fig. 70), which is retained in the anaphases. From the more common radial arrangement of the chromosomes in the equatorial plate, and the attachment of the spindle fibres to the inner end of the daughter chromosomes on the side toward the pole, it is plain that this short hook will in most cases be turned toward the interior of the spindle, and so will not ordinarily be visible if the chromosome be viewed from the side turned outward; either a lateral view, or one of that side of the chromosome turned toward the interior of the spindle, will be necessary to show the presence of the hook.

At about the stage represented by Fig. 69, namely, that at which the daughter chromosomes remain in contact only by their equatorial ends, a longitudinal split (Figs. 58, 74-77) appears in each daughter chromosome. The occurrence of this split seems to be very sudden, and when first seen 
it usually extends the full length of the daughter chromosome, excepting at its polar end. Fig. 73 represents the only instance $I$ have found in which an early stage of the split was visible. In this case a fission appears in the middle portion of one daughter chromosome, the equatorial end still showing no evidence of division. This fission of the daughter chromosomes is usually in a plane which passes through the chromosome and the central axis of the spindle; it would seem, therefore, to represent a split at right angles to the original one which produced the daughter chromosomes. But on account of the twisting and untwisting which the chromosomes have undergone, it is impossible to be certain upon this point.

The newly separated granddaughter chromosomes immediately diverge at their equatorial ends, giving to each daughter chromosome the form of a $\mathrm{V}$, with the apex toward the pole. All four equatorial ends of the $\mathrm{V}$ are usually turned outward (Figs. 74, 75, 77); in Fig. 77 the chromosomes are shown as seen from the interior of the spindle, the equatorial ends then being turned away from the observer. Fig. 76 shows an unusual case, in that the two V's lie in planes perpendicular to each other; the four equatorial ends are in this case also turned outward. The upper daughter chromosome in this figure shows some evidence of being split throughout its length, the polar end being apparently double.

As the V-shaped daughter chromosomes finally separate from each other and approach the poles of the spindle (Figs. 79, 88), they commonly contract more or less, losing the long-drawn-out appearance which they have frequently presented during the process of separation, and regaining about the same length that they had in the equatorial plate.

It is not uncommon for single chromosomes to remain attached in the equatorial plane, even after their fellows have reached, or nearly reached, the poles. Fig. 78 represents two $\mathrm{V}$-shaped daughter chromosomes which have undergone longitudinal splitting; one arm of one has separated from the corresponding arm of the other, but the remaining two arms are still in contact, and indeed are so closely attached as to appear fused. In this case the angles of the V's have been pulled nearly to the poles of the spindle. A similar case is shown in Fig. $5^{8}$. These are instances of the possibility of a fusion, or apparent fusion, between two separate portions of the chromosome substance when closely appressed-a possibility which was illustrated in an earlier stage by the occasional fusion of the daughter chromosomes at their ends. It is not surprising that such a fusion of two masses of this very plastic substance should occur; the striking fact is rather that it occurs so seldom. That in such cases there is no real fusion, but only a temporary adhesion, is suggested by the history of the chromosomes, which, in the nucleus of the animal sperm, form a seemingly homogeneous mass, but which reappear as separate entities before the fusion of the sexual nuclei. 
Such appearances as those of Figs. 79 and 88 would lead to the conclusion that the newly-formed segments of the daughter chromosomes remain attached at the angle of the $\mathrm{V}$-in other words, that the second longitudinal split is not completed, at least in this mitosis. This is the regular appearance if the chromosomes are viewed, as is the case in these figures, from the exterior of the spindle. But a very different impression is gained (Fig. 80) by observing that side of the chromosomes turned inward. It will be remembered that the slight hook which is commonly formed upon the polar ends is usually turned inward. The hooked shape of the daughter chromosomes is shown in Fig. 80, and it is plain that each is split throughout its whole length, the polar end of each granddaughter chromosome being turned inward, its equatorial end, as we have seen, turned outward. It would seem that this inward hooking of the polar ends, with often more or less overlapping of the hooked ends of the granddaughter chromosomes, obscures the view of the splitting from the outer side, and gives the appearance of a continuity between the two arms of the $\mathrm{V}$ at the angle. At the angle of each $\mathrm{V}$ in Fig. 79 there is a slight indentation, which is doubtless an indication of the completed splitting. It is not always the case that an interior view shows the completed splitting so plainly as does Fig. 80, but such figures are so common that there is no doubt that the complete separation of the granddaughter chromosomes in the anaphases of this division is the general rule. It will be seen that the splitting of the daughter chromosomes shown in Fig. 80 has been accompanied by the separation of the spindle fibres into distinct clusters, one cluster attached to each granddaughter chromosome.

The appearances just described are characteristic for the large majority of the chromosomes; but in cases of the attachment of the spindle fibres otherwise than at the ends of the daughter chromosomes (Figs. 65-67) the resulting figures are somewhat different. Figs. $8 I$ and $8_{3}$ represent later stages in the separation of such chromosomes; and it will be seen that, as the daughter chromosomes retreat toward the poles, a bend occurs at the point of attachment ; that is, the more common hooked form is exaggerated, and each daughter chromosome consists of two arms whose relative length depends upon the point of attachment of the fibres. The result of the splitting of such daughter chromosomes is shown in Figs. 82 and 86 ; the derivation of Fig. 82 from such a form as is shown in Fig. 81 is plain; and, on the other hand, Fig. 82 differs from the commoner type (Fig. 80) only in the greater length of the hook at the polar end of each granddaughter chromosome. If the fibres are attached near the middle, the two arms of each daughter chromosome, and, after the second longitudinal split, those of each granddaughter chromosome, will be of about equal length; each daughter chromosome will then (Fig. 85) consist of two V's with their angles in contact and turned toward the pole, and with their arms diverging. 
Fig. 84 shows an early stage in the longitudinal split; one end of each $\mathrm{V}$-shaped daughter chromosome is here double, the other end still undivided. Fig. 85 is therefore to be compared with Fig. 76 , the difference in appearance between the two figures being due solely to a difference in the place of attachment of the spindle fibres. Fig. 87 shows two pairs of daughter chromosomes from the same spindle, each pair showing the completed longitudinal fission; in one case the granddaughter chromosomes are only slightly hooked, in the other they are $\mathrm{V}$-shaped. In this case, comparison shows that the total length of the two arms of the V-shaped granddaughter chromosomes is about equal to that of the single arm, with its short hook, of the commoner form.

Fig. 88, P1. IX, shows the daughter chromosomes approaching one pole ; in Fig. 89 they have reached the diaster stage. Twelve V's are shown in Fig. 88 ; in Fig. 89 the daughter chromosomes are so close together that it is impossible to distinguish them at their angles; twenty-two ends turned away from the pole are visible, and in the preparation two others may be observed underneath those shown in the figure. In each of these cases, therefore, all of the chromosomes were originally attached to the spindle at their ends, and the longitudinal split of each daughter chromosome resulted in a single V. Fig. 90 (from a section too thin to contain all of the chromosomes) represents a slightly later stage than Fig. 89 ; the chromosomes have been drawn closely together at the poles. A large number of 'extranuclear nucleoles' are still present, and they show a tendency to accumulate in the equatorial region, in which the new cell-plate is to be formed.

\section{The Reconstruction of the Daughter Nuclei.}

When the daughter chromosomes reach the polar region they are drawn tightly together, as we have seen, the free ends of the V's radiating outward and curving toward the equatorial region. These free ends now come closer and closer together, the ultimate result being an extremely dense mass (Fig. 9I), in which it is difficult to trace the outline of any individual chromosome. At this stage a membrane appears about the daughter nucleus. After the membrane is formed, the nucleus begins to grow in size (Fig. 92), and the chromosomes become separated once more by clear spaces filled with nuclear sap. This growth of the nucleus is contemporaneous with the formation of the cell-plate and the new cellwall. After the appearance of the nuclear membrane, the extra-nuclear nucleoles are most numerous in the neighbourhood of the daughter nuclei (Figs. 9I-93); many of the nucleoles are larger than during the continuance of mitosis, as though some of the smaller ones had united. I have never seen any nucleolar substance within the daughter nucleus, however, at this or at later stages. This seems to be generally the case in the daughter 
nuclei of the first division in the pollen mother-cells of Angiosperms. In Podophyllum and Helleborus, however, according to Mottier ('97), nucleoles appear in these nuclei.

The nucleus lies very close to the cell-wall; its outline, when the nuclear membrane first appears (Fig. 9I), is irregular, especially on the side toward the equatorial plane of the spindle; as the nucleus grows it becomes more rounded (Fig. 92), but remains always flattened in the axial plane of the spindle.

While the nucleus is growing, the chromosomes seem to stretch out, becoming longer and slenderer (Figs. 92, 93). Their free ends, extending toward the equatorial plane of the spindle, become curved in such a way as to bring the end of one arm of a $\mathrm{V}$ into contact with the end of an arm of another $\mathrm{V}$; these ends then apparently fuse. At the same time, the ends by which the granddaughter chromosomes were in contact at the angles of the V's also seem to have fused, the final result being a single continuous closed spirem. Fig. 92 shows the spirem, viewed laterally, at the time of the formation of the cell-plate; Fig. 93 shows an oblique view of the nucleus after the completion of cell-division. From these figures it appears that, although the strands of the spirem become somewhat bent and curved, they still retain the general form which results from the joining of the $\mathrm{V}$-shaped chromosomes in the manner just described. Looking at the nucleus, therefore, as in Fig. 93, one sees a sort of rosette, formed by the arms of the V's diverging from an open space about what was formerly the polar region, the spirem lying almost entirely in the peripheral region of the nucleus. The nucleus never passes into anything resembling a resting condition. A few achromatic fibres are sometimes seen attached to the spirem strands; but the latter retain their distinct outlines and show no sign of breaking up or reticulation. I do not find, as did Mottier ('97) at the time of the formation of the cell-plate, a shortening of the spindle fibres and a closer approximation of the daughter nuclei; in Lilium canadense the nuclei remain near the cell-wall in about the positions occupied by the poles of the first spindle.

\section{The Homoeotypic Division.}

\section{The Prophases.}

While the processes involved in the division of the pollen mother-cell nucleus extend over a very long time, the succession of events in the division of the daughter nuclei is extremely rapid. Practically the whole series of stages may often be traced within a single anther sac.

The first evidence of a preparation for the new division is seen in a further increase in size of the nucleus, accompanied by a loosening 
and spreading apart of the spirem thread, which is now seen to be composed of segments (Figs. 94, 95), with their ends often close together or in contact, as though they had just broken apart from one another. Each segment has the shape of a $\mathrm{V}$ with its arms more or less curved. The angle of the $\mathrm{V}$ is on what was in the former division the polar side of the nucleus, and its free ends are on the side toward the partition-wall between the daughter-cells (the equatorial plane of the first division figure). Fig. 94 shows this arrangement of the V's, the closed angles being on the upper side of the figure; a few free ends are visible on the lower side. In some cases an end of one $\mathrm{V}$ lies directly over the end of a neighbouring $\mathrm{V}$, and it is impossible to determine whether they are separate or attached. A comparison of Fig. 94 with Figs. 89 and 92 can leave no doubt, I think, that the V-shaped chromosomes which appear in the prophases of the second division are identical with the daughter chromosomes of the first division. Their arrangement is the same, except for the bending and curving due to their being gathered into the rounded cavity of the daughter nucleus. They are somewhat longer and thinner, a result of the elongation which, as has been mentioned, occurs after the formation of the daughter nucleus. The $\mathrm{V}$-shaped chromosomes in Fig. 94 seem to be closed at their angles ; but certain of the V's in Fig. 95, which gives a more oblique view of the nucleus than does Fig. 94, lie in such a way that it is evident that the two arms (the granddaughter chromosomes of the former division) are only in contact, but not fused, at the angle of the $\mathrm{V}$. In the nucleus shown in Fig. 95, as in that of Fig. 94, there are twelve V's.

The nucleus continues to increase in size, becoming at the same time less flattened, so that it is, at the time of the disappearance of the nuclear membrane, nearly spherical. The chromosomes remain in the peripheral region, the central portion being occupied by nuclear sap.

As the membrane breaks down and the cytoplasmic fibres enter the nuclear cavity (Fig. 96), the chromosomes are crowded into a close mass, as in the previous division. No material change has taken place in the appearance of the chromosomes since the segmentation of the spirem. When they are being pulled into place on the spindle it is often apparent that the two arms of each are really separate. Figs. 97-100 represent individual chromosomes at this stage. The arms remain in contact at the end at which they were in contact in the anaphases of the previous division; but at other points they may be variously in contact or divergent, resulting in figures which remind one of many of the various forms of the chromosomes of the first mitosis. They differ, however, from the heterotypic chromosomes in that there is never any twisting of the two parts about each other.

Immediately after the disappearance of the nuclear membrane, as in the first division, the chromosomes lose the ragged fibres which have 
been attached to them; these fibres seem to be used in the formation of the spindle. Each daughter chromosome has now only a single bundle of fibres attached, in the majority of cases, at, or close to, its end.

\section{The Equatorial Plate.}

Fig. IOI shows the equatorial plate in lateral view ; in Figs. 104-106 are represented individual chromosomes similarly viewed. The majority of the chromosomes are attached to the spindle at, or very close to, the end at which the daughter chromosomes are in contact with each other. To each daughter chromosome a bundle of fibres is attached, running toward the corresponding spindle-pole. In general the chromosomes lie in a direction which approximates more or less closely that of the long axis of the spindle. The two daughter chromosomes may be nearly parallel with each other, pointing toward the same pole (Fig. 104); or they may diverge toward opposite poles (Fig. I06). Less commonly, the chromosomes stand out nearly or quite at right angles to the axis of the spindle (Fig. I05).

The arrangement of the chromosomes in the equatorial plate, as well as their number, are best determined in a polar view (Figs. I02, I03). Usually the chromosomes are attached at the periphery of the spindle; it is not common to find any of them in the interior of the equatorial plate, as is regularly the case in the first division, although this occasionally happens, as appears in the lower of the two cells represented in Fig. 103. The general appearance of the chromosomes in polar view is that of V's, usually considerably foreshortened on account of the orientation just described. The inner end of one arm of a $\mathrm{V}$ is directly superposed in such a view over the inner end of the other arm, as follows from the manner of attachment to the spindle shown in Figs. 104-106. The chromosome as a whole, then, lies in a plane nearly perpendicular to the equatorial plane.

The plate shown in Fig. IO2 contains fourteen V's, instead of twelve, which, as has been said, is the number of chromosomes that, so far as I can determine, constantly occurs. The discrepancy in this case seems to be accounted for by the fact that in two instances (at $a$ and $b$ ) two V's are in close contact with each other. Furthermore, as appears especially well at $a$, each $\mathrm{V}$ lies in the plane of the equatorial plate, instead of nearly at right angles to that plane as is ordinarily the case. The two V's at $a$, Fig. I02, are, therefore, in all probability, to be thought of as corresponding respectively to the two arms of the $\mathrm{V}$-shaped chromosome at $c$ (same figure). One $\mathrm{V}$-shaped daughter chromosome at $a$ is superposed over its sister segment in exactly the same way that one of the rod-shaped daughter chromosomes at $c$ is superposed over its sister. In other words, the varying methods of attachment of the chromosomes to the spindle fibres in the heterotypic division reappear in the homoeotypic division; and, 
just as was the case with the granddaughter chromosomes of the previous division, so with the same segments (now daughter chromosomes) in the present division-the majority are attached to the spindle at or close to their ends, resulting in giving them the shape of a straight or hooked rod, while a few (usually not more than one or two in a cell) are attached at some point between the two ends, resulting in the shape of a $\mathrm{V}$, whose arms may or may not be of equal length. The same fact is very well illustrated in Fig. I03, which represents a polar view of the equatorial plates of two sister-cells. The chromosomes $a$ and $b$ in the upper cell, $a^{\prime}$ and $b^{\prime}$ in the lower, consist each of two V-shaped daughter segments, one superposed upon the other, while each of the other chromosomes in either cell consists of two rod-shaped segments similarly superposed one upon the other. From the fact that in each sister-cell appears the same number of chromosomes of each form, and the further fact that chromosomes $a$ and $b$ in the upper cell correspond very closely in position with chromosomes $a^{\prime}$ and $b^{\prime}$ in the lower, it seems quite certain that $a$ and $a^{\prime}$, $b$ and $b^{\prime}$ are respectively sister chromosomes of the previous division, comparable with those shown in Fig. 85 ; and the conclusion is strongly suggested that the method of attachment of each individual chromosome persists from one division to the next. All the evidence furnished by the shape and point of attachment of the chromosomes of the homoeotypic division, and by the general numerical proportion of the different forms at various stages, confirms this notion of a persistence in the point of attachment. Such a persistence is hardly conceivable, it seems to me, without supposing also that some of the kinoplasmic fibres have a continuous existence; and so the facts just described afford some confirmation for the doctrine of fibrillar persistence.

\section{The Metaphases and Anaphases.}

The separation of the more numerous rod-shaped daughter chromosomes begins, as a result of the method of their attachment to the spindle, at the ends which have been so long in contact. As these ends are pulled apart (Fig. 107), the unattached, originally more or less divergent, ends are frequently brought into contact, and the final separation of the daughter chromosomes is then at the junction of these originally free ends in the equatorial plane. The ends which are now turned toward the poles are hooked (as was the case in the previous division), due to the lagging behind of some of the substance of the attached end of the chromosome, or to a bending at the point of attachment if this is not quite at the end, so that the daughter chromosome has the shape of a J. Some are not hooked, but appear as straight rods.

The same variations in shape of the daughter chromosomes which 
were noted in the equatorial plate appear during their separation. At $a$ and $a^{\prime}$, Fig. 107, appear two, evidently sister chromosomes, showing a form intermediate between that of a hooked rod and a $\mathrm{V}$; and at $b$ and $b^{\prime}$ (same figure) are two $\mathrm{V}$-shaped sister chromosomes, each having one arm somewhat shorter than the other. Similar forms appear in later stages in the separation of the chromosomes, and during their passage toward the poles.

As the chromosomes approach the poles, they become considerably straightened out, the rod-shaped ones then often reaching nearly from the pole to the equator. After reaching the pole, however, they seem to become shorter and thicker (a process which was also noted in the previous division). The equatorial ends then become curved, and finally all the chromosomes are bent and closely compacted together. The extra-nuclear nucleoles, which were numerous in the prophases, become less numerous, and frequently almost entirely disappear by the time of the formation of the mature spindle. They reappear, however, in considerable numbers during the separation of the daughter chromosomes, and at first are especially numerous in the equatorial region. After the formation of the cell-plate, as in the preceding division, they gather in the neighbourhood of the reforming daughter nuclei, and often some of the smaller ones seem to fuse into larger bodies. The reconstruction of the daughter nuclei is closely parallel to the corresponding process in the preceding division.

\section{Discussion.}

\section{The Visible Idioplasmic Structures.}

It is well established that in both plants and animals, as first shown by van Beneden ('83) for Ascaris, the union of the sexual nuclei involves no fusion of their chromosomes; the latter pass, apparently unchanged, into the fusion nucleus. We must also, as the case stands at present (see Boveri, '04), accept the notion of the general persistence of individual chromosomes, and the consequent reappearance in the division of any somatic nucleus of the same chromosomes which were present in the anaphases of the division immediately preceding. New evidence of this general fact, derived from a study of plant nuclei, has recently been published by Rosenberg ('04 c).

The acceptance of the doctrines just stated involves the further notion that the chromosomes received respectively from the germ-cells of the male and female parents remain separate throughout the life-history of the offspring. Every nucleus of the new generation is therefore double, in the sense that it contains two uncombined sets of chromosomes, and therefore 
(on the assumption that the chromosome substance is the bearer of the hereditary characters of the organism) the basis for two separate and more or less different sets of individual qualities. A considerable amount of evidence has been brought forward, especially by Rückert ('95) and Häcker ('97, '02), tending to show that not only do the parental chromosomes retain their individuality, but, at least in the earlier divisions, present a distinct separation into two groups; and Häcker finds that at various stages in the ancestry of the germ-cells, even down to the appearance of the primary oöcyte and primary spermatocyte, the nuclei show, by their two-parted, two-lobed or flattened form, and by the possession of two nucleoles and occasionally of two spirems, evidences of their twofold nature. On the other hand, Moenkhaus ('04), who succeeded in obtaining hybrids between two species of fishes having chromosomes differing in form and size, finds that, although the chromosomes retain their morphological individuality, they lose their original grouping after the first two cleavage divisions. The fact that in these later stages Moenkhaus found bilobed and binucleolated nuclei, as well as a grouping of chromosomes into two (mingled) groups, shows that while the phenomena discussed by Häcker may result from the continued independence of the two parental substances, they are not sufficient evidence for the acceptance of the view that these substances are isolated in different regions of the nucleus.

It should be added that there is nothing in the evidence now at hand which absolutely negatives the possibility of an interaction between the two sets of chromosomes present in each somatic nucleus, by which during the life of the organism some chemical or other change is effected in the constitution of the chromosomes themselves. All that seems reasonably certain is that the chromosomes remain as distinct entities, and that (at least in the direct ancestry of the germ-cells) they undergo no visible modifications except those attendant upon their alternate growth and division from one cell generation to another.

In connexion with the constancy of the chromosome number and the persistence of individual chromosomes, the question arises whether all the chromosomes in a given nucleus are essentially similar to one another, or whether they differ in structure and function. That the chromosomes received by the organism from either parent are sufficient for its complete development is shown by Boveri's ('89) experiments on the fertilization of enucleated egg-fragments, and by recent work on artificially-induced parthenogenesis (Loeb, '99; Wilson, '01). The nucleus of the sexually-produced individual, then, contains at least two complete sets of hereditary substances, either set capable of inducing the development of a complete individual. Boveri's ('02) experiments on double-fertilized sea-urchin eggs, which divide simultaneously into three or four cells containing varying numbers of chromosomes, go far toward showing a qualitative 
difference between the individual chromosomes derived from either germnucleus.

In harmony with this evidence as to a difference in function is the fact that the chromosomes of a single nucleus often differ greatly among themselves as to size and shape. Such differences have been noted, for example, by Guignard ('99) in the pollen mother-cells of Naias, and by Boveri ('04) in sea-urchin eggs. I have already spoken of the variations in size of the chromosomes of the lily in both the heterotypic and homoeotypic divisions. Strasburger ('00) finds in the pollen mother-cells of Funkia two sorts of chromosomes-some short, hardly longer than broad, and others several times as long as the former. Perhaps the most remarkable observations of similar phenomena are those of Sutton ('02) on the spermatogonial chromosomes of Brachystola. For nine cell generations preceding the formation of the primary spermatocytes he finds in each nucleus twenty-three chromosomes of varying size; of these, one is the 'accessory chromosome.' The remaining twenty-two may be arranged, according to their size, in eleven pairs, those of each pair being approximately equal in size, but differing in this respect from those of any other pair ; and the eleven pairs form a progression from smallest to largest, such that the proportional difference in size between any two pairs in one nucleus is practically the same as that between the corresponding pairs in any other nucleus. It seems very natural, at least, to suppose that such constant differences in appearance between the individual chromosomes correspond in some way to the functional differences which Boveri's experiments indicate. Sutton's observations also seem to make it certain that of each pair of similar chromosomes in a somatic nucleus, one was ultimately derived from each parent ; the two elements of a pair are, therefore, in a sense, homologous, and are probably to be thought of as covering the same portion of the field of individual development. Very similar size relations have been found by Montgomery ('04) in the spermatogonia of Plethodon and Desmognathus.

Somewhat analogous phenomena are those which consist in the appearance of one or two chromosomes differing greatly in size from the other elements within the nucleus. To this class belongs the peculiar body called by McClung ('99) the 'accessory chromosome', which seems to have been first discovered by Henking ('91) in the spermatocytes of Pyrrhocoris. McClung ('02) has suggested a possible function for this particular element, namely, that it determines the production of male reproductive cells in the individual in which it occurs. Montgomery ('04) has classed this and similar aberrant chromosomes under the general term 'heterochromosomes.' Schreiner ('04) also finds marked differences in size between the chromosomes in the spermatogonia and spermatocytes of Myxine. In the spermatogonia two chromosomes are especially distinguished by their larger size from their fellows. 
Not only do the chromosomes in all probability differ among themselves in structure and function; but, in view of the extremely complicated facts of heredity, as well as of the pains taken in somatic divisions to ensure an exact longitudinal halving of each chromosome, we are forced to think of these elements as by no means simple in structure, but rather as having a characteristic and complex organization. Observation has shown the chromosomes, or at least the spirem-thread before segmentation, to be made up as a rule of chromatin bodies (chromomeres) embedded in a less chromatic ground-substance (linin). Strasburger ('82) found that the chromomeres are formed by a progressive fusion of much smaller granules, and this observation has been confirmed in many cases. The chromomeres, as I have observed them in the lily, seem quite plainly to be aggregates of smaller bodies. Little has been done toward a determination of the exact number of either the chromomeres or their constituent parts, largely because the differential staining power of the two substances in the spirem is commonly lost as the contraction of the thread proceeds, and the chromosomes appear homogeneous. An elaborate organization of the chromosomes, which are subdivided into 'chromomeres,' and these into 'chromioles,' has been described by Eisen ('00) for the spermatogenetic divisions of Batrachoseps.

It was first observed by Pfitzner ('81) and Flemming ('81) that the longitudinal splitting of the spirem is preceded by a fission of the chromomeres; and the common assumption has been that this process involves also a fission of each of the smaller granules of which the chromomere is composed. This assumption is usually incapable of proof by direct observation; but it is supported by Brauer's ('93) discovery of a fission of each of the chromatin granules in the thread; these granules are very small at this stage, and later combine into a much smaller number of chromomeres.

Weismann ('92) identified the darkly-staining chromomeres with his hypothetical 'ids,' or 'ancestral germ plasms,' each of which contains within itself all of the qualities of the species, but differs from its fellows by the possession of a certain ancestral combination of individual characters. This notion of the identity of the 'id' with one of the visible chromatin bodies was accepted by Strasburger ('94). He considered the 'id' as made up of a number of smaller chromatin granules, together with more or less linin. Brauer ('93) thought that the chromatin granules, rather than the chromosomes, are the elements which retain an individual existence from one mitosis to the next. From the facts that have been mentioned regarding the formation of the chromatin bodies in the spirem by an aggregation of smaller granules, it is plain that the use of such terms as 'id,' 'chromomere,' or 'chromiole' cannot imply any certain homology between the structures to which the same name is applied in different species. As 
the contraction of the spirem proceeds, constantly larger aggregates of granules result; and it is not improbable that the 'chromomeres' observed in two different cases may represent very different degrees of aggregation. Nor is there any reason to suppose that the smallest visible granules represent either the ultimate units (if such there be) or, in different cases, homologous combinations of such units. Therefore the notion that a longitudinal splitting of the spirem involves a fission of ultimate hereditary units, while it is in consonance with observed facts, does not at present rest upon any sort of direct proof.

\section{Outward Manifestations of Idioplasmic Activity.}

In an experimental study of heredity we have to deal, at least in large part, with the reappearance or non-reappearance of the offspring of certain parental characters. The reappearance of one such character seems in many cases to be independent of the presence or absence in the same individual of any other character; in other words, the hereditary endowment of an individual is at least in part analyzable into separate qualities which seem to act as independent units. For such a unit quality Bateson ('02) has proposed the name 'allelomorph.' Whether the whole hereditary endowment of an individual is capable of analysis into unit qualities is as yet undetermined. Further, there is evidence that in some cases a correlation exists between these simple allelomorphs, so that two or more of them may form a sort of compound unit; in such a case, one quality always appears accompanied by the correlated quality. For instance, Bateson and Saunders ('02) found, in their Matthiola experiments, that a correlation always exists between green seeds and purple or claret flowers; and similar instances are common in the experience of plant and animal breeders. In other cases, there may perhaps be an apparently simple character, which, however, is really compound, and which, although normally transmitted as a unit, under certain conditions may split up into its components. Bateson and Saunders have shown that the conception of such 'hypallelomorphs,' which may break up into simpler units as a result of cross-fertilization, offers at least a convenient hypothesis for the explanation of some apparently aberrant phenomena.

These conceptions, derived from experimental study, of simple units (allelomorphs) and units of a higher order (correlated allelomorphs and hypallelomorphs), seem to find an analogy in the structure of the spiremthread, containing, as it does, a series of chromomeres, which in turn are composed of smaller bodies. It is impossible to avoid the notion that this structure of the hereditary substance in some way corresponds to the compound nature noted in the character of an organism. More than this it is probably not safe to say at present. The smallest visible chromatin 
granules may themselves well possess an inconceivably complex structure ; and it is not yet practicable to attempt to identify the lowest observable order of elements in the spirem-thread as the bearers of the apparently simple unit qualities manifested by the organism.

If the parents, the transmission of whose qualities to their offspring is to be studied, are of the same race, and so differ from each other only in the minor respects which fall within the range of individual variation, the study of heredity offers serious difficulties. It is, therefore, when the parents differ from each other by characters of a racial or of a higher order that the inheritance or non-inheritance of special parental qualities is most easily determined; and consequently, the experimental facts which are of most value for correlation with, and elucidation of, the results of cytological study are, in general, those derived from a study of crossbreeding between individuals of different races, varieties, species, or even genera.

It has been shown that the parental hereditary substances (idioplasms) to all appearances remain separate during the life of a sexually-produced individual, so that each cell of such an individual contains the physical basis for two complete sets of individual qualities. As to any particular quality, then, with respect to which the parents differed-e.g. shape of leaves - there are in the offspring two different, and therefore more or less conflicting, hereditary tendencies. As a consequence of the joint action of these two tendencies, some resultant quality must appear in the offspring, whose relation to the corresponding qualities of the parents may be shown in one of two ways-either the resultant quality may be intermediate between the parental qualities; or one parental quality may entirely predominate over its opponent, and the offspring in this respect exactly resemble one parent. Observation shows that both of these hypothetical cases are actually realized.

A well-known instance of a blending of parental characters is furnished by the hybrid Drosera obovata, whose leaves are intermediate in shape between those of the parents, $D$. rotundifolia and D. longifolia. Mendel ('65) found that in various Pisum hybrids the time of flowering was almost exactly intermediate between the times of the parents. Macfarlane ('90) observed in numerous cases that the blending extends to matters of cellular structure; for example, in a hybrid Hedychium the starch-grains were intermediate as to size and shape between those of the parents. A different sort of blending, apparently clearly due to the independent existence within the cell of the parental idioplasms, is that noted by Hildebrand ('89) in a hybrid between two species of Oxalis; in this instance both forms of hairs characteristic of the parent species arise from a single epidermal cell.

What may perhaps be considered a special case of the blending of parental characters is that in which the resultant quality appears to be, 
not intermediate, but quite different from that of either parent. This occurs frequently with reference to qualities which may be taken as indicating an increased or decreased vigour in the offspring; as, for instance, Burbank's walnut hybrid (Swingle and Webber, '98), a cross between Fuglans regia and $\mathcal{F}$. Californica, which grows twice as fast as the combined growth of both parents. In the same category is a result obtained by Mendel ('65), who found that crossing a long-stemmed and a short-stemmed variety of pea gave a hybrid with a stem longer than that of either parent. The flower colours of several of Correns' ('02) Mirabilis hybrids are analogous phenomena; for instance, crosses between a whiteflowered ( $M$. Falapa alba) and a yellow-flowered race ( $M$. Falapa flava) have red flowers. In the appearance of a hybrid character entirely different from the corresponding character of either parent, there is, as Bateson ('02) suggests, something analogous to the result of a chemical reaction. Since the idioplasm is composed of a complex chemical substance, or, more properly, substances, and since, as I have pointed out, the possibility of some interaction between two parental idioplasms within the same nucleus is not excluded by anything that we know at present, and since, further, the determination of cell characters by the idioplasm undoubtedly involves a series of chemical reactions, it is not surprising that we should obtain results of this character in many instances of the combined action of two different idioplasms.

In discussing such cases as those last mentioned it is necessary to be certain that, with respect to the quality in question, both parents were pure-bred; otherwise, the appearance of a character different from the corresponding character of either parent may be simply the reappearance of a quality of a more remote ancestor, and not at all the result of a combination of the two parental qualities. Cases of the appearance of a character different from that of either parent are, therefore, unless the pedigree of the parents is fully known, liable to the suspicion that they are merely due to the reappearance of a latent or recessive allelomorph.

On the other hand, a conflicting action of the parental idioplasms may result in a quality which is in no sense intermediate, but which exactly resembles the corresponding character in one parent. It was the observation of such phenomena that led Mendel ('65) to the conception of parental qualities as either 'dominant' or 'recessive.' When, for instance, he crossed two varieties of Pisum, one having green, the other yellow, cotyledons, all the offspring had yellow cotyledons; in other words, the character of possessing yellow cotyledons is dominant, that of possessing green cotyledons is recessive. In the same way, the possession of round, smooth seeds is a dominant quality, that of angular, wrinkled seeds is recessive. The so-called 'law of dominance' was never stated by Mendel as a general law; and cases of intermediate character similar to those 
I have just mentioned show that, although in many instances it holds with greater or less exactness, it is very far from being universal. It should be noted also that even in cases which are classed as illustrations of dominance, as Correns ('03 $a,{ }^{\prime} 03 b$ ) has pointed out, the dominant quality by no means always appears in the offspring in the intensity which was characteristic of the dominant parent. Thus, Mendel says that 'the hybrid character resembles that of one of the parental forms so closely that the other either escapes observation completely or cannot be detected with certainty.' This is illustrated by the colour of the embryo in the Matthiola crosses of Bateson and Saunders ('02), in which green usually appeared to be the dominant colour, but was often much diminished in the crosses. A series of such facts might be collected, which would show every conceivable gradation between the complete dominance of one parental quality and the appearance of an exactly intermediate character in the offspring. Nevertheless, the frequently-occurring fact of dominance, taken in connexion with the reappearance of the recessive character in the next generation, is important as showing that the physical bases for two more or less antagonistic qualities may exist side by side in the same nucleus without any such interaction as materially affects the nature of either.

Considering the cross-bred individual as a whole, it constitutes a complex of qualities, some of which may approach, or be identical with, the corresponding qualities of the father; others bear a like relation to those of the mother, and still others are intermediate between, or even entirely different from, the corresponding qualities of either parent. As a result of the summation of all these various qualities, the offspring occupies, in general, a position intermediate between the respective parents. In the simplest possible case-that, namely, in which the parents differ in only one quality-if dominance occurs with respect to that quality, the offspring exactly resembles one parent. The same result may follow in more complicated cases, provided all the characters of one parent in respect to which the parents differ happen to be dominant. This, however, becomes less probable with an increase in the number of differences between the parents. The possibility of an exact resemblance between the hybrid and one parent may be illustrated by the much-discussed 'false hybrids' of Millardet ('94). The fact that these hybrids breed true may be due to what we may term a permanent dominance, as distinguished from the ordinary (Mendelian) form ; or it may result from a complete disappearance of one set of characters, due to something like a destruction or extrusion of one parental idioplasm.

It will naturally be expected that whatever balance may be struck in one case as the result of the combined action of two idioplasms will appear in other cases in which, under substantially similar conditions, the same or similar idioplasms come into a like relation. This implies that 
the individual resulting from a particular cross will display throughout life the same combination of congenital qualities; and also that different individuals resulting from the same cross will closely resemble each other. These expectations also are in general realized by the facts presented by hybridization experiments. It appears, however, not unnaturally, that the balance which may be struck between the more or less conflicting idioplasms is a matter of delicate adjustment, subject to modification by various influences, such as differences of nutrition, and perhaps in many cases by internal causes which cannot at present be traced.

As to the general constancy during ontogeny of the characters of a hybrid individual, it is a recognized rule that, for instance, the colour, shape, and size of the flowers of a hybrid plant are as constant as in a pure-bred individual. In the case of the Drosera hybrid already mentioned, the characteristic leaf-form prevails throughout ontogeny. The same is true regarding the various characters studied by Mendel in his Pisum hybrids.

But it is not difficult to find exceptions to this rule, which illustrates the comparative instability of the balance between the parental idioplasms. One class of exceptions includes the 'mosaic' hybrids, several of which were described by Darwin ('68). Among these are Lecoq's crosses between different coloured varieties of Mirabilis, some of which produced flowers half of one colour, half of another ; and the case of a mongrel dog, part of whose skin was hairy and part naked, the parts being distinctly separated. The flowers of crosses between the carnations Scott and McGowan (Swingle and Webber, '98) show, side by side, the colours of the two parents. A frequently cited instance is Cytisus Adami, occasional branches or single flowers of which revert to the type of either parent. De Vries ('03), who considers this plant a true hybrid, and Lotsy ('04) suggest that the reversion of certain members may be due to a qualitatively unequal nuclear division interpolated among the normal somatic divisions, so that certain cells receive only one parental idioplasm in nearly or quite pure form. Correns ('03 $b$ ) and Halsted ('04) have obtained hybrid maize-grains whose endosperm displays in different parts of the same grain the distinctive characters of the two parents.

A very different class of exceptions to the same rule consists of those hybrids which undergo changes during ontogeny. In this class Darwin ('68) cites Gärtner's hybrids between Tropaeolum minus and T. majus, whose flowers were at first intermediate, but some of which later in the season produced flowers in all respects like those of one parent. Cannon ('03 a) mentions several analogous cases. Whether such exceptional behaviour is due to environmental influences, or to local internal conditions, it accords well with the conception of the presence throughout the life of the hybrid of two separate, independent idioplasms. 
The rule as to the similarity among individuals of the same cross is by no means of so general application as that of the constancy of individual characters during ontogeny. Nägeli (quoted by Swingle and Webber, '98) finds that 'in general the hybrids in the first generation vary the less the more distantly related the parent forms are; that is, the specific hybrids vary less than the varietal hybrids, the former often being characterized by great uniformity, the latter by great diversity of form.' And Swingle and Webber note the general fact that 'races of cultivated plants, even though very diverse, produce very variable hybrids in the first generation, while usually by crossing wild species closely resembling each other hybrids are obtained which are constant in the first generation.' Similarity between hybrids of the same parentage is illustrated by most of the cases already considered, notably by Mendel's Pisum hybrids. Instances of variation are furnished by the Hieracium hybrids produced by Mendel ('69); also (Swingle and Webber, '98) by the two different crosses obtained by Gärtner between Nicotiana quadrivalvus and N. macrophylla.

Satisfactory evidence upon this point is, however, difficult to obtain, for the reason that the parents of any particular individual were themselves sexually produced; each of them received from its parents two different idioplasms, and the generation with which we are directly concerned is affected by the unequal distribution among its members of these grandparental idioplasms. In determining the amount of variation among the individuals produced by a given cross it is, therefore, necessary to be certain that the parental idioplasms were pure as respects the particular qualities under consideration. Absolute certainty upon this point is probably always impossible, and even approximate certainty is out of the question unless, as is usually not the case, we know the pedigree of the parents for many generations. In cases of variation among hybrids of the same cross, therefore, it is necessary always to take into consideration the possibility that the variation is due to ancestral influences, a possibility which is especially strong in the case of cultivated races, and which, no doubt, accounts for much of the variation noted among hybrids of such races. It is very possible that, if perfect certainty with respect to ancestry were attainable, uniformity among offspring of the same cross between pure-bred parents would be found much more nearly universal than at present it appears to be.

A special case, to be classed with those just discussed, is afforded by the fact that, in most cases, it makes no difference in which direction the cross takes place-that is, a cross between $A$ male and $B$ female gives the same results as one between $A$ female and $B$ male. This seems to imply that differences in the source of the respective idioplasms do not, by differences in their relative position within the nucleus or otherwise, affect their capacity for determining or influencing external characters. Occasional 
notable exceptions to this rule are known, in the form of differences between reciprocal crosses, e. g. the mule and hinny, Gärtner's and Focke's (Swingle and Webber, '98) Digitalis crosses, the Nymphaea hybrids of Caspary, and some of the grape hybrids studied by Millardet.

In the foregoing paragraphs I have attempted to point out what seems to me the remarkable parallel existing between the data obtained by the experimental study of plant and animal breeding on the one hand, and, on the other, such results of cytological investigation as the constancy of the chromosome number, the continuous separation between the parental elements within the nuclei of the offspring, the individual persistence and distinctive appearance of the chromosomes, and the finer details of their structure. I shall return later to a consideration of the experimentallyderived facts and of the light that they may throw upon the problems with which the present paper is especially concerned.

\section{The Reduction of the Chromosome Number.}

The conception of the individuality of the chromosomes, together with the fact of the general constancy of their number in any particular species, involve, as Boveri ('88, '90) early pointed out, the necessity, at some period in ontogeny, of a reduction of their number to one-half, in order that that number may not be doubled in each generation by the fusion of the sexual nuclei. We now know that such a reduction does occur at a definite point in the life-history of every sexually-produced individual, at least among the higher animals and the higher plants; that in some way two successive nuclear divisions, differing from the ordinary type, are concerned in this numerical reduction; and that the reduced number of elements (whether at this stage involving a real or only an apparent reduction) is first to be observed in the prophases of the earlier of these two peculiar divisions. We know, too, that in the Metazoa the divisions concerned in chromosome reduction are the two immediately preceding the formation of the definitive sexual cells; and that in the Spermaphytes, Pteridophytes, and Bryophytes, these divisions are the two which result in spore-formation, and which, therefore, determine the transition from the sporophyte to the gametophyte generation.

The prophases of the first of the two divisions just referred to (the heterotypic division) are characterized by their unusually long duration, and by the appearance of a stage in which the nuclear constituents are aggregated into a more or less compact mass, usually in contact with one side of the nuclear membrane. This stage of aggregation, to which Moore ('95 a) gave the name 'synapsis,' is regularly found, so far as we now know, only in the prophases of this division. Although this condition had been described by various writers, Brauer ('93) seems to have been the first to 
suggest that it is in some way connected with the formation of only half the usual number of chromosomes; and Moore ('94, '95 a) first definitely maintained that it is during synapsis that the numerical reduction occurs.

Those observers who have found what they consider reduction divisions in Weismann's sense have for the most part interpreted their results in essential accordance with those of Rückert ('92 $a$, '92 $b$, '94), Häcker ('90, '92, '93, '95, '99), and vom Rath ('92, '93); that is, they find that in the prophases of the heterotypic division the chromosomes are bivalent, consisting of two somatic chromosomes attached end to end; and that in one or the other of the two succeeding divisions these two somatic chromosomes are distributed to different nuclei. This method of reduction has been described especially among the Arthropods. Montgomery ('01) suggested that the two chromosomes so joined end to end are always derived from different parents ; synapsis is, then, a process of conjugation of the maternal and paternal elements, its object being a 'rejuvenescence' of the chromosomes. He thought it probable that there is an exchange of substances during this temporary contact.

Cannon ('02, '03 a) suggested, as a cytological basis for Mendel's law of the purity of the germ-cells, that 'the chromosomes derived from the father and the mother unite in synapsis and separate in the metaphase of one of the maturation divisions, and also a single longitudinal division occurs, so that the end is attained that the chromatin is distributed in such a way that two of the cells receive pure paternal and two cells pure maternal chromosomes, and no cells receive chromosomes from both the father and the mother.' Cannon's notion of the purity of the germ-cells at this time was plainly quite different from that of Mendel, for the sort of division postulated by Cannon could not possibly result in new combinations of parental qualities such as Mendel actually found. This difficulty was recognized by Sutton ('03), and later by Cannon himself ('03 $b$ ). Sutton proposed to modify Cannon's conception by assuming that it is a matter of chance whether one or the other chromosome of a pair goes to a particular daughter nucleus; and this notion has been accepted by Boveri ('04). The result of the operation of chance in this respect would be that in a sufficiently large number of germ-cells from the same individual every possible combination of the parental chromosomes will occur. The number of possible varieties to be found among the offspring would depend, accordingly, upon the number of chromosomes characteristic of the species. Sutton showed that in cases of the occurrence of the commoner chromosome numbers the amount of variation thus made possible is relatively great; for instance, if, as in the lily, the reduced number of chromosomes is twelve, the number of possible combinations that may occur in the germ-cells of one parent is 4,096 ; and, as the result of the fusion of these germ-cells with those from a similar parent, the number of possible combinations of parental characters 
in the offspring is $16,777,216$. On the other hand, the reduced number of chromosomes in the pea, as Cannon ('03 $b$ ) finds, is seven; and he has pointed out that on Sutton's hypothesis there can be only seven groups of characters, each of which groups can be transmitted independently of any other. Now, Mendel found in varieties of the pea seven separate characters which were transmitted independently of each other; and if Sutton's notion be correct, each of these characters must be one of a set which corresponds to one of the indivisible chromosomes; and Mendel could not possibly, therefore, have found an eighth character which would follow his law of the separation of parental qualities. To suppose that Mendel so completely exhausted the possibilities of the case is probably giving him more credit than even his most devoted followers would be inclined to allow.

Montgomery's notion, that any two chromosomes which conjugate in synapsis are derived respectively from the male and the female parents, was supported by his observation ('01) that when, as in Protenor, Peliopelta, and $Z$ aitha, certain spermatogonial chromosomes are distinguishable from the others by their size, these peculiar chromosomes pair with each other in synapsis. A striking case of the same sort is furnished by Brachystola, according to Sutton ('02). Here all the spermatogonial chromosomes, as already mentioned, can be arranged according to their varying sizes in pairs; and each bivalent heterotypic chromosome is formed by one of these pairs of hitherto separate elements. Similar phenomena to those found by Sutton are described by Montgomery ('04) for the spermatogenesis of Plethodon and Desmognathus, and for the oögenesis of Ascaris megalocephala bivalens.

Häcker ('02, '04) has observed phenomena in the oögenesis of Cyclops brevicornis, which he interprets as a conjugation of paternal and maternal chromosomes. In the germinal vesicle the bivalent chromosomes are arranged in two groups, representing respectively, he thinks, the maternal and paternal elements. The first maturation division is equational, so that the chromosomes passing to the secondary oöcyte may be represented by $a b, c d, \ldots$ (male), and $n o, p q, \ldots$ (female). In the secondary oöcyte nucleus, a conjugation in pairs occurs between these chromosomes-e. g. $a b$ (male), which is bent at its middle, comes into contact at the point of bending with the similarly bent no (female). In the second maturation division, a transverse division of each chromosome occurs at the point of bending, so that the separation in this division may be represented thus :

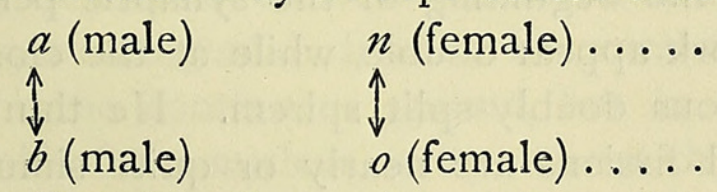

There is thus effected a thorough mixing of the parental elements, and each germ-cell receives an equal number of chromosomes originally derived from each parent. 
These attempts to explain chromosome reduction by a separation of entire chromosomes are based, as has been said, upon what appear to be the facts particularly among the Arthropods. For those cases in which a double longitudinal splitting is observed, and in which, therefore, both heterotypic and homoeotypic divisions seem to be equational, it has been found much more difficult to frame a satisfactory hypothesis. Such a double longitudinal splitting was described by Brauer ('93) in the spermatogenesis of Ascaris; and a similar process has been found by various authors in widely divergent groups of plants and animals, particularly among the Vertebrates (Flemming, '87 ; Moore, '95 b; Meves, '96 ; McGregor, '99 ; Kingsbury, '99, \&c.); and among the Seed Plants (Strasburger, '95, '00; Mottier, '03 ; Guignard, '99 ; Grégoire, '99, and others).

O. Hertwig ('90) conceived of the fusion of the sexual cells as involving a fusion of the parental idioplasms in such a way as to give rise to a new and different idioplasm characteristic of the new individual. The divisions resulting in the formation of the germ-cells, he thought, are equation divisions, and the germ-cells formed by the same individual are all similar. Strasburger ('94) thought that in the prophases of the heterotypic division each 'id' derived from one parent fuses with an 'id ' derived from the other parent, the result being a new idioplasm which is equationally divided among the germ-cells. Brauer seems to have considered that no such fusion is necessary, but that the two parental idioplasms remain and are simply reduced in mass by two equation divisions. Montgomery ('01), Sutton ('03), and Boveri ('04) have suggested that the phenomena in Vertebrates may be harmonized with those in Arthropods by supposing that in the former the chromosomes conjugate side by side instead of end to end, and that one of the apparent longitudinal splittings is, therefore, really a separation of two independent somatic chromosomes. This suggestion is an approximation to the facts as I have described them in the lily; but the fusion of the two spirems into a single thread, as I have observed it, is a very different process from a temporary attachment of the chromosomes end to end; and the two methods may be expected, if they actually occur in different groups of organisms, to lead to very different results as regards the transmission of hereditary characters.

It seems quite possible from the figures of Brauer ('93) that the occurrences in Ascaris are really very similar to those in the lily. $\mathrm{He}$ finds that at about the beginning of the synaptic period certain strands of the nuclear network appear double, while at the close of synapsis there is present a continuous doubly-split spirem. He thinks it probable that the two longitudinal fissions are nearly or quite simultaneous, and that, owing to their fineness in the earlier stages, the strands appear double when they may really be four-parted. The double longitudinal splitting of the spirem certainly occurs earlier in Ascaris than in the lily; but 
between the first appearance of double strands and that of a four-parted spirem a considerable time evidently, from Brauer's figures and descriptions, elapses; and it is at least conceivable that the occurrence of a double thread at the very beginning of synapsis is the same phenomenon that I have observed at the same stage in the lily, and that in Ascaris also these two threads actually fuse into one, which soon after is doubly split. Miss Sargant ('96, '97) and Farmer and Moore ('95) also describe two rows of 'chromatin dots' in the nuclear threads of the lily previous to synapsis; but, as I have pointed out, there is some doubt as to the real nature of these bodies.

Sabaschnikoff ('97) attempts to harmonize the occurrences in the oögenesis of Ascaris with Weismann's notion of a reduction division. $\mathrm{He}$ thinks that, during synapsis and previous to the formation of a spirem, the chromatin granules become arranged into groups of four, not by a double fission of single granules, but by the approximation of originally separate bodies. The tetrad groups are connected with one another by fine linin fibres; they approach each other and become arranged to form a spirem, which is thus composed from the start of four threads. Sabaschnikoff's view is not very different from that of a conjugation of separate spirem threads, or at least of their constituent chromatin granules; but it involves no notion of a fusion; the grouping of the granules is simply preparatory to their ultimate distribution into different germ nuclei.

Winiwarter ('00) seems to have been the first actually to observe a fusion of parallel threads in the prophases of the heterotypic division. He finds this process to occur during synapsis in the oögenesis of the rabbit and of man, and his figures are very similar to mine. The result of the fusion is a comparatively thick moniliform thread (whether continuous or not at this period he does not determine), which later splits longitudinally. A complete fusion in pairs of all the chromomeres seems not to occur; the double nature of the thread remains always apparent in places. Winiwarter considers the longitudinal splitting to involve merely a separation of the threads which previously fused. Schoenfeld ('01) finds in bovine spermatogenesis a similar fusion of slender threads in pairs.

In a recent preliminary paper, A. and K. E. Schreiner ('04) describe a like series of processes in the spermatogenetic divisions of Myxine and Spinax. According to these authors, the material of the daughter chromosomes of the last spermatogonial division becomes distributed upon fine linin fibres; there is no continuous spirem, but in synapsis the strands aggregate in that half of the nuclear cavity nearest the centrosphere; they lie parallel to each other, or converge slightly toward the pole. The strands now approach each other and gradually fuse in pairs. Somewhat later a longitudinal splitting appears, which the authors seem to consider 
as a separation of the original threads, which have been for a time in contact. Each of the parallel threads now contains a row of granules substantially uniform in size. In this stage in Myxine there is sometimes present also an indication of a second longitudinal split at right angles to the first. As a result of shortening and thickening, and of different degrees of separation of the daughter segments, the mature chromosomes appear variously as rings, 8's, loops, V's, X's, or pairs of parallel rods; they also often plainly show the second split. The separation in the first mitosis, as in the lily, is in the plane of the first split; each daughter chromosome is two-parted as a result of the second split, and the two parts are separated in the next mitosis.

The Schreiners accept Sutton's notion of a pairing of homologous paternal and maternal chromosomes, and their subsequent separation in such a way that it is purely a matter of chance whether a particular chromosome shall pass to one or the other daughter nucleus. During the time of contact of the two chromosomes of a pair, there occurs a more or less intimate fusion (conjugation or copulation). These authors attempt to harmonize the facts of chromosome reduction in the Arthropods with their own observations on Vertebrates by assuming that in the former group there occurs first a parallel arrangement of two chromosomes, then a separation at one end, the chromosomes remaining attached at the other, so that when they are finally separated in the metaphases of one division or the other the appearance is that of a transverse separation. This supposition is supported by the various appearances of the chromosomes in Spinax. Here the most common form is that of a closed ring, resulting from the continued attachment of the chromosomes of a pair at both ends ; but a separation may occur at one end, leading to all possible variations in form from that of a ring broken at one point to that of two straight rods attached at one end and making various angles with each other. If the latter form should become common, the appearance of the chromosomes would be similar to that described for many Arthropods.

De Vries, largely upon hypothetical grounds, has recently ('03) concluded that, shortly before the separation in the heterotypic division, the chromosomes become arranged side by side in pairs, the arrangement being such that each paternal chromosome is paired with a homologous maternal chromosome, and each paternal pangen, or group of pangens, is opposite the corresponding maternal structure. In this condition of intimate contact between the parental idioplasms, a mutual interchange of some of their pangens occurs, in such a way that when the chromosomes later separate, each set, whether paternal or maternal, contains a complete set of pangens, but some of the latter are paternal, some maternal, in origin. This interchange of pangens is determined entirely by chance, so that, if the same process is repeated in a sufficiently large number of cells, every possible 
combination of a complete set of paternal and maternal pangens will result. The separation of the chromosomes after this interchange results in the appearance of a longitudinal splitting of the chromosomes-the 'first longitudinal fission,' which has been observed in many cases, especially in plants. It is true that in the case of many animals this separation seems to be transverse; but de Vries suggests, as do the Schreiners, that after the longitudinal fission the chromosomes may remain temporarily in contact by their ends, their final complete separation then producing the effect of a transverse breaking. In the case of the offspring of two individuals of the same race or variety, the two idioplasms resemble each other exactly as to the number and general nature of their pangens; the process just described, then, results in an exchange of like elements, which differ from each other only in those minute details which correspond to the externally apparent differences between individuals of the same race. In the case of a cross between a variety and its mother species, we have to deal with two idioplasms which differ from one another only as regards a single pangen, which is present in both, but is active in one case, latent in the other. Evidently the active and the latent pangen are as capable of being exchanged as are any of the other pangens, and the two idioplasms may apply themselves to each other as exactly as in the case first mentioned. When we come to a cross between two different species, however, an exact correspondence between the two idioplasms is no longer to be expected; the number of pangens, or their arrangement, may differ, and so the application of the idioplasms to each other and the consequent interchange of pangens is made difficult. If the parents belong to very closely related species, this difficulty may not be a serious one; but as the relationship becomes more distant the difficulty increases until the processes leading to the formation of the germ-cells become impossible, and the hybrid is necessarily sterile.

Lotsy ('04) agrees with de Vries that in those cases in which a double longitudinal fission of the chromosomes has been observed, each chromosome must be considered as bivalent, and as resulting from a lateral apposition of a paternal and a maternal segment. He points out that, depending upon the plane in which the split occurs, a longitudinal division of such a bivalent chromosome may be either equational or qualitative; and he concludes that of the two longitudinal fissions observed to occur, one results in an equation division, the other in a reduction division. He points out that the difference between the two planes of separation is brought about either by the fact that the successive division-spindles lie in planes at right angles to each other, as in the division of animal spermatocytes, or, if the two divisions are to be in the same plane, as in the formation of polar bodies from the animal egg, by a revolution of the chromosomes themselves through an arc of $90^{\circ}$. Lotsy considers that, as 
de Vries has suggested, the object of the lateral apposition of paternal and maternal chromosomes is an exchange of pangens, and that as a result of the heterotypic and homoeotypic divisions each germ-cell contains only paternal or only maternal chromosomes.

Very interesting phenomena have been observed by Rosenberg ('04 $b$ ) in the pollen mother-cells of Drosera. He finds that shortly after synapsis the short chromosomes lie side by side in pairs ; at first the two of a pair may be some distance apart, but soon they come into close contact with each other. The number of pairs is the reduced chromosome number. A fission of each chromosome occurs early, sometimes before the two of a pair are in contact; this fission may be parallel or at right angles with the plane of contact of the chromosomes. The heterotypic division separates the chromosomes of a pair; and the separation in the homoeotypic division is in the plane of the fission just mentioned. Rosenberg ('03, '04 a) has also studied a hybrid between Drosera rotundifolia and $D$. longifolia. The reduced number of chromosomes in the parents is respectively ten and twenty; thirty is the number in the somatic cells of the hybrid. In the heterotypic division in the pollen mother-cells of the hybrid twenty chromosomes appear, ten of which are double, ten single. The ten double chromosomes divide in the usual way; the single chromosomes either pass undivided to one or the other pole, or else are left on the spindle and take no part in the formation of the daughter nuclei. From the occurrences in the pollen mother-cells of the pure species, it must be inferred that each double chromosome in the hybrid results from the conjugation of a maternal and a paternal element; while the single chromosomes are those derived from the longifolia parent which have failed to find mates among the smaller number from the rotundifolia parent. This inference is confirmed by the fact that the chromosomes of $D$. rotundifolia are much larger than those of D. longifolia; and that each double chromosome in the hybrid consists of a larger and smaller daughter segment.

Berghs ('04) has studied the heterotypic and homoeotypic divisions in the microsporogenesis of Allium fistulosum and Lilium speciosum; and his latest results, as reported by Grégoire ('04), agree very closely, as to the fusion in pairs of the strands of the spirem during synapsis, the double longitudinal splitting, and the subsequent history of the chromosomes, with my observations. Both of these authors seem inclined to deny the formation of a single continuous spirem, although Grégoire (p. 308) says that after the completion of the fusion the spirem appears to be unsegmented. They consider the first longitudinal splitting as merely the separation of threads which have been for a time in contact but have retained their autonomy.

The apparent difficulty of reconciling the notion of a double longi- 
tudinal splitting with the facts developed in recent experimental studies of hybridization, has led a number of observers to a re-examination of those cases in which the double splitting had been described; and some of these observers have been convinced that such a double splitting actually does not occur. Farmer and Moore ('03), reversing their former ('95) views, now hold that the apparently double chromosomes appearing in the heterotypic mitoses in both plants and animals are formed by a bending upon itself in the middle of each segment of the spirem. The spirem splits longitudinally before segmentation, but the split becomes nearly or quite obscured, to reappear as a fission of the daughter chromosomes during or after their separation in the metaphases. This notion, if correct, would bring the facts in the Seed Plants and Vertebrates more nearly into harmony with those commonly described for the Arthropods. A study of the sporogenous divisions of several species of Ferns by Gregory ('04) gives results similar to those of Farmer and Moore; and Williams ('04), who finds chromosome reduction to occur in the formation of the tetraspores of Dictyota, obtains in this material further corroborative evidence as to the method of formation of the chromosomes. Cannon ('03 $b$ ) has brought forward some (by no means convincing) evidence that, in the ancestry of the microspores of both pure and hybrid races of peas, the chromosomes become arranged in pairs end to end (or, in one case, side by side) in the anaphases of the last pre-heterotypic division. Montgomery ('03) has recently attempted to show that in Amphibia as in Arthropods there occurs a conjugation of chromosomes end to end in pairs, and that the heterotypic division separates the two chromosomes of a pair. He finds, therefore, only a single longitudinal splitting.

Strasburger ('04) has also reversed his former opinion ('O0) concerning a double longitudinal splitting in the prophases of the heterotypic division, and comes to substantially the same conclusions as Farmer and Moore. He finds that in the pollen mother-cells of Galtonia and Tradescantia each chromosome divides transversely into two segments, which are finally separated in the heterotypic mitosis ; from the method of their formation, it follows that the segments of a pair are contiguous to each other in the spirem before segmentation. The longitudinal split, which was visible in the spirem at an early stage and then disappeared, reappears in the metaphases and anaphases of the heterotypic division, forming the granddaughter chromosomes which are to be separated in the homoeotypic division. Strasburger finds some evidence, in the arrangement of the chromosomes in the equatorial plate in the heterotypic mitosis of Tradescantia, of variations in the arrangement of different pairs of daughter chromosomes which might result in such varying combinations of maternal and paternal segments as is postulated by Sutton and Boveri. Strasburger has also studied the stages preceding those just mentioned, and he finds 
during synapsis occurrences which seem to him to throw much light upon the real nature of the heterotypic division. In the synapsis stage in Galtonia and Thalictrum he finds (as is reported also by J. B. Overton, '04) that the chromatin becomes separated from the linin fibres, and, in the form of fine granules, aggregates into groups whose number corresponds to the reduced number of chromosomes which are later to be formed. The granules of each group unite into a small, dense body (zygosome), which elongates somewhat, becomes constricted in the middle, and then breaks up again into granules; these become distributed along the linin, so forming a continuous spirem thread, which, after the disappearance of the synaptic condition, splits longitudinally. Strasburger considers that the formation of the zygosomes is a means for bringing into intimate contact the chromatin from two hitherto separate homologous chromosomes, one paternal and one maternal; and that the material of each zygosome becomes distributed along the linin thread to form a heterotypic chromosome, whose later transverse division has been foreshadowed in the constriction of the zygosome.

The evidence for these most recently developed views is not yet published except in preliminary form, and it seems very difficult to bring them into harmony with the best-known facts as to the heterotypic figures in the lily. My own preparations certainly show that two longitudinal splittings occur during the heterotypic division. The real significance of these two fissions, however, can be determined only in connexion with the fact that early in the prophases two spirems are formed, which come to lie alongside of each other, and finally fuse into a single thread. Häcker ('02) has been able to show that in Diaptomus the double nature of the nucleus may show itself even as late as the prophases of the last preheterotypic division, by the formation of a double spirem. The conclusion is inevitable, though, so far as my observations go, not susceptible of direct proof, that the two spirems which fuse in synapsis contain the substances derived respectively from the male and female parents. It is not surprising that the approximation of the two spirems should result in a massing of their substance in a space much less than that which it formerly occupied. The peculiar appearances of synapsis, so far as these concern the material of the spirem thread, thus receive a natural explanation; but the metamorphoses undergone by the nucleolar substance are not so easily accounted for. From my own observations, any transfer of substance from the nucleoles to the spirem or vice versa, at this or any other stage, seems to be excluded. But the constant occurrence in so many species of extremely flattened nucleoles at the time of synapsis may perhaps have a significance of which as yet we can form no conception. In this connexion some observations of Häcker ('02) are of interest. One of the most frequent indications of the 'autonomy of the nuclear halves' is the 
appearance in the young nucleus of two nucleoles, which, if a long resting period ensues, commonly fuse into one. In the primary spermatocytes of Diaptomus two nucleoles appear in the early prophases and become fused during synapsis. This seems to be the only case he has discovered in which a fusion of nucleoles occurs during the prophases; and this unusual occurrence during this particular mitosis in Diaptomus may very well be a manifestation of the same general tendency toward a fusion of two groups of nuclear substances which shows itself, apparently universally, in a rearrangement of the chromatin. The fusion of the two spirems involves a change in the position of the material of one or both; it would be extremely interesting to determine whether there is a mutual approximation, or whether in this respect one is passive, the other active; but upon this point I have no evidence to offer.

The aggregation of the nuclear material begins, as I have said, in the very early stages of the formation of a uniform spirem ; the movement, then, is not by the fully-formed spirem threads, but, in part at least, by the knots and fibrous material which constitute the reticulum. This fact also appears from the not infrequent occurrence, in the formation of the spirem, of two short threads ending in the same knot; such figures may well result from a previous fusion of the knots in pairs. But this occurrence is by no means general. The fusion of the two threads is followed by the fusion of the chromomeres in pairs ; this fusion is not completed for some time after the threads have come in contact, but finally no evidence remains in the appearance of the chromomeres of their double origin. Occasionally a chromomere seems not to find a mate, but such occurrences are exceptional; and the most striking fact apparent in the approximation of the threads is that they come together in such a way that in general each chromomere in one thread lies opposite a chromomere in the other thread. All appearances indicate that the object of the whole process is the fusion of the chromomeres. The result, therefore, seems to be the bringing into at least intimate contact of the chromatin derived respectively from the two parental germ nuclei. In speaking of the fusion of the chromomeres I do not mean to imply that I have observed any indication of the actual fusion of the smaller granules of which the chromomeres are composed; all that is apparent is a flowing together of two masses of granules into a single mass. How the number of granules present after the union compares with the total number before it is impossible to determine; plainly there are several conceivable possibilities in the case, which will be discussed in another connexion. It is sufficient for the present to say that the fusion of the two spirems effects that intimate association of diverse hereditary substances which was anticipated in the fusion of the parental germ-cells some hundreds or thousands of cell generations previously.

After the completion of the union of the two threads, the now seem- 
ingly single spirem gradually distributes itself more uniformly throughout the nuclear cavity. An important difference is manifest between the arrangement of the spirem at this time and its arrangement in the prophases of previous divisions. In the earlier divisions the arrangement of the spirem displayed a distinct polarity, and was always closely similar to its arrangement in the preceding anaphases. This is not the case, so far as my observation goes, at any stage in the prophases of the heterotypic division. It is true that, as already noted, some authors have found a certain polarity in the arrangement of the chromosomes after segmentation, and Strasburger has noted a regularity in the course of the spirem of Tradescantia; and it is quite possible that in all cases some order prevails in the course of the unsegmented thread which has not been detected. But such polarity as may exist, at least in the case of the lily, is certainly very much less striking and characteristic than in the somatic divisions. It seems that the transformations undergone by the nuclear material during synapsis have resulted in the obliteration of nearly or quite all traces of its former symmetrical arrangement.

The condition of apparently complete fusion persists, as has been said, for a long time, certainly for several days. There then occurs a longitudinal splitting of the spirem, which is preceded by a fission of each chromomere, and which to all appearances is similar to the splitting that occurs in the prophases of a somatic mitosis. This longitudinal splitting, if we were ignorant of the processes preceding, would naturally seem to be preparatory to an 'equation division'; and so it has been interpreted by most of those who have observed it in the prophases of the heterotypic division, either in animals or plants. But, on the other hand, the figures produced by this splitting are so closely similar to those which were observed in the fusion that produced the single spirem as to suggest that possibly this splitting is really the separation of the two threads which have been for some time in very close combination. This view would make of the splitting a preparation for a separation of the idioplasms which have existed together throughout the life of the sexually-produced individual. The question of the nature of this splitting, and therefore of the heterotypic mitosis, depends upon what has occurred within each individual chromomere since the time of its formation from two separate bodies; and this problem is as yet beyond the reach of observation. One a priori argument, however, is of some weight in this connexion-namely, that it is hardly conceivable that the fusion of the threads, with all of the elaborate adjustments that it involves, should have occurred if they are afterward to separate without any sort of interaction or inter-relation between them or their constituent parts. Experimental data, to which I shall refer on a later page, suggest more definite conceptions of the processes involved in the fusion and subsequent splitting of the spirem. 
The stages in the heterotypic division which succeed the longitudinal splitting of the spirem thread show many peculiarities, most of which are, I think, explicable in the light of the facts already described. Segmentation of the thread into one-half the somatic number of chromosomes results naturally from the fusion of the two threads side by side. Segmentation occurs at every point in the thread at which two chromosomes are joined; and there is thus no such difficulty as is involved in the notion of 'bivalent' chromosomes which result from the segmentation of the thread at only half the points of union between its constituent segments. Each segment of the thread has been formed by a maternal and a paternal chromosome lying side by side; but whether these parental chromosomes are to be thought of as corresponding respectively to the two visible segments resulting from longitudinal splitting is a question which, as I have said, cannot be answered from direct observation. However this may be, from its method of origin it is to be expected that each heterotypic chromosome in its mature form will have twice the thickness of a somatic chromosome; and it is well known that the chromosomes in this mitosis are much thicker than those that appear in any other division. They are, in fact, somewhat shorter and thicker, though not greatly so, than would be accounted for by the lateral apposition of two somatic chromosomes; this is doubtless to be explained by a slight increase in the amount of contraction which the chromosomes normally undergo during the prophases. The process of growth in mass of the nuclear material which occurs during the resting stage is followed during each somatic mitosis by the longitudinal splitting of each chromatic segment. A similar increase in mass occurs, as my figures show, in the stages succeeding the anaphases of the last preheterotypic division. As a result of this growth and of the fusion of the threads in synapsis, the spirem must undergo two longitudinal fissions in order to produce segments which shall approximately correspond in size and chromatin content to the daughter chromosomes of a somatic mitosis. This, as we have seen, is what actually happens. The longitudinal splitting which occurs before segmentation seems to be the one necessitated by the fusion of the two threads; and the splitting which is completed in the metaphases is the one provided for by the growth of the chromatin which has occurred since the anaphases of the last preceding division.

Evidences of the second splitting appear in the lily, as I have shown, shortly after segmentation. In many cases described by other authors, no trace of this fission appears until after the separation of the daughter chromosomes. It is quite possible that further study may show that the fission in these species also appears at the earlier stage; but, in any event, the thick chromosomes of the heterotypic mitosis are at least potentially four-parted, instead of being, like those of any somatic mitosis, two-parted; and in order that daughter chromosomes may be produced 
which are comparable to those produced by a somatic division, the two mitoses must follow each other without an intervening stage of growth. This is the reason why the condition of distribution of the chromatinthe 'resting' stage-is commonly omitted between the heterotypic and homoeotypic divisions. In cases in which some time elapses between these two divisions (e.g. in the embryo-sac of Lilium) the material of the chromosomes shows a tendency to pass into the usual distributed condition; but that no growth occurs at this time is shown by the size of the chromosomes when they appear upon the hornoeotypic spindle.

It seems, then, that all of the characteristic peculiarities of the heterotypic and homoeotypic mitoses result from the fact that the fusion of the hereditary substances contained in the parental germ nuclei, instead of being effected by the fusion of the germ-cells, is postponed until the close of the generation which results from the fusion of these cells. The fusion of the hereditary substances necessitates a further set of processes (the heterotypic mitosis) which shall reduce the mass of the chromatin in each segment of the fusion thread to that characteristic of the prophases of an ordinary mitosis. The period of growth which precedes synapsis, therefore, may be thought of as belonging strictly to the prophases of the homoeotypic division, which have been interrupted by the occurrence of the fusion and the further processes necessitated by it.

It must be remembered that we have no direct evidence that all the segments of one of the two daughter spirems produced by longitudinal fission pass finally into the same daughter nucleus. It is possible that it is entirely a matter of chance whether one or the other daughter segment of any particular chromosome shall pass into a particular daughter nucleus. The possibility of such variations, as already mentioned, has been considered by Sutton ('03), and has served as a basis for an attempt to harmonize his conception of chromosome reduction with Mendelian results in hybridization. On the other hand, the regularity of the processes leading to the separation of the chromosomes in this and in other divisions, and the elaborateness of the mechanism devised apparently for the securing of a very definite result, make it seem unlikely that the element of chance should play so large a part in this or in any other mitosis. It seems to me much more probable that each daughter thread resulting from the longitudinal splitting contains the chromatic substance destined for one of the daughter nuclei, and that the phenomena of chromosome reduction in the lily offer an explanation of the experimental facts without involving the hypothesis of a chance distribution of the chromosomes between the daughter nuclei.

\section{The Distribution of Parental Characters to the Germ-cells.}

In respect to the nature of the germ-cells produced by the heterotypic and homoeotypic divisions, there is an important difference between the 
higher animals and plants. In animals, each of these cells is a sexual cell destined to fuse with another, usually from another individual, and so to give rise at once to a new animal provided with the parental idioplasms. In the case of plants, the cells in question are asexual spores, which give rise to a new generation which in turn produces the sexual cells. Each cell of the generation produced by the germination of the spore is characterized, like the spore, by the presence of the reduced number of chromosomes. The sexual cell ultimately produced by this generation, therefore, since it is descended directly from the spore through a series of cell divisions interrupted by no cell fusions, presumably resembles the spore in its idioplasm content; and therefore the generation produced by the fusion of two such sexual cells resembles the sexually-produced animal in its endowment of two separate idioplasms. Now it happens that in the Spermaphytes, which are the only types of plants to be considered in the present discussion, we are practically confined, so far as the study of hereditary characters is concerned, to the sexually-produced generation, the sporophyte, since the gametophyte, characterized by the possession of the reduced idioplasm, is in this group a very short-lived, few-celled generation. So far, therefore, as concerns the determination of the characters of the predominant phase in its life-history by two independent idioplasms, a Seed Plant essentially resembles one of the Metazoa.

The observations of others, as well as my own, seem to show that the division of the chromatin in the homoeotypic mitosis is essentially similar, except for the reduced number of chromosomes, to that characteristic of somatic divisions. This being the case, it is in the first longitudinal splitting, which determines the grouping of the hereditary materials that are to be distributed in the heterotypic mitosis, that we must seek an explanation of the nature of chromosome reduction.

The fusion of the two spirems and the subsequent splitting of the fusion thread may be imagined to produce any one of several different results, as regards the chromatin bodies within the threads, and these various possibilities will be considered separately.

I. There may be a complete fusion in pairs, not only of the chromomeres and of their visible component granules, but also of the smaller units, if such there be, resulting in the production of a single idioplasm different from that of either parent. The subsequent fission of the thread must then be equational, since any other method of division would result in germ-cells each provided with only a partial set of idioplasmic structures, and hence, so far as we can judge, incapable of giving rise to a complete individual. Such an entire fusion of the parental idioplasms was postulated by Strasburger ('94), and is, indeed, so far as I can see, the only hypothesis which is compatible with the notion of the universal occurrence in all mitoses (including the heterotypic) of an 'equation division.' Hertwig ('90) also 
maintained that the two parental idioplasms fuse to form a new idioplasm different from either; but he conceived this process as involved in the fusion of the germ nuclei, instead of being, as we now see it must be, postponed to a much later period.

Such a complete fusion of the parental idioplasms, with a subsequent equational division, would result in the production of only one kind of germcells. If the individual producing these germ-cells be a hybrid, then the generation produced by fertilization between this and other hybrids from the same cross will consist of individuals all of one sort. I shall speak of the generation resulting from the inbreeding of hybrids from the same cross as the second hybrid generation. Now, with regard to this second generation, while its members all resemble each other, two possibilities arise as regards a comparison between them and their parents, the hybrids of the first generation. First, the two generations may be exactly similar; in other words, the original hybrids may breed true, and so constitute a variety which, having once appeared, is constant. But this is not, at least theoretically, necessary. We may imagine that the set of characters resulting from the intimate fusion of two idioplasms is something quite different from the set produced by the joint action of the same idioplasms existing separately within the same cell. So the possibility arises that the hybrids of the second generation, while resembling each other, may differ from their parents, the first generation hybrids.

So far as I am familiar with the literature, no instances have been reported which seem to correspond to the latter-mentioned possibility; hybrids which breed true, however, have been described in a number of cases. Well-known instances are the Hieracium hybrids of Mendel ('69); those of Salix reported by Wichura ('65); de Vries' ('01) hybrid between Oenothera rubrinervis and O. nanella; and Burbank's cross (Swingle and Webber, '98) between Rubus ursinus and $R$. crataegifolius. In this class too may possibly be included Millardet's 'false hybrids' already mentioned. In these there occurs apparently a complete dominance in the first hybrid generation of all the characters of one parent ; and this complete dominance of one set of characters persists in the offspring of the second and later generations. Cases of constant hybrids are numerous enough to justify the assumption that a complete fusion of the parental idioplasms is possible; and that, therefore, the heterotypic division may, in certain instances, be an equational one. But their comparative rarity is evidence that this method of chromosome reduction is not usual; although the possibility remains that hybrids do not furnish a fair test in this matter, that a complete fusion may more readily occur between the idioplasms of parents of the same race, and that, therefore, such a fusion with later equational division may be commoner than now seems probable. On the other hand, de Vries ('03) points out that constant hybrids, so far as known, result from the crossing of parents 
belonging to separate species. I have already referred to his views as to the difficulty of adjustment of parental idioplasms derived from different species in the heterotypic prophases; and he suggests that this inability of the idioplasms to adjust themselves to one another in some way makes impossible the 'splitting' of parental qualities which occurs in the formation of the germ-cells of varietal hybrids. I confess that I find it impossible to imagine how such a failure of adjustment of the two idioplasms could lead to the production of a constant idioplasm, unless it be supposed that it necessitates an actual complete fusion of the two parental substances; and such a fusion could hardly occur in such a case unless the possibility of fusion is characteristic of the structure of the idioplasms themselves. I am inclined to think, therefore, even though at present the known constant hybrids be all of specific rank, that their occurrence is evidence of the possibility of the perfectly normal occurrence of a more or less complete fusion of the idioplasms in the prophases of the heterotypic division. This conception of de Vries' has been adversely criticized also by Correns ('03c).

2. There may be in part a fusion such as was described above, while certain portions of the two idioplasms remain uncombined and capable of distribution to the germ-cells in varying combinations. This case is a transitional one, and will, therefore, be considered in connexion with the next.

3. There may be more or less mixture of the idioplasms as a result of the contact of the two threads, but no actual fusion. The substance to be separated into two portions by the splitting of the thread is then not a single idioplasm, and, unless we suppose that the actual number of idioplasmic structures may be increased from generation to generation, there cannot be an equation division; but, for the production of functional germcells, it seems most likely that there should be a redistribution of the parental materials in such a way that each daughter thread receives an endowment corresponding to a complete individual. But the two resultant idioplasms may contain the materials of the parental idioplasms arranged into entirely new and different combinations. This redistribution of the materials of the parental idioplasms is a process which can occur only at a certain point in ontogeny; it is here, then, if anywhere, that the element of chance may be supposed to enter, especially as its operation will effect the greatest possible amount of variation among the offspring. A similar operation of the law of chance has been suggested by Strasburger ('04) in the separation of the chromatin granules as a result of the division of the 'zygosome.' As a result of the mixing of the parental idioplasms and their redistribution, we should then find, if the cases at hand be numerous enough, every possible combination of different portions of the two idioplasms which is capable of giving rise to a complete set of individual characters. But this is virtually a restatement of Mendel's 'law of the 
purity of the germ-cells.' That is to say, the method of mingling and redistribution of the parental idioplasms which we are now considering would naturally lead to a purely Mendelian distribution of parental characters in the pure-bred offspring of the next generation.

A purely Mendelian distribution of parental characters is as yet, however, a purely hypothetical case. The utmost that can be said is that many crosses follow the Mendelian law with reference to certain isolated characters; and that if we can cross two races in which occur two, three, or more pairs of Mendelian 'allelomorphs', each pair will follow the law independently of the presence of the others, and we shall obtain results with reference to these few pairs of allelomorphs which are reasonably consistent with what the law teaches us to expect. But it has never been shown that, in a cross between two individuals, whether of the same or of different races, which differ from one another in many points, the law of gametic purity holds with respect to all the differing qualities. On the contrary, all of the recorded cases of obedience to the Mendelian law are instances of isolated qualities of plants or animals whose other qualities either have not been shown to follow the law or have been shown to deviate from it in a marked degree.

A priori, Mendel's law can apply to all the qualities of an individual only on condition that the character of the individual is constituted entirely of unit qualities, each of which is represented by an element of the idioplasm which can be transmitted as such without reference to any of the other elements. Such a constitution has not been shown in any case. All that has been shown is that certain qualities may act as though they were such isolated units; and it seems probable that in certain other cases there may be combinations of simple units (perhaps separable under particular conditions) into units of a higher order. As regards the great mass of the hereditary endowment of any individual, we do not yet know that it is so divisible into unit qualities of any order; and so the present evidence suffices only to show that, as regards certain portions of the parental idioplasm, a rearrangement and redistribution, without fusion, may occur. In other words, we cannot say as yet that the possibility under consideration of a complete redistribution of the idioplasmic structures of any order ever actually occurs.

Conversely, it is of course possible that further study may show variation in hitherto unnoticed points between the offspring of apparently constant hybrids. So it may be that there are no cases either of complete and perfect fusion of the parental idioplasms, or of their complete analysis into separable units ; and that, therefore, the results of chromatin reduction actually belong always to category (2), (I) and (3) being limiting cases which are seldom or never reached.

4. It is conceivable that such a rearrangement occurs as described 
under case (3), but that the chromosomes are the units whose redistribution takes place according to the Mendelian law. This possibility has been discussed in connexion with Sutton's ('03) hypothesis. It is not out of harmony with the facts already referred to of the correlation of individual characters. Thus Mendel ('65) found that in Pisum a grey, grey-brown, or leather-brown colour of the seed-coat always occurs in connexion with violet-red blossoms and reddish spots in the leaf-axils. On the other hand, this hypothesis, at least in the form in which Sutton stated it, seems to be inapplicable to the cases of constant hybrids; and it is negatived by the cytological facts in the lily, and in other cases in which a double longitudinal splitting occurs. The possibility remains, as I have suggested, that radically different methods of chromosome reduction prevail in different groups of organisms, although before the fact of such variation can be finally accepted it must be confirmed by much better evidence than is now available.

5. It is possible that portions of the idioplasms which do not fuse, or the idioplasms as wholes, may interact, perhaps chemically, upon each other while in intimate contact in the fusion thread, so that when they are afterward separated any particular portion has not the same hereditary value that it had before. Such interaction might conceivably result in the parental idioplasms, though remaining separate, coming to resemble each other more or less closely; and in this case the results of their separation in the germ-cells, so far as concerns the hereditary endowment of the offspring, might be indistinguishable from the results of a complete fusion and subsequent equation division (hypothesis $\mathrm{I}$ ). The reactions that may be imagined to occur in this way belong in the same category as those to which I have referred as not impossible in the somatic nuclei. Such reactions between the substances of the parental idioplasms would in any case produce results extremely difficult to trace in the hereditary characters of the next generation; and in the present state of our knowledge of the facts of heredity it is probably quite impossible to test the question of their occurrence.

6. It is also possible that, after their contact in the fusion thread, the parental idioplasms may be completely separated by the longitudinal splitting, so that each germ-cell receives the pure idioplasm of one or the other parent. This would result in something similar to Cannon's conception of the 'purity of the germ-cells.' Such a complete separation might be a regular occurrence, or it might occur as an individual case under Mendel's law, since one of the possible recombinations of idioplasmic units would be identical with the previously-existing combination. This also is a possibility which, so far as I can discover, has no basis in the observed facts of heredity. It is strongly suggested, as has been said, by the striking resemblance between the appearance of the thread when splitting and its appearance at the previous stage of fusion. But it would be extremely 
surprising to find such pains taken to ensure an exact adjustment and fusion of the two threads, if they are to be completely separated again at a later stage. The latter objection might be met, of course, by supposing that the two idioplasms, while remaining distinct in the fusion thread, interact without an interchange of substance, as suggested in hypothesis (5), already discussed.

As a result of the comparison which I have attempted to trace between the results of experiment and those of cytological study, it seems to me safe to say that the intimate contact of the parental idioplasms in the prophases of the heterotypic division, and the subsequent separation of their substance by the longitudinal splitting of the spirem, produce results of different nature in different instances. In a few well-authenticated cases (instances of constant hybrids) there appears to be a thorough fusion of the idioplasms and a subsequent equational splitting; although it remains possible that a more careful analysis of these same cases may show that the fusion is not so complete as the facts now seem to indicate. In a considerable number of other cases there appear to be certain elements of either parental idioplasm which remain distinct, and by the longitudinal fission of the thread are redistributed to the germ-cells according to Mendel's law. In none of these cases has it yet been shown that the whole idioplasm is divisible into units which are capable of a Mendelian redistribution.

It remains possible, therefore, that in every case there is at least a partial fusion of the idioplasms; and that in every case also certain portions remain uncombined and are later separated. The questions whether there ever occurs a complete fusion, or whether in any case no fusion at all occurs, and whether the problem may not be further complicated by some of the other factors that I have mentioned, must be left for future investigation.

The studies whose results are embodied in the foregoing paper were begun at the suggestion of Professor R. A. Harper, and have been carried on under his direction and with the constant assistance of his helpful criticism.

MADISON, WisCONSIN

August 8, 1904.

\section{LITERATURE CITED.}

Allen, C. E. ('03): The Early Stages of Spindle-formation in the Pollen Mother-cells of Larix. Ann. of Bot., vol. xvii, p. 28I.

('04): Chromosome Reduction in Lilium canadense. Bot. Gaz., vol. xxxvii, p. 464.

Balbiani, E. G. ('76): Sur les phénomènes de la division du noyau cellulaire. Compt. Rend., tom. Ixxxiii, p. 83 I. 
Balbiani, E. G. ('81): Sur la structure du noyau des cellules salivaires chez les larves de Chironomus. Zool. Anz., Bd. iv, pp 637,662 .

Bateson, W. ('02): Mendel's Principles of Heredity. A Defence. Cambridge.

Bateson, W., and Saunders, E. R. ('02) : Experimental Studies in the Physiology of Heredity. Reports to the Evolution Committee, Royal Society, Report I.

van Beneden, E. ('83): Recherches sur la maturation de l'œuf, la fécondation, et la division cellulaire. Arch. de Biol., tom. iv, p. 403.

van Beneden, E., and Julin, C. ('84): La spermatogenèse chez l'Ascaride mégalocéphale. Bull. Acad. roy. sc. Belg., $3^{\mathrm{e}}$ sér., tom. vii.

BERGHS, J. ('04) : La formation des chromosomes hétérotypiques dans la sporogenèse végétale. I. Depuis le spirème jusqu'aux chromosomes mûrs, dans la microsporogenèse d'Allium fistulosum et de Lilium lancifolium (speciosum). La Cellule, tom. xxi, p. I73.

Boveri, T. ('88): Zellenstudien. II. Die Befruchtung und Teilung des Eies von Ascaris megalocephala. Jen. Zeitschr., Bd. xxii, p. 685 .

- ('89): Ein geschlechtlich erzeugter Organismus ohne mütterliche Eigenschaften. Sitzber. Ges. Morph. und Phys. München, Bd. v, p. 73. Eng. trans. by T. H. Morgan, Amer. Nat., vol. xxvii, p. 222.

('90): Zellenstudien. III. Ueber das Verhalten der chromatischen Kernsubstanz bei der Bildung der Richtungskörper und bei der Befruchtung. Jen. Zeitschr., Bd. xxiv, p. 314. ('02): Ueber mehrpolige Mitosen als Mittel zur Analyse des Zellkerns. Verh. Phys.Med. Ges. Würzburg, N. F., Bd. xxxv, p. 67 .

('04): Ergebnisse über die Konstitution der chromatischen Substanz des Zellkerns. Jena.

Brauer, A. ('93) : Zur Kenntniss der Spermatogenese von Ascaris megalocephala. Arch. mikr. Anat., Bd. xlii, p. I 53 .

Cannon, W. A. ('02): A Cytological Basis for the Mendelian Laws. Bull. Torrey Bot. Club, vol. xxix, p. 657 .

('03 a): Studies in Plant Hybrids : the Spermatogenesis of Hybrid Cotton. Bull. Torrey Bot. Club, vol. xxx, p. 133 .

Torrey Bot. Club, vol. xxx, p. 519 .

Correns, C. ('02): Ueber Bastardierungsversuche mit Mirabilis-Sippen. Ber. deut. bot. Ges., Bd. $x x$, p. 594 .

('03 a) : Ueber die dominierenden Merkmale der Bastarde. Ber. deut. bot. Ges., Bd. $x x i$, p. 133 .

( $(036)$ : Weitere Beiträge zur Kenntniss der dominierenden Merkmale und der Mosaikbildung der Bastarde. Ber. deut. bot. Ges., Bd. xxi, p. I95.

('03c): Die Merkmalspaare beim Studium der Bastarde. Ber. deut. bot. Ges., Bd. xxi, p. 202.

Darwin, C. ('68): The Variation of Animals and Plants under Domestication. Amer. ed., 2 vols. New York

EISEN, G. ('00) : The Spermatogenesis of Batrachoseps. Journ. of Morph., vol. xvii, p. I.

ERnst, A. ('02): Chromosomenreduction, Entwickelung des Embryosackes und Befruchtung bei Paris quadrifolia L. und Trillium grandiflorum Salisb. Flora, Bd. xci, p. I.

Farmer, J. B, and Moore, J. E. S. ('95): On the Essential Similarities existing between the Heterotype Nuclear Divisions in Animals and Plants. Anat. Anz., Bd. xi, p. 7 I.

('03): New Investigations into the Reduction Phenomena of Animals and Plants. Preliminary Communication. Proc. Roy. Soc., vol. Ixxii, p. I04.

Flemming, W. ('78) : Beiträge zur Kenntniss der Zelle und ihrer Lebenserscheinungen. I. Arch. mikr. Anat., Bd. xvi, p. 302 .

('80): Beiträge zur Kenntniss der Zelle und ihrer Lebenserscheinungen。 II. Arch. mikr. Anat., Bd. xviii, p. ${ }_{15}$ I.

('81) : Beiträge zur Kenntniss der Zelle und ihrer Lebenserscheinungen. III. Arch. mikr. Anat., Bd. xx, p. I.

('82): Zellsubstanz, Kern- und Zellteilung. Leipzig.

('87) : Neue Beitıäge zur Kenntniss der Zelle. Arch. mikr. Anat., Bd. xxix, p. 389.

FoL, H. ('91): Le quadrille des centres. Un épisode nouveau dans l'histoire de la fécondation. Arch. sci. phys. et nat., $3^{\text {me }}$ sér., tom. xxv, p. 393 . 
Grḱgolre, V. ('99): Les cinèses polliniques dans les Liliacées. La Cellule, tom. xvi, p. 235. ('04): La réduction numérique des chromosomes et les cinèses de maturation. La Cellule, tom. xxi, p. 297.

Gregory, R. P. ('04): The Reduction Division in Ferns. Proc. Roy. Soc., vol. lxxiii, p. 86.

GuignarD, L. ('84): Recherches sur la structure et la division du noyau cellulaire chez les végétaux. Ann. sci. nat., bot., $6^{\mathrm{e}}$ sér., tom. xvii, p. 5 .

('85): Nouvelles recherches sur le noyau cellulaire et les phénomènes de la division communs aux végétaux et aux animaux. Ann. sci. nat., bot., $6^{\mathrm{e}}$ sér., tom. $\mathrm{xx}, \mathrm{p}$. $3 \mathrm{I}$.

('91): Nouvelles études sur la fécondation. Comparaison des phénomènes morphologiques observés chez les plantes et chez les animaux. Ann. sci. nat., bot., $\gamma^{e}$ sér., tom. xiv, p. 163 .

('99) : Le développement du pollen et la réduction chromatique dans le Naias major. Arch. d'anat. micr., tom. ii, p. 455 .

Häcker, V. ('90): Ueber die Reifungsvorgänge bei Cyclops. Zool. Anz., Bd. xiii, p. 55 I.

('92): Die Eibildung bei Cyclops und Canthocamptus. Zool. Jahrb., Bd. v, p. 2 Ir.

('93): Das Keimbläschen, seine Elemente und Lageveränderungen. I. Ueber die biologische Bedeutung des Keimbläschenstadiums und über die Bildung der Vierergruppen. Arch. mikr. Anat., Bd. xli, p. $45^{2}$.

('95): The Reduction of the Chromosomes in the Sexual Cells as described by Botanists ;

a Reply to Prof. Strasburger. Ann. of Bot., vol. ix, p. 95.

('97): Die Keimbahn von Cyclops. Neue Beiträge zur Kenntniss der GeschlechtszellenSonderung. Arch. mikr. Anat., Bd, xlix, p. 35 .

- ('99): Die Reifungserscheinungen. Ergebnisse der Anatomie und Entwickelungsgeschichte (Merkel und Bonnet), Bd. viii (1898), p. 847 .

('02): Ueber das Schicksal der elterlichen und grosselterlichen Kernantheile. Morphologische Beiträge zum Ausbau der Vererbungslehre. Jen. Zeitschr, N. F., Bd. xxx, p. 297 .

('04) : Bastardierung und Geschlechtszellenbildung. Zool. Jahrb., Supp. vii, p. I6r.

Halsted, B. D. ('04): Report of the Botanical Department of the New Jersey Agricultural College Experiment Station for the Year 1903. Somerville.

Henking, H. ('91): Untersuchungen über die ersten Entwicklungsvorgänge in den Eiern der Insekten. II. Ueber Spermatogenese und deren Beziehung zur Eientwicklung bei Pyrrhocoris apterus L. Zeitschr. wiss. Zool., Bd. li, p. 685.

Hertwig, O. ('90): Vergleich der Ei- und Samenbildung bei Nematoden. Eine Grundlage für celluläre Streitfragen. Arch. mikr. Anat., Bd. xxxvi, p. I.

Heuse R, E. ('84) : Beobachtungen über Zellkerntheilung. Bot. Centralbl., Bd. xvii, pp. 27, 57, 85, I 17, I 54 .

Hildebrand, F. ('89): Ueber einige Pflanzenbastardierungen. Jen. Zeitschr., Bd. xxiii,

Kingsbury, B. F. ('99): The Reducing Divisions in the Spermatogenesis of Desmognathus. Zool. Bull., vol. ii.

Kultschitzky, N. ('88) : Ueber die Eireifung und die Befruchtungsvorgänge bei Ascaris marginata. Arch. mikr. Anat., Bd. xxxii, p. 671 .

LoEb, J. ('99): On the Nature of the Process of Fertilization and the Artificial Production of Normal Larvae (Plutei) from the Unfertilized Egg of the Sea-urchin. Amer. Journ. Physiol., vol. iii.

Lotsy, J. P. ('04) : Die Wendung der Dyaden beim Reifen der Tiereier als Stütze für die Bivalenz der Chromosomen nach der numerischen Reduktion. Flora, Bd. xciii, p. $6_{5}$.

McClung, C. E. ('99): A Peculiar Nuclear Element in the Male Reproductive Cells of Insects. Zool. Bull., vol. ii.

('02): The Accessory Chromosome, Sex Determinant? Biol. Bull., vol. iii, p. 43 .

Macfarlane, J. M. ('90): The Microscopic Structure of Hybrids. Gardeners' Chronicle, N. S., vol. vii, p. 543 .

MCGregor, J. H. ('99): The Spermatogenesis of Amphiuma. Journ. of Morph., vol. xv, supp.

Mendel, G. J. ('65): Versuche uiber Pflanzenhybriden. Abh. naturf. Ver. Brünn, Bd. iv, p. I. Reprinted in Ostwald's 'Klassiker der exakten Wissenschaften,' no. I2I. Also in Flora, I 901. Eng. trans., Journ. Roy. Hort. Soc., vol. xxvi. Same trans., revised, in Bateson's 'Mendel's Principles of Heredity,' Cambridge, I902. 
Mendel, G. J. ('69): Ueber einige aus künstlicher Befruchtung gewonnenen Hieracium-Bastarde. Abh. naturf. Ver. Brünn, Bd. viii, p. 26. Reprinted in Ostwald's 'Klassiker der exakten Wissenschaften,' no. I 2 I. Eng. trans. in Bateson's 'Mendel's Principles of Heredity.'

Meves, F. ('96): Ueber die Entwicklung der männlichen Geschlechtszellen von Salamandra. Arch. mikr. Anat., Bd. xlviii.

Millardet, A. ('94): Note sur l'hybridation sans croisement, ou fausse hybridation. Mém. soc. sci. Bordeaux, $4^{\mathrm{e}}$ sér., tom. iv, p. 347 .

Moenkhaus, W. J. ('04): The Development of the Hybrids between Fundulus heteroclitus and Menidia notata with Especial Reference to the Behaviour of the Maternal and Paternal Chromatin. Amer. Journ. Anat., vol, iii, p. 29.

Montgomery, T. H., Jr. ('01): A Study of the Chromosomes of the Germ-cells of the Metazoa. Trans. Amer. Phil. Soc., N. S., vol. xx, p. I54.

Significance. Biol. Bull., vol. iv, p. 259.

('04): Some Observations and Considerations upon the Maturation Phenomena of the Germ-Cells. Biol. Bull., vol. vi, p. I37.

Moore, J. E. S. ('94): On the Germinal Blastema and the Nature of the So-called 'Reduction Division' in the Cartilaginous Fishes. Anat. Anz., Bd. ix, p. 547.

('95a): On the Essential Similarity of the Process of Chromosome Reduction in Animals and Plants. Ann. of Bot., vol. ix, p. 43I.

('95b): On the Structural Changes in the Reproductive Cells during the Spermatogenesis of Elasmobranchs. Quart. Journ. Micr. Sci., vol. xxxviii.

Mottier, D. M. ('97) : Beiträge zur Kenntniss der Kerntheilung in den Pollenmutterzellen einiger Dikotylen und Monokotylen. Jahrb. wiss. Bot., Bd. xxx, p. I69.

('03): The Behavior of the Chromosomes in the Spore Mother-cells of Higher Plants and the Homology of the Pollen and Embryo-sac Mother-cells. Bot. Gaz., vol. xxxv, p. 250.

Overton, E. ('91) : Beitrag zur Kenntniss der Entwickelung und Vereinigung der Geschlechtsproducte bei Lilium Martagon. Festschr. f. Kölliker und Nägeli, Univ. Zürich.

Overton, J. B. ('04): Ueber Parthenogenesis bei Thalictrum purpurascens. Ber. deut. bot. Ges., Bd. xxii, p. 274 .

Pfitzner, W. ('81): Ueber den feineren Bau der bei der Zelltheilung auftretenden fadenformigen Differenzirungen des Zellkerns. Morph. Jahrb., Bd. vii, p. 289.

Rabl, C. ('85): Ueber Zelltheilung. Morph. Jahrb., Bd. x, p. 214.

vom Rath, O. ('92): Zur Kenntniss der Spermatogenese von Gryllotalpa vulgaris Latr. Arch. mikr. Anat., Bd. xl, p. Io2.

('93): Beiträge zur Kenntniss der Spermatogenese von Salamandra maculosa. Zeitschr. wiss. Zool., Bd. 1vii, p. 97 .

Rosenberg, O. ('03): Das Verhalten der Chromosomen in einer hybriden Pflanze. Ber. deut. bot. Ges., Bd. xxi, p. I 10.

('04 a) : Ueber die Tetradentheilung eines Drosera-Bastardes. Ber. deut. bot. Ges., Bd. xxii, p. 47 .

('04b): Ueber die Reduktionsteilung in Drosera. Meddelande från Stockholms Högskolas Botaniska Institut. Stockholm.

('04c): Ueber die Individualität der Chromosomen im Pflanzenreich. Flora, Bd. xciii, p. 25 I.

Rückert, J. ('92a) : Zur Entwickelungsgeschichte des Ovarialeies bei Selachiern. Anat. Anz., Bd. vii, p. 107 .

('92 b) : Ueber die Verdoppelung der Chromosomen im Keimbläschen des Selachiereies. Anat. Anz., Bd. viii, p. 44 .

('94): Die Chromatinreduktion bei der Reifung der Sexualzellen. Ergebnisse der Anatomie und Entwickelungsgeschichte (Merkel und Bonnet), Bd. iii (1893), p. 5 I 7 .

('95) : Ueber das Selbständigbleiben der väterlichen und mütterlichen Kernsubstanz während der ersten Entwicklung des befruchteten Cyclops-Eies. Arch. mikr. Anat., Bd. xlv, p. 339 .

Sabaschnikoff, M. ('97): Beiträge zur Kenntniss der Chromatinreduction in der Ovogenese von Ascaris megalocephala bivalens. Bull. Soc. Imp. Nat. Moscou, N. S., Bd. xi, p. 82. 
Sargant, E. ('96): The Formation of the Sexual Nuclei in Lilium Martagon. I. Oögenesis. Ann. of Bot., vol. x, p. 445 .

('97) : The Formation of the Sexual Nuclei in Lilium Martagon. II. Spermatogenesis. Ann. of Bot., vol. xi, p. 187 .

Schaffner, J. H. ('97): The Division of the Macrospore Nucleus. Bot. Gaz., vol. xxiii, p. 430.

Schoenfeld, H. ('01): La spermatogenèse chez le taureau et chez les mammifères en général. Arch. de Biol., tom. xviii, p. I.

Schreiner, A., and Schreiner, K. E. ('04): Die Reifungsteilungen bei den Wirbeltieren. Ein Beitrag zur Frage nach der Chromatinreduktion. Anat. Anz., Bd. xxiv, p. 56r.

Schwarz, F. ('87): Die morphologische und chemische Zusammensetzung des Protoplasmas. Cohn's Beitr. z. Biol. d. Pflanzen, Bd. v, p. I.

Strasburger, E. ('82): Ueber den Theilungsvorgang der Zellkerne und das Verhältniss der Kerntheilung zur Zelltheilung. Arch. mikr. Anat., Bd. xxi, p. 476.

Befruchtung. Hist. Beit., I. Jena.

('94): The Periodic Reduction of the Number of the Chromosomes in the Lifehistory of Living Organisms. Ann. of Bot., vol. viii, p. 28 I.

('95): Karyokinetische Probleme. Jahrb. wiss. Bot., Bd. xxviii, p. I5I.

('00): Ueber Reduktionstheilung, Spindelbildung, Centrosomen und Cilienbildner im Pflanzenreich. Hist. Beit., VI. Jena.

('04) : Ueber Reduktionsteilung. Sitzber. kön. Preuss. Akad. Wiss., Bd. xviii.

Sutron, W. S. ('02): On the Morphology of the Chromosome Group in Brachystola magna. Biol. Bull., vol. iv, p. 24.

('03): The Chromosomes in Heredity. Biol. Bull., vol. iv, p. $23 \mathrm{I}$.

Swingle, W. T., and Webber, H. J. ('98): Hybrids and their Utilization in Plant Breeding. Yearbook U. S. Dept. Agric., I 897, p. $3^{8} 3$.

TANgL, E. ('82): Die Kern- und Zelltheilung bei der Bildung des Pollens von Hemerocallis fulva L. Denkschr. Kais. Akad. Wiss. Wien, Bd. xlv, p. 65.

Tschistiakoff, J. ('75) : Beiträge zur Physiologie der Pflanzenzelle. Kurze Notizen und vorläufige Mittheilungen über die Entwickelung der Sporen und des Pollens. Bot. Zeit., Bd. xxxiii, pp. I, I $7,33,81,97$.

DE Vries, H. ('01): Die Mutationstheorie. Erster Band: Die Entstehung der Arten durch Mutation. Leipzig.

('03): Befruchtung und Bastardierung. Leipzig.

Weismann, A. ('92): Das Keimplasma. Jena. Eng. trans. New York.

Wichura, M. ('65): Die Bastardbefruchtung im Pflanzenreich erläutert an den Bastarden der Weiden. Breslau.

Williams, J. L. ('04): Studies in the Dictyotaceae. I. The Cytology of the Tetrasporangium and the Germinating Tetraspore. Ann. of Bot., vol. xviii, p. I4I.

Wilson, E. B. ('01): Experimental Studies in Cytology. I. A Cytological Study of Artificial Parthenogenesis in Sea-urchin Eggs. Arch. f. Entw.-Mech., Bd. xii, p. $5^{29}$.

von Winiwarter, H. ('00): Recherches sur l'ovogenèse et l'organogenèse de l'ovaire des mammifères (Lapin et Homme). Arch. de Biol., tom. xvii, p. 33 .

Zacharias, E. ('82) : Ueber den Zellkern. Bot. Zeit., Bd. xl, p. 6i i. 


\title{
DESCRIPTION OF FIGURES IN PLATES VI, VII, VIII, AND IX.
}

\author{
Illustrating Prof. Allen's paper on the Pollen Mother-cells of Lilium canadense.
}

All the figures were drawn with the aid of a camera lucida, and with a Zeiss apochromatic $2 \mathrm{~mm}$. objective, I.30 apert.: Figs. ${ }^{5} 5,16,17,18,24,27$, and 31 with compens. oc. 18 ; all the others with compens. oc. I 2 .

\section{PLATE VI.}

Fig. I. Reconstructing nuclens of pollen mother-cell, shortly after close of last pre-heterotypic division. Spindle fibres (not shown) still attached on equatorial side (lower side in figure).

Fig. 2. Somewhat older nucleus, showing increased size ; irregular nucleolar masses.

Fig. 3. Tangential view of portion of nuclear reticulum, same stage as Fig. 2.

Fig. 4. Pollen mother-cell at slightly later stage.

Fig. 5. Still older nucleus; peripheral arrangement of chromatic material; rounded, vacuolated nucleole.

Fig. 6. Tangential view of portion of nuclear reticulum, same stage as Fig. 5 . spirem.

Fig. 7. Median section of still older nucleus, shortly before synapsis ; beginning of formation of

Fig. 8. Tangential view of nucleus, same stage as Fig. 7 .

Fig. 9. Portion of nuclear reticulum showing paired fibres; same stage as Figs. 7 and 8.

Figs. 10, I I. Stages in the transition to synapsis.

Fig. I2. Nucleus in synapsis, tangential view; spirem composed of two parallel threads; no free ends; flattened nucleole.

Fig. I3. Portion of double spirem, same stage as Fig. I 2.

Fig. I4. Median section of cell with nucleus in synapsis; paired strands at $a$.

Figs. I5-18. Stages in the fusion of the parallel threads; substance of threads differentiated into chromatin and linin.

Fig. 19. Late synapsis stage, with single thick spirem; cell has separated from its fellows and rounded up.

Fig. 20. Cell showing stage in transition from synapsis.

\section{PLATE VII.}

Fig. 21. Later stage in transition from synapsis.

Fig. 22. Median section of cell with uniformly distributed spirem.

Fig. 23. Nearly complete nucleus, showing course of spirem, at same stage as Fig. 22. The free ends visible are all in the plane of cutting.

Fig. 24. Portion of thread, stage of Fig. 23, showing single row of chromomeres.

Fig. 25. Portion of tangential view of nucleus, showing longitudinal splitting of the spirem.

Fig. 26. Median section of cell, same stage as Fig. 25.

Fig. 27. Portions of spirem, showing process of longitudinal splitting.

Fig. 28. Early stage in segmentation; a few free ends, all in the periphery.

Fig. 29. Later stage in segmentation.

Fig. 30. Nucleus some time after segmentation; chromosomes mostly in the periphery and somewhat shorter and thicker than in Fig. 29.

Fig. 31. Two chromosomes, same stage as Fig. 30 ; two rows of chromomeres in each daughter chromosome; traces of second longitudinal splitting at $a$ and $b$.

Fig. 32. Nucleus just before formation of multipolar spindle; short, thick chromosomes.

Fig. 33. Chromosome at time of completion of segmentation.

Figs. 34, 35. Chromosomes, showing early stages in the process of shortening and thickening. 


\section{PLA: II.}

Figs. 36-54. Further stages in the shortening of the chromosomes.

Fig. 55. Cell at stage of multipolar spindle; extra-nuclear nucleoles.

Fig. 56. Cell at equatorial plate stage.

Fig. 57. Equatorial plate, polar view.

Fig. 58. Metaphase ; longitudinal splitting of daughter chromosomes.

Fig. 59. Polar view of single chromosome from an equatorial plate.

Figs. 60-67. Lateral views of chromosomes from various equatorial plates.

Figs. 68-87. Stages in the separation of the daughter chromosomes.

\section{PLATE IX.}

Fig. 88. Daughter chromosomes approaching the pole.

Fig. 89. Daughter chromosomes at the pole (diaster stage).

Fig. 90. Slightly later than Fig. 89 ; shortening of daughter chromosomes. formation.

Fig. 91. Formation of daughter nuclei; chromosomes densely massed; beginning of cell-plate

Fig. 92. Reconstructed spirem in daughter nucleus; cell-plate.

Fig. 93. Oblique view of daughter-cell and nucleus; cell-division complete.

\section{HOMOEOTYPIC DIVISION.}

Figs. 94, 95. Separation of chromosomes in the prophases.

Fig. 96. Multipolar spindle.

Figs. 97-100. Single chromosomes during the prophases.

Fig. IOI. Equatorial plate, lateral view.

Figs. I02, I03. Equatorial plates in polar view.

Figs. 104-106. Lateral views of chromosomes from the equatorial plate.

Fig. 107. Metaphase. 
Annals of Botany.
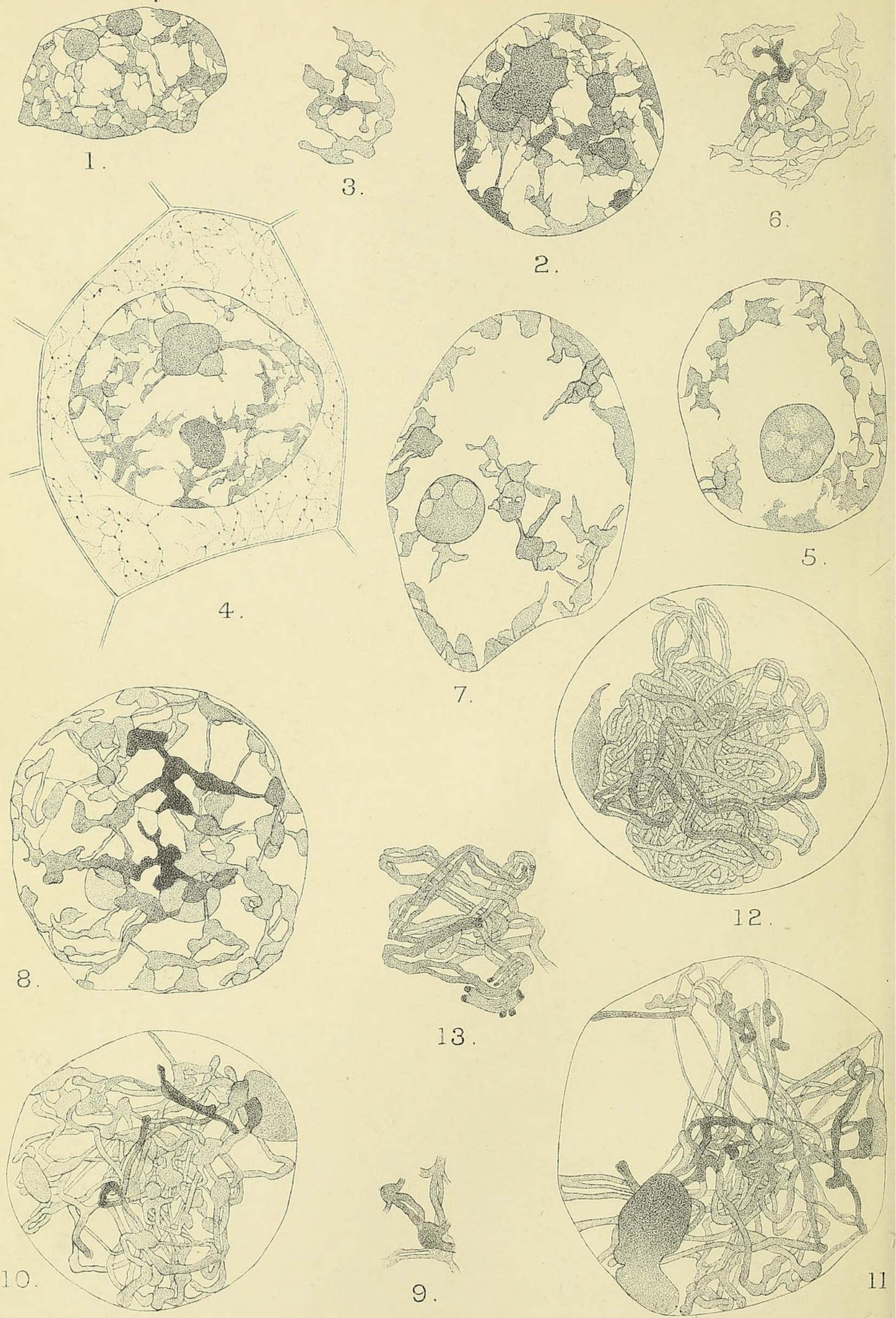


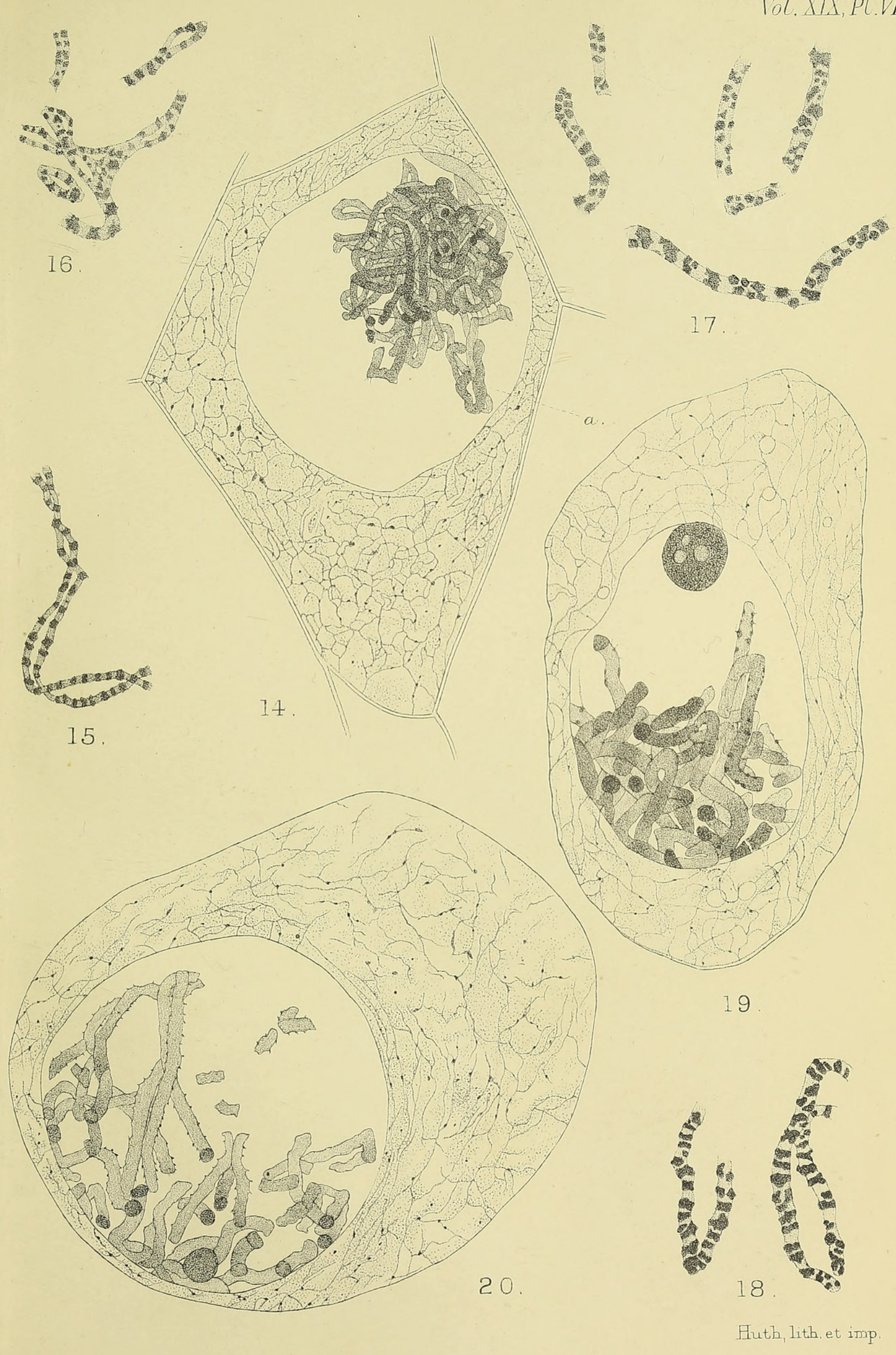


- Arnals of Botany.

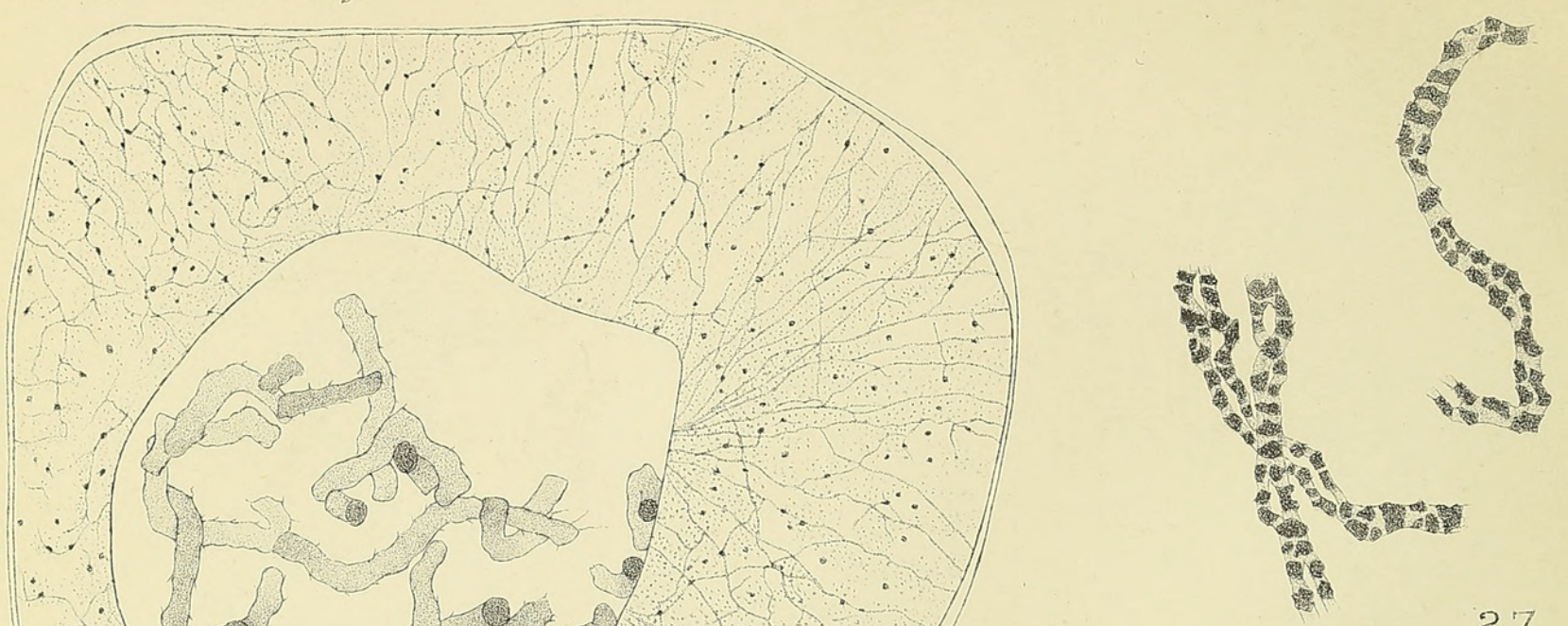

27
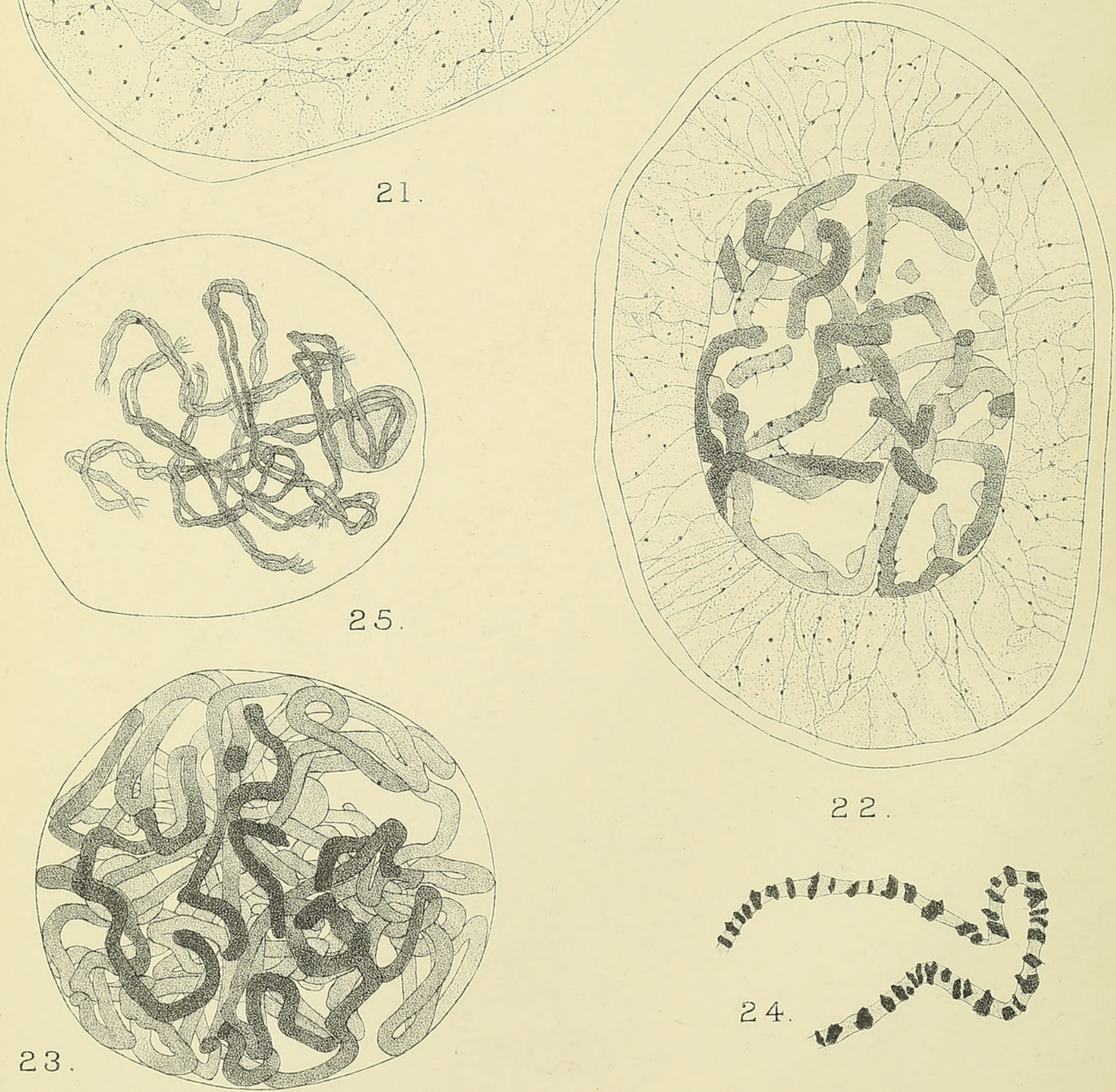

22

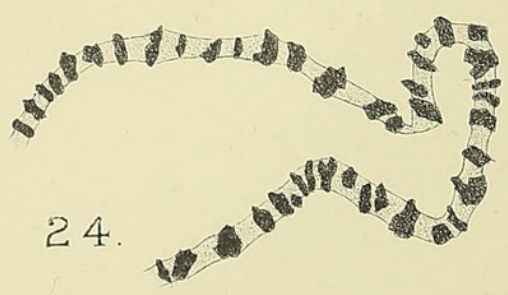


Vol. XIX, Pl.VII.
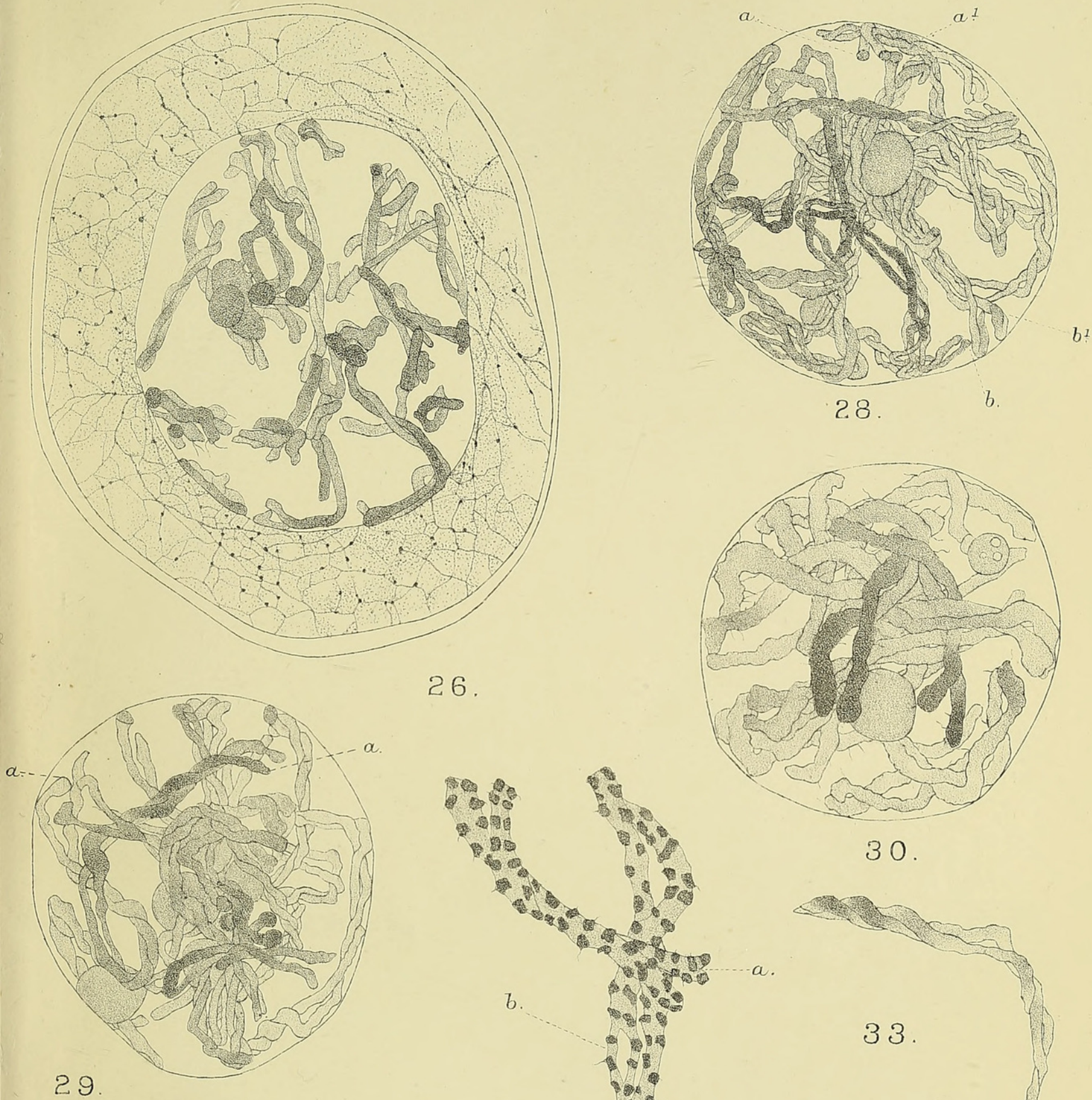

26

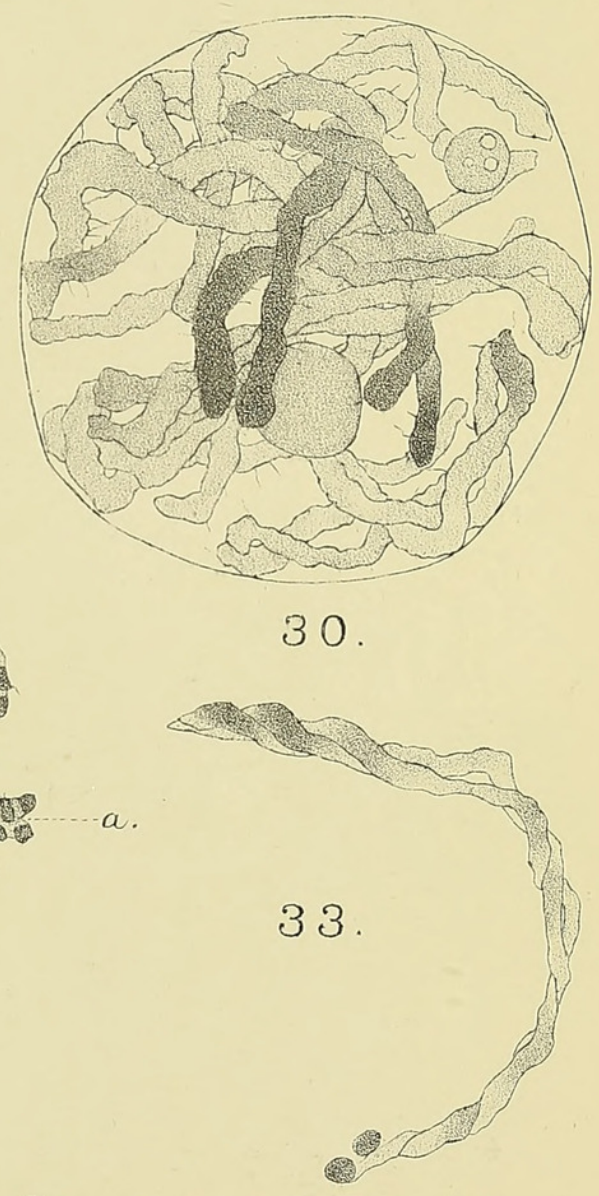

32
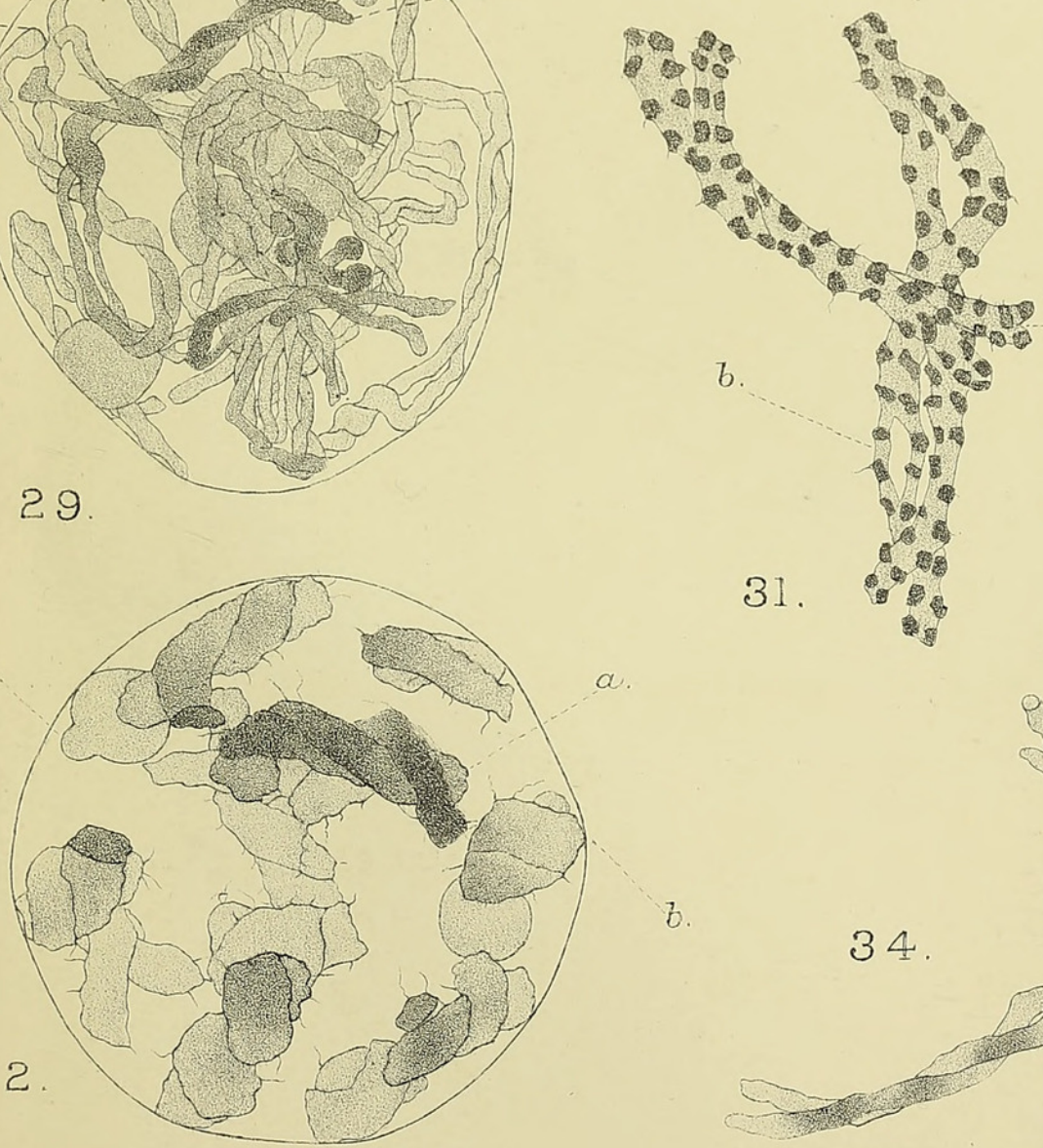

b.
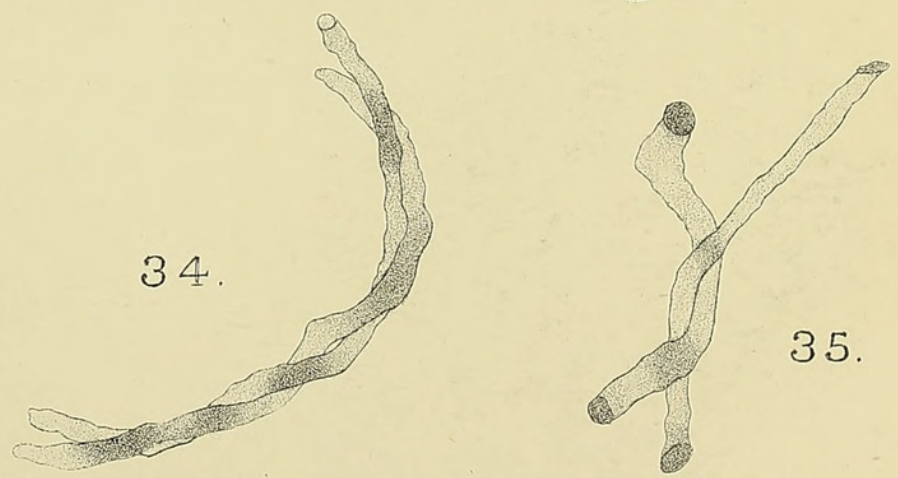
eAnnals of Botany.
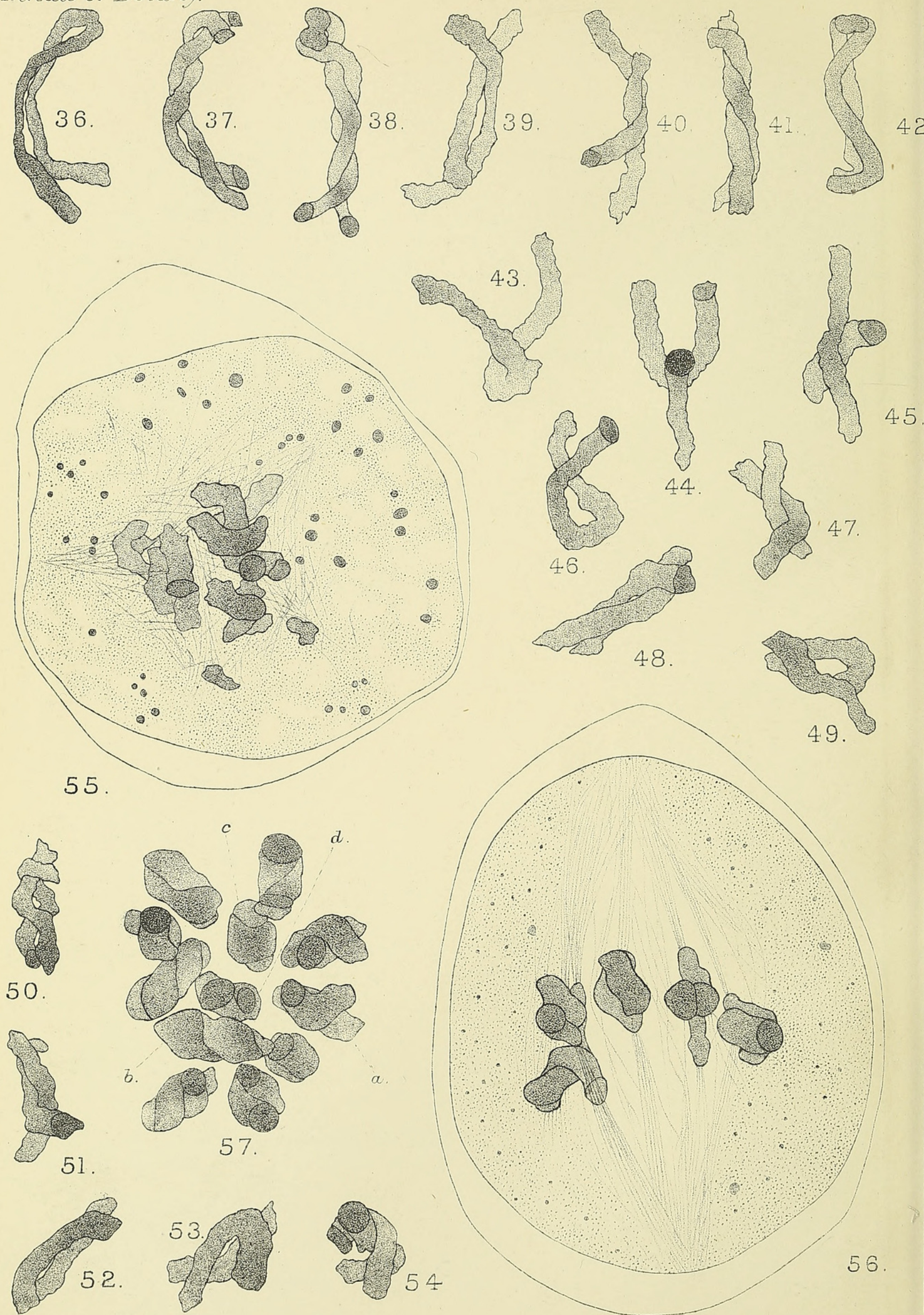

C.E.A. del. 
Vol. XIX PI. VIIII.

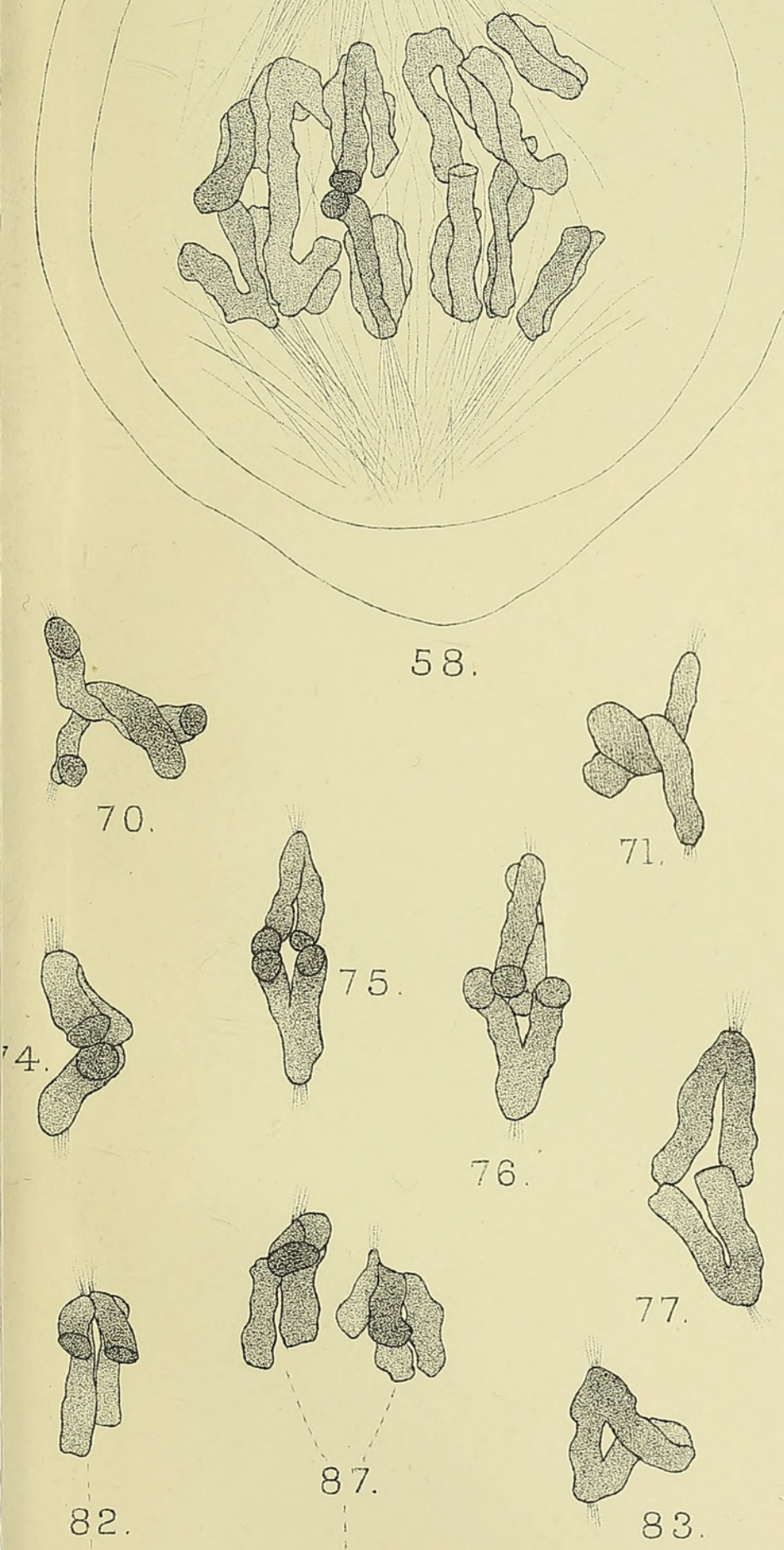

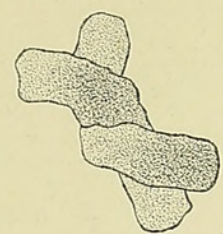

59.

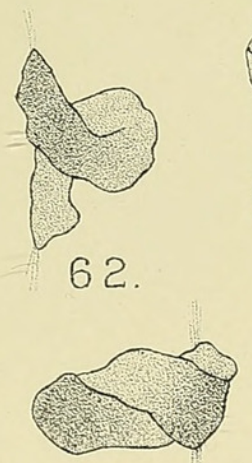

65.
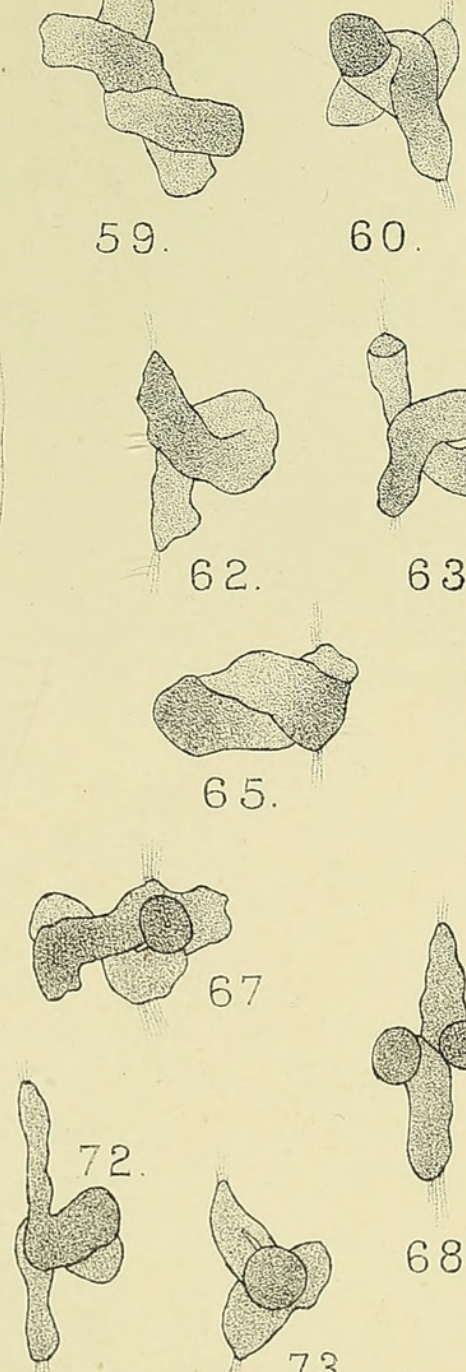

60

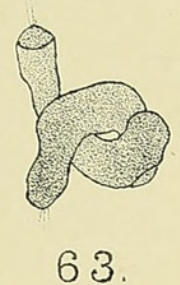

64.
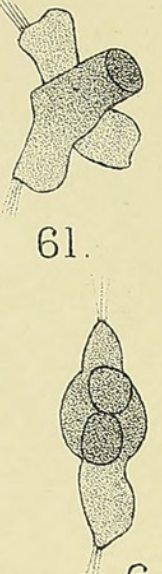

61.
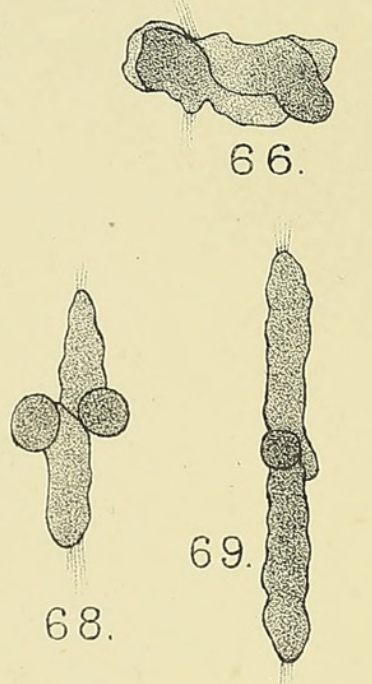
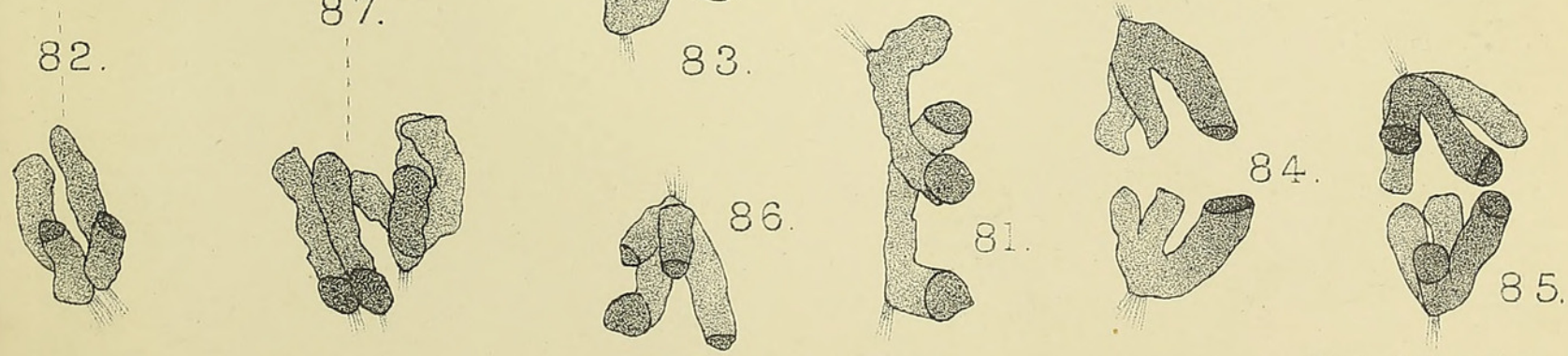


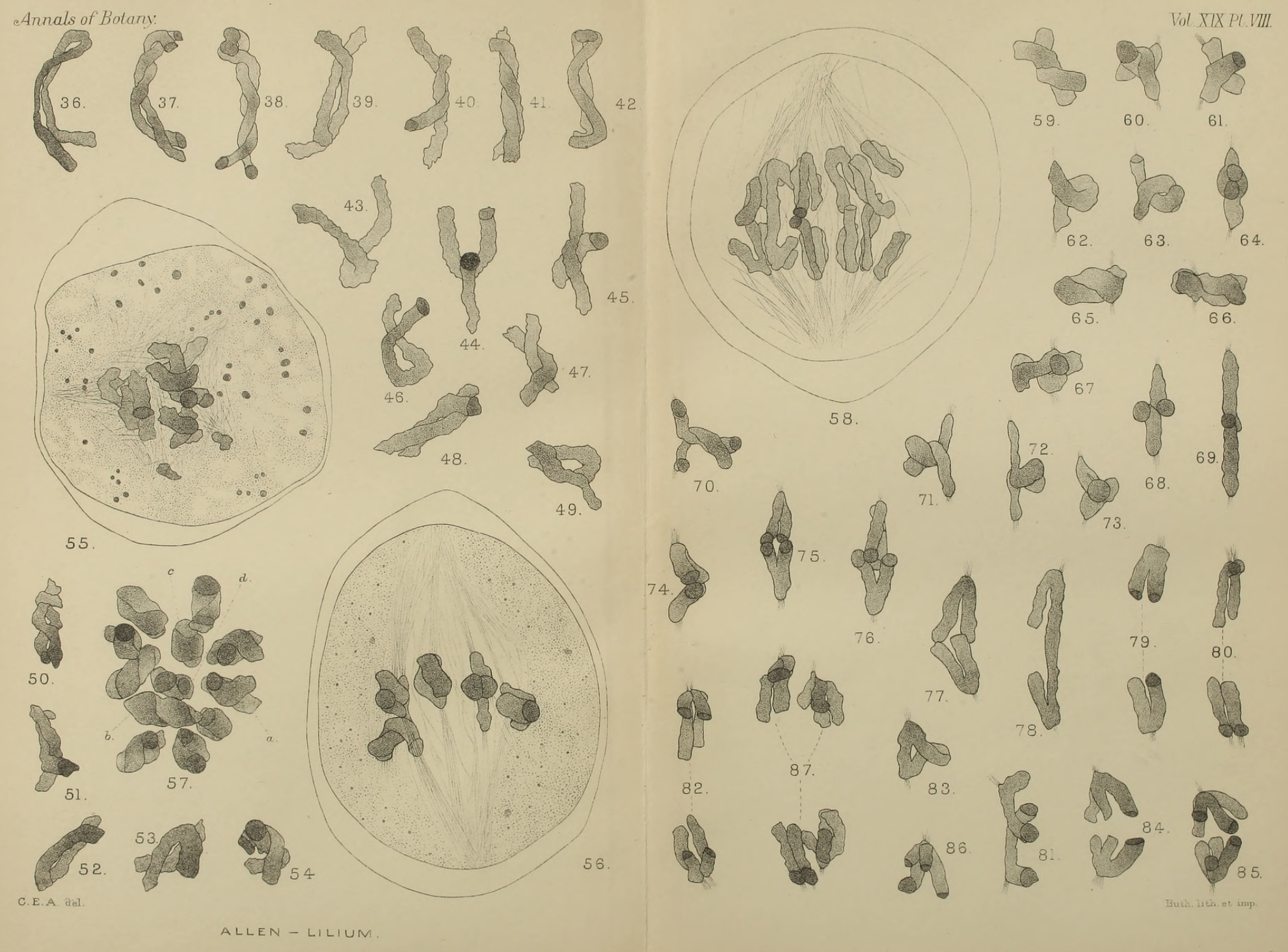


Annals of Botany.
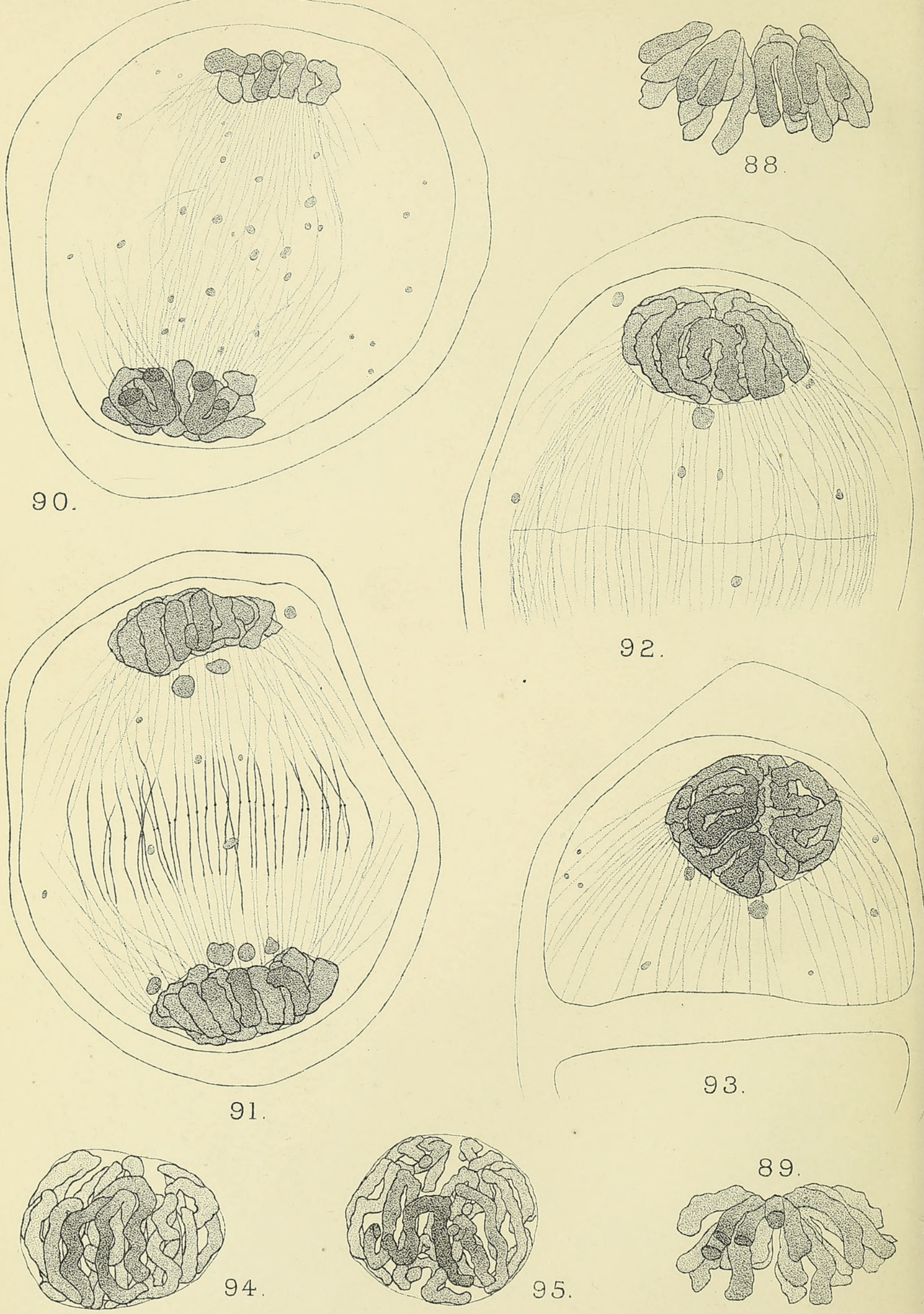

C. E. A. del 
Vol. XIX, Pl IX.
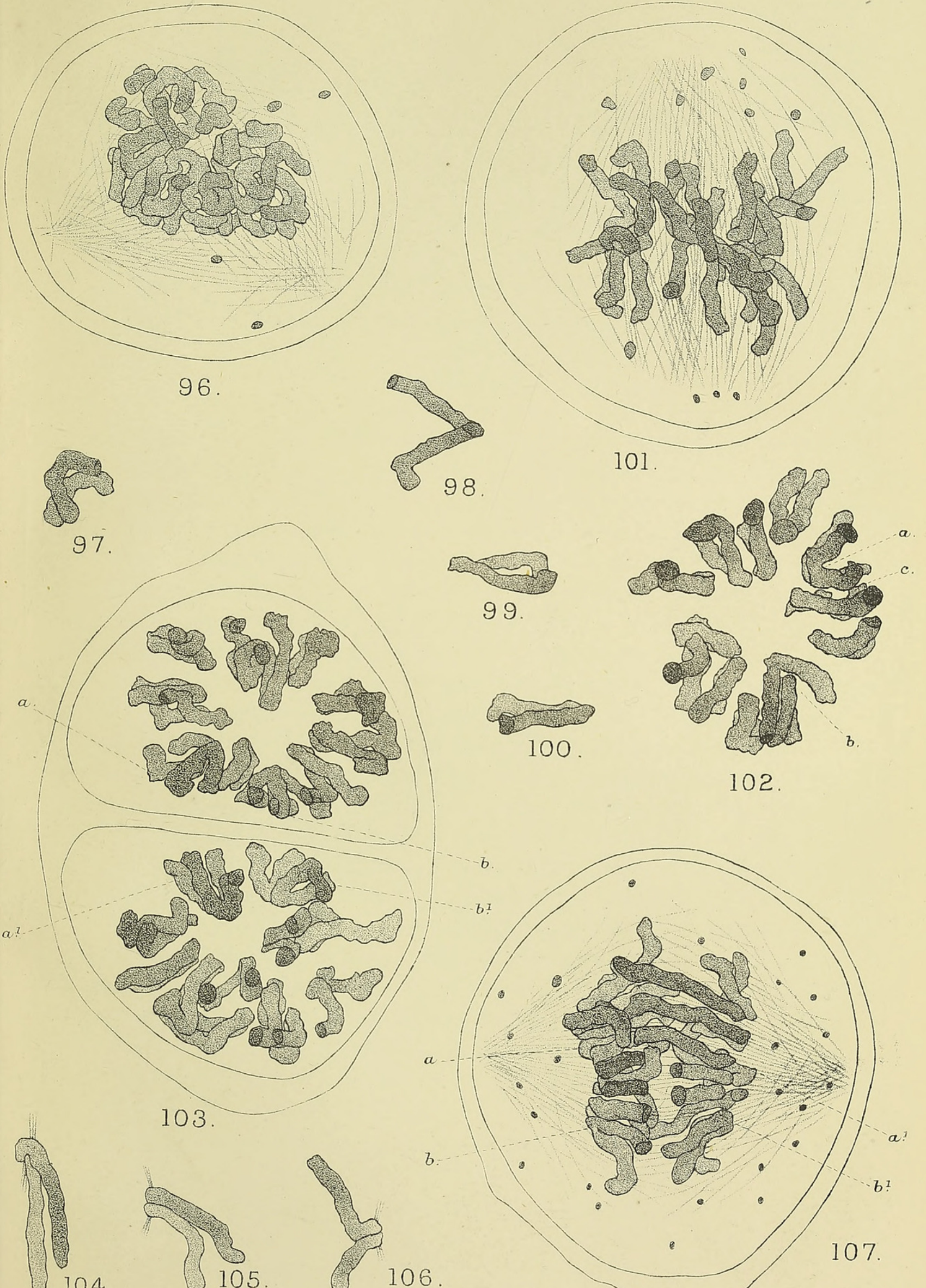

97.
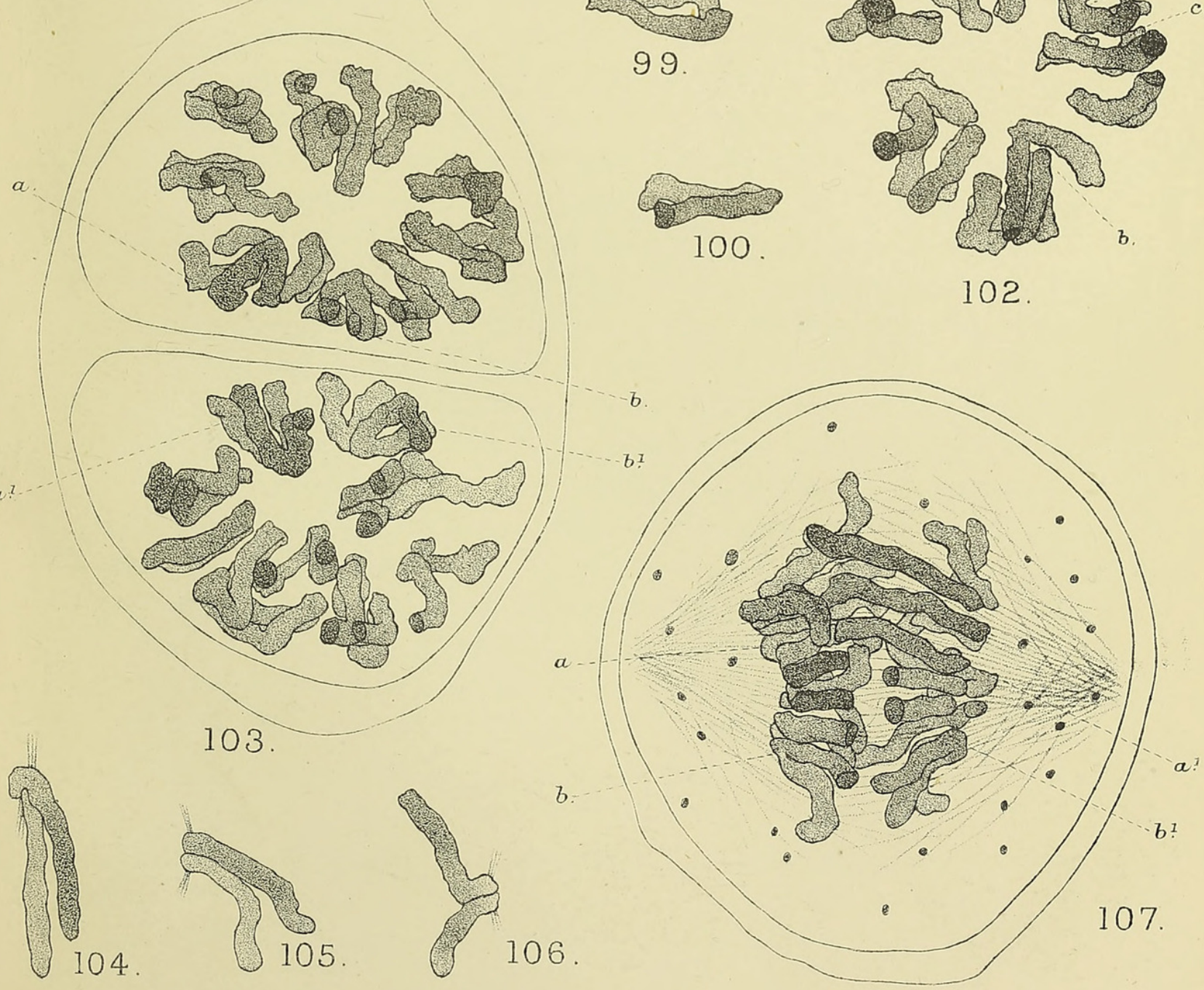
Annals of Botany.
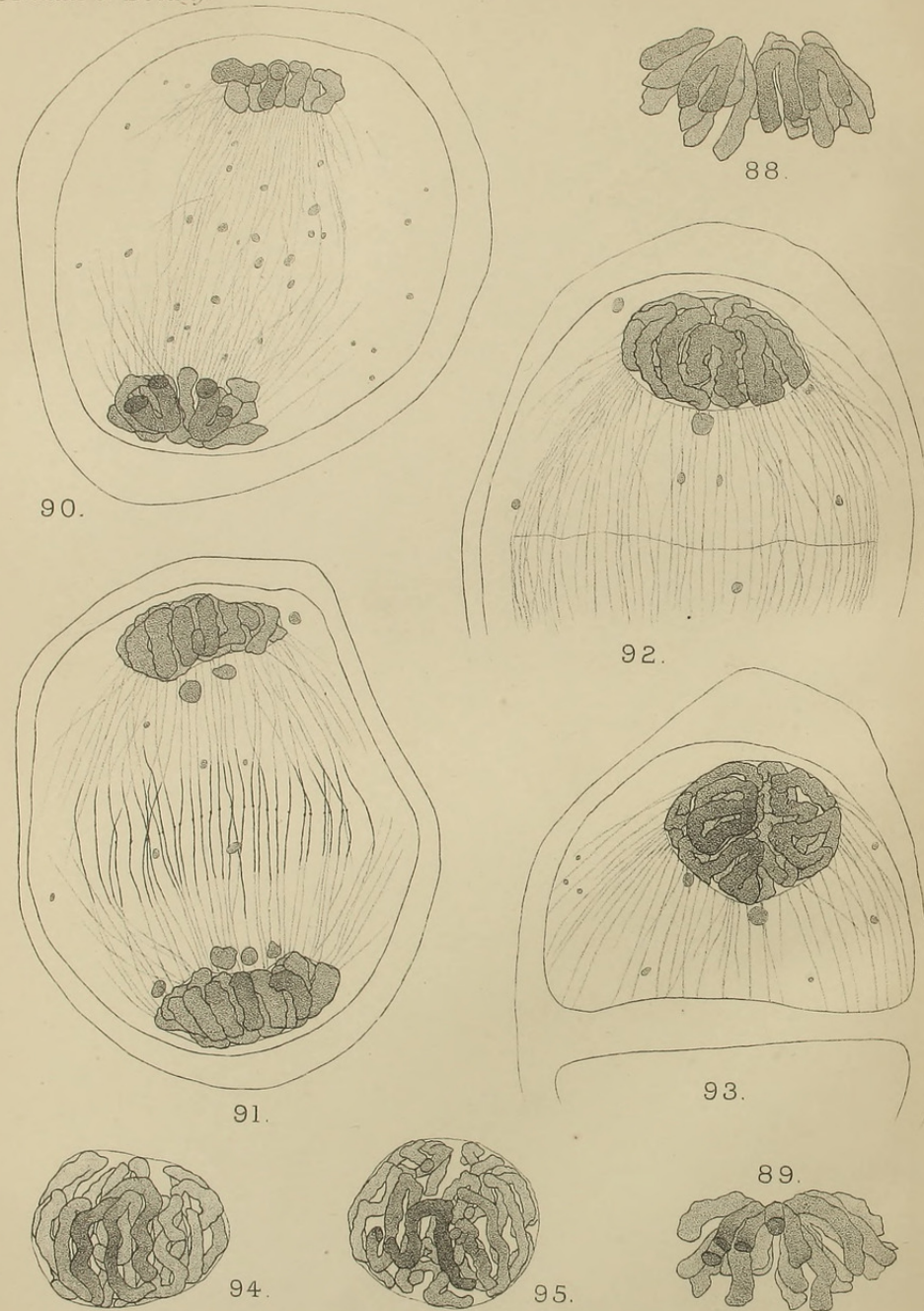

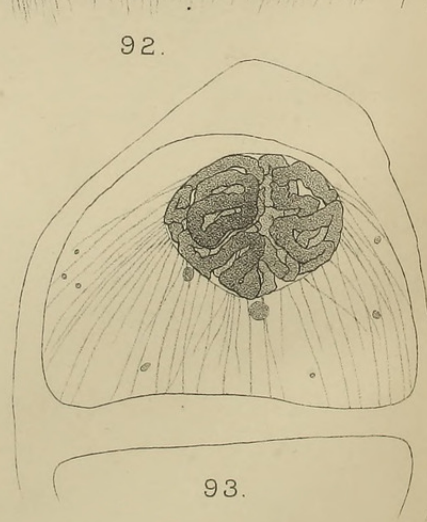

89.

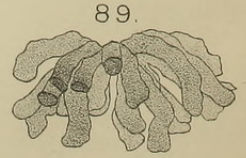

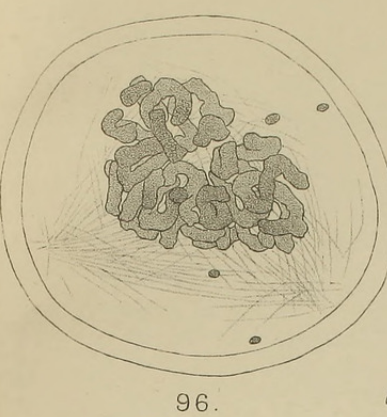

5
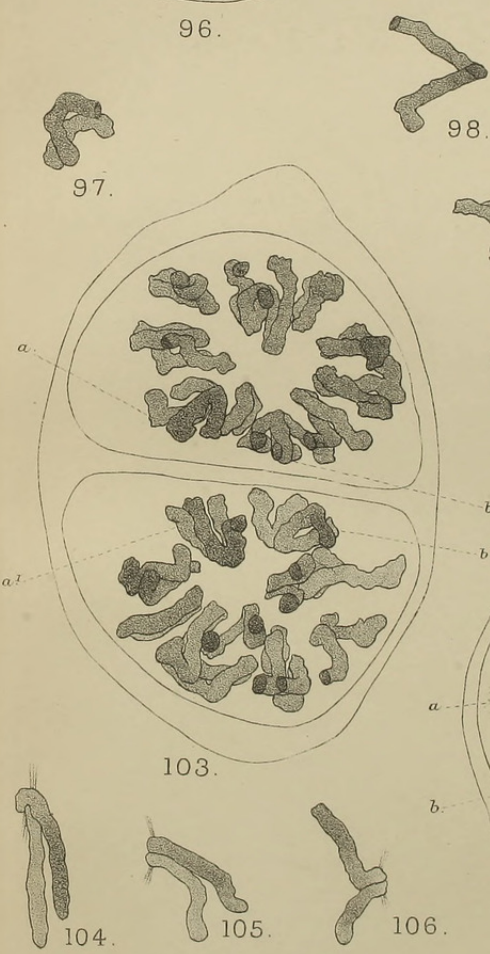


\section{$2 \mathrm{BHL}$ Biodiversity Heritage Library}

Allen, Charles E. 1905. "Nuclear division in the pollen mother-cells of Lilium canadense." Annals of botany 19, 189-258.

https://doi.org/10.1093/oxfordjournals.aob.a088997.

View This Item Online: https://www.biodiversitylibrary.org/item/233541

DOI: https://doi.org/10.1093/oxfordjournals.aob.a088997

Permalink: https://www.biodiversitylibrary.org/partpdf/318795

\section{Holding Institution}

Smithsonian Libraries

\section{Sponsored by}

Biodiversity Heritage Library

\section{Copyright \& Reuse}

Copyright Status: Not in copyright. The BHL knows of no copyright restrictions on this item.

This document was created from content at the Biodiversity Heritage Library, the world's largest open access digital library for biodiversity literature and archives. Visit BHL at https://www.biodiversitylibrary.org. 